\title{
POSTURAL RISKS ASSOCIATED WITH LAPTOP USE ON A BED
}

\author{
A Thesis \\ Presented to the Faculty of the Graduate School \\ of Cornell University \\ In Partial Fulfillment of the Requirements for the Degree of \\ Master of Science
}

by

Katherine Alison Bubric

May 2014 
(C) 2014 Katherine Alison Bubric 


\begin{abstract}
This study consists of a survey and experiment to identify the postural risks associated with laptop use in non-traditional work settings. The survey gauged the prevalence of musculoskeletal discomfort among 186 college students, and also identified the configurations in which male and female students most frequently use laptop computers. Previous work suggests that females report a higher prevalence of musculoskeletal discomfort associated with laptop use than males, and the results of the survey confirmed this, but only for neck and shoulder discomfort. Differences in how males and females reported working were also revealed, with females more likely to use a laptop positioned on the lap and also while sitting with their legs crossed. Males, on the other hand, were more likely to report using a laptop while sitting in positions that required large trunk deviations, such as bending over a coffee table or to the side.

The experiment, which was based on the survey findings, explored the reasons why females reported experiencing more frequent neck and shoulder discomfort when using a laptop than did males. It was hypothesized that this was because females use laptop computers more frequently in deviated postures. Three configurations that females reported working in more frequently than males in the survey were selected for testing, each within the context of a bed/mattress. Postural analysis and discomfort data was collected for 36 participants (18 males, 18 females) performing a 25-minute typing task in each of the three conditions to determine whether these configurations placed the participants in highly deviated postures. Gender comparisons of postural deviation and self-reported discomfort ratings after completion of a typing task in each position were made.

Both male and female participants reported very low levels of discomfort in each of the three conditions, and there was no significant gender difference. Participants displayed highly
\end{abstract}


deviated postures, particularly in the neck, shoulders, and wrists, in all three conditions and there were few gender differences. Any gender differences that were discovered were not consistently in favor of one gender. Males had a slight tendency to work in more deviated postures than females, however both genders were in undesirable postures for much of the experiment. It is most likely that any increased prevalence of musculoskeletal discomfort in females compared to males is due to their choice of working configuration, rather than inherent differences in posture. However, there are a number of other factors that may account for any gender differences in musculoskeletal discomfort, including the finding that females report spending more hours per week using a computer. Further study to identify the contribution of each factor, both in males and females, would be valuable in order to understand the impact that working configuration has on musculoskeletal discomfort and injury 


\section{BIOGRAPHICAL SKETCH}

Katherine Bubric was born in Calgary, Alberta, where she received a Bachelor of Science in Psychology from the University of Calgary in 2010. After graduating, she spent two years working as a human factors researcher at the University of Calgary studying topics related to vision and aging, and also developing screening tools for elderly drivers and drivers with mild cognitive impairment and Alzheimer's disease. It was after spending this time working in a research setting that she decided to pursue a Master of Science in Human Environment Relations, with a concentration in Human Factors and Ergonomics at Cornell University. 


\section{ACKNOWLEDGEMENTS}

I would first like to thank my parents, John and Helen Bubric, for their unconditional belief and support in me. There was never any doubt in you that I could achieve whatever I set my mind to, and it always kept me motivated to impress you. To my sister Laura, I want to thank you for keeping me entertained and connected to the rest of my family while I was away from home, and for bringing the bundle of joy that is my niece, Emma, into this world. I also want to thank Chris Kelly, for always standing by my side and for your constant encouragement. Thank you for all of your love and support.

I could not have done this without my advisor, Alan Hedge, who gave me both the freedom to explore and the guidance to help refine my ideas into a practical and rewarding project. Thank you for your confidence in me, and your expertise. I have the upmost respect for you, and working with you was an invaluable experience that has given me direction that I know will help to guide my career. I also want to thank my minor advisor, Sue Fussell, for bringing a perspective to my project that I would not have considered otherwise. Your expertise in the fields of communication and information science has allowed me to appreciate implications ergonomics research may have on social and psychological phenomenon. I greatly appreciate your support and insights throughout the course of my studies.

I would like to thank Chip Scialfa and Jeff Caird, both of whom were hugely influential in my decision to pursue a career in human factors. I greatly appreciate the time you both took to recognize and help me develop my skills and interests, and the belief and trust you placed in me during my time at the University of Calgary. Without you I would not be where I am today.

I would like to extend my appreciation to the Department of Design and Analysis and the College of Human Ecology for their financial support in employing me as a teaching assistant. 
Because of this, I am able to graduate in a position where I am free of any significant financial burden.

Finally, I want to thank the friends that I have made in Ithaca, who have shared this experience with me. Your support and friendship has meant the world to me, and I thank you for making my time here something I will never forget. 


\section{TABLE OF CONTENTS}

Biographical Sketch ......................................................................................................................... $\mathrm{i}$

Acknowledgements ............................................................................................................

Table of Contents ........................................................................................................................ iv

List of Abbreviations ................................................................................................................ vii

\section{CHAPTER 1}

\section{Introduction}

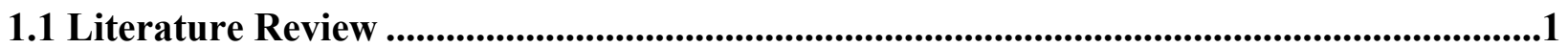

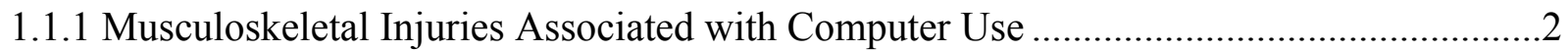

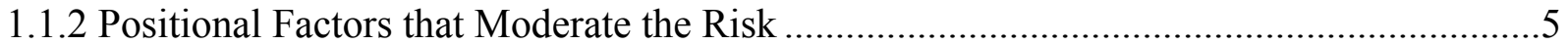

1.1.3 Risk Factors Associated with Laptop Computer Use ........................................................

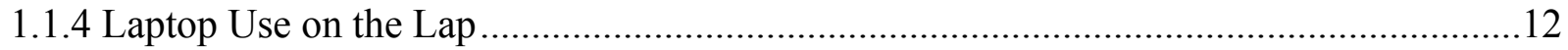

1.1.5 Laptop Use in Alternative Configurations ................................................................15

1.1.6 Current Direction .................................................................................................18

\section{CHAPTER 2}

\section{Part I: Survey of Laptop Use}

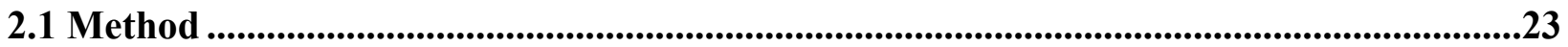

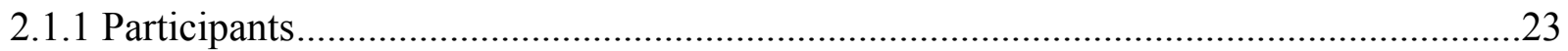

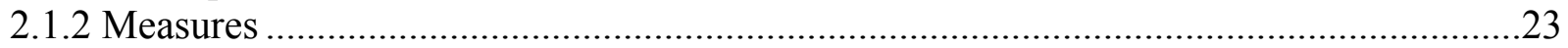

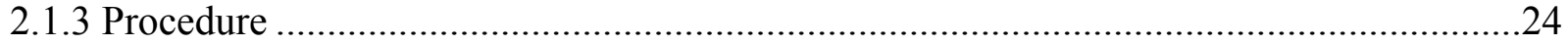

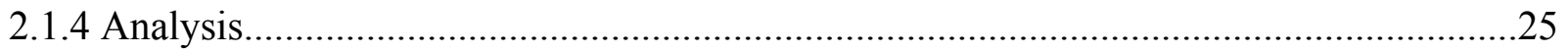

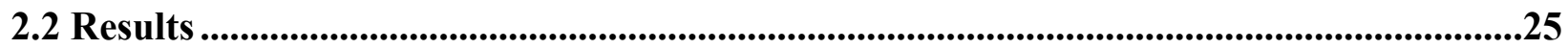

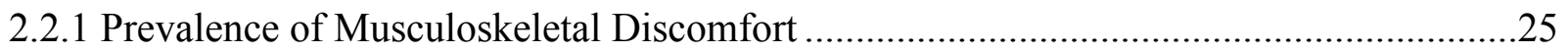

2.2.2 Time Spent Using a Laptop Computer in Various Configurations....................................27

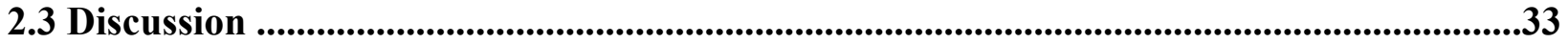

\section{CHAPTER 3}

\section{Part II: Postural Analysis of Laptop Use on a Bed}

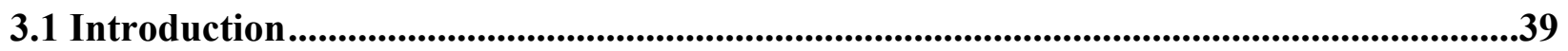

3.2 Method ...........................................................................................................................................40

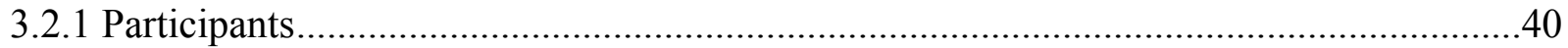

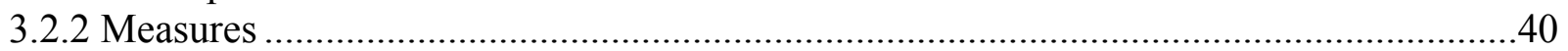

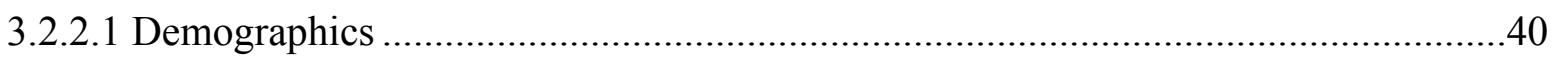

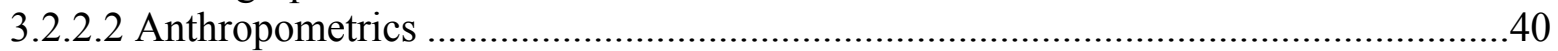

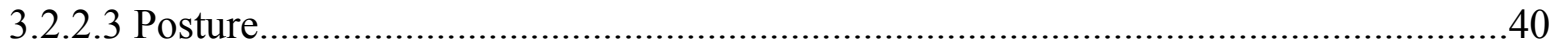

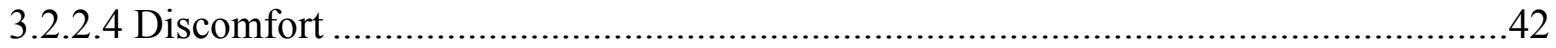




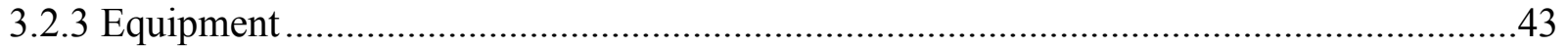

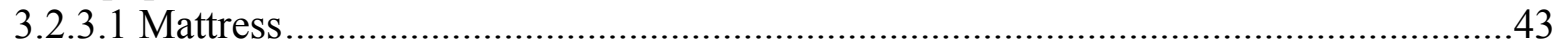

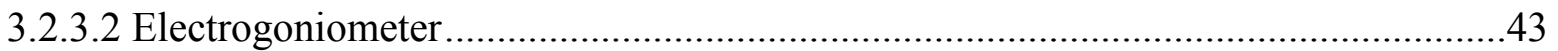

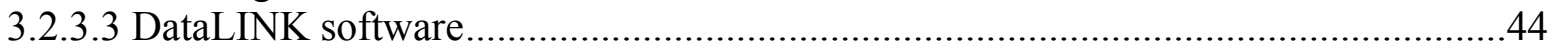

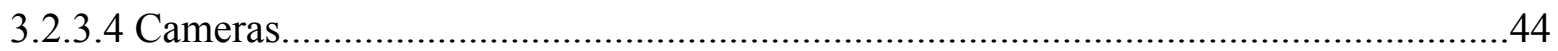

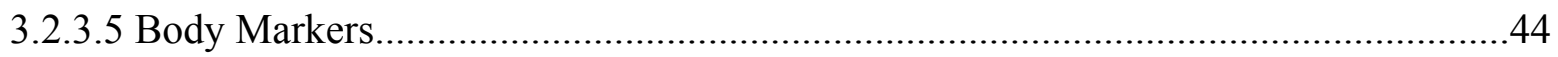

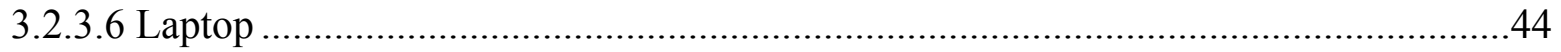

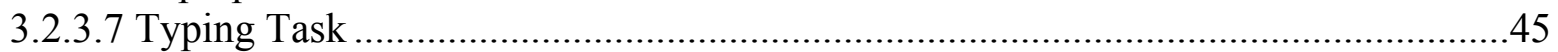

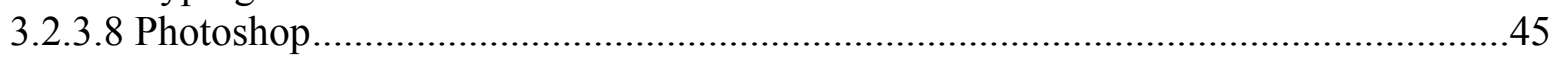

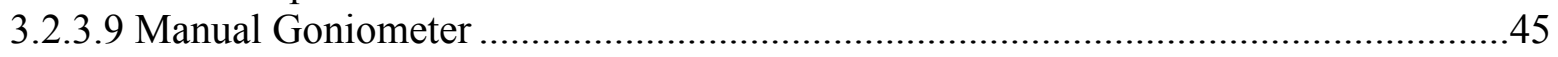

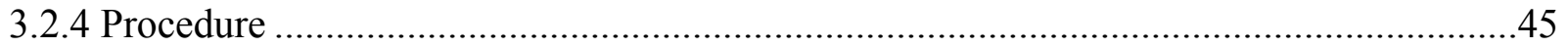

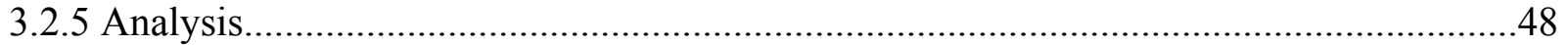

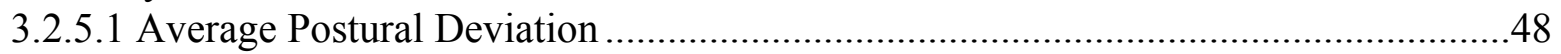

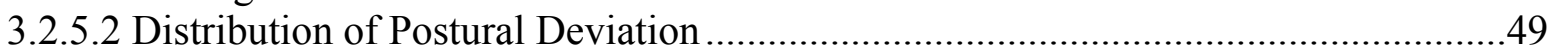

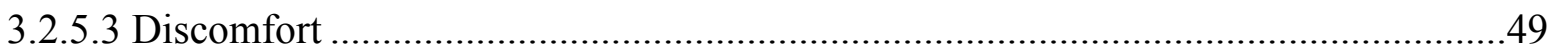

3.2.5.4 Relationship Between Posture and Discomfort ……………….............................50

3.3 Results ..........................................................................................................................................50

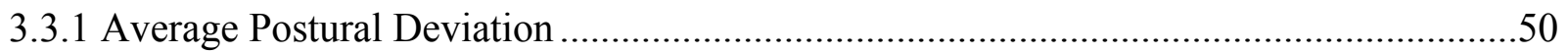

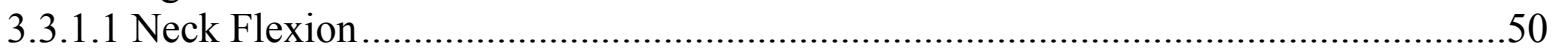

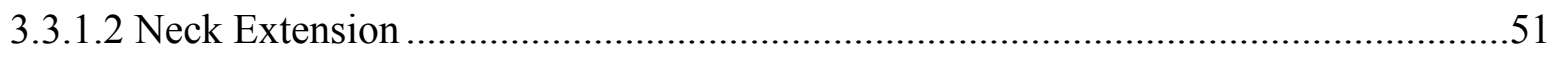

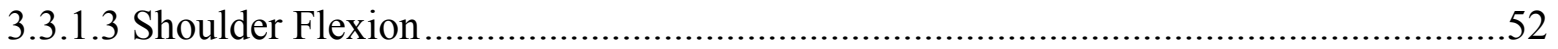

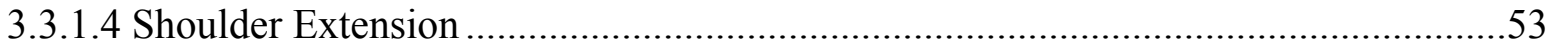

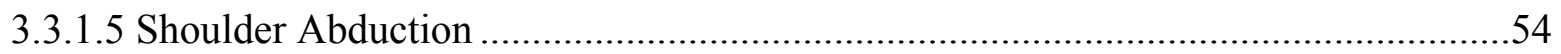

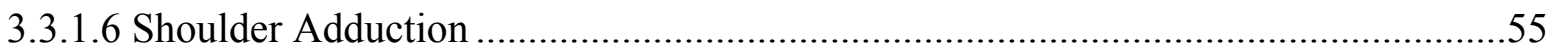

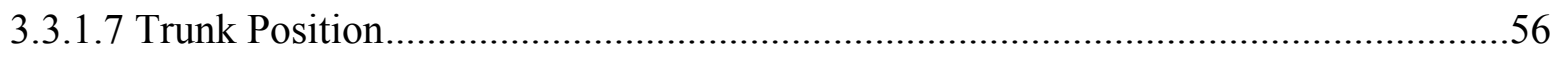

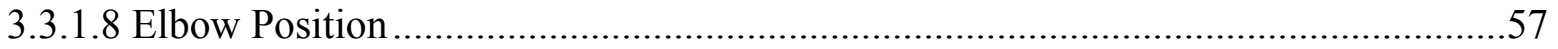

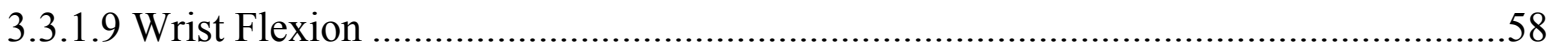

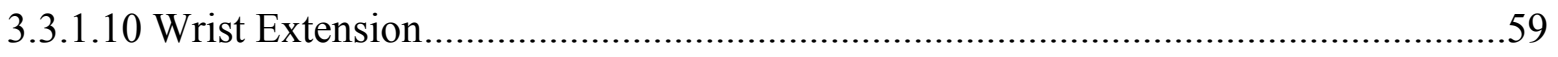

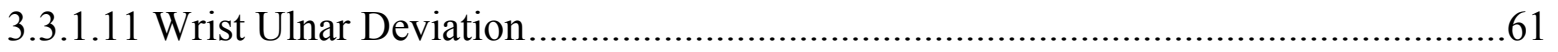

3.3.1.12 Wrist Radial Deviation .................................................................................62

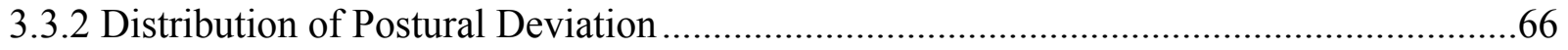

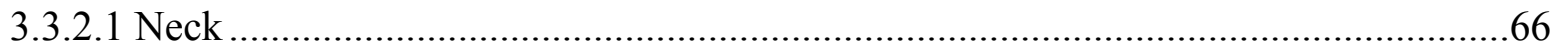

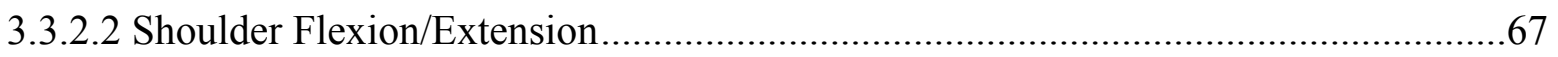

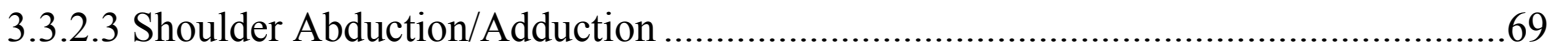

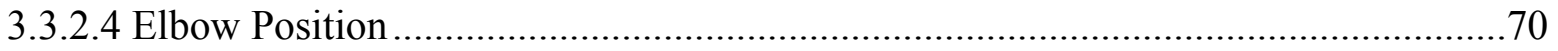

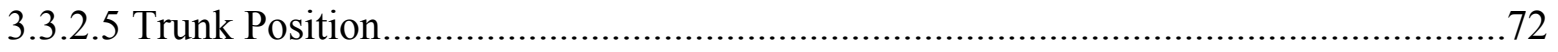

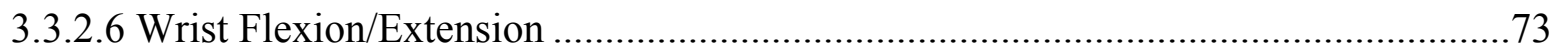

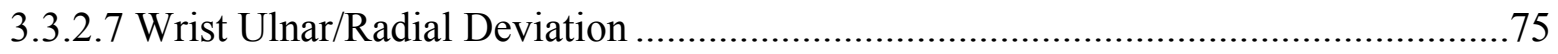

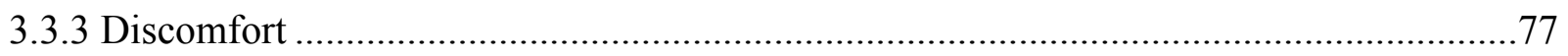

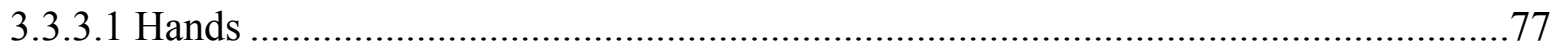

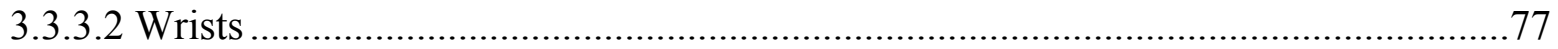

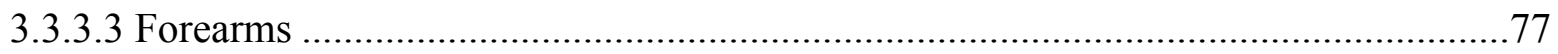

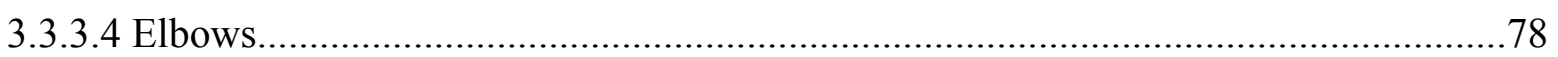

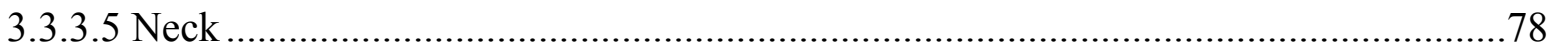

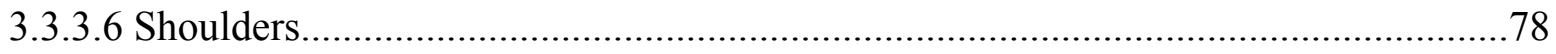

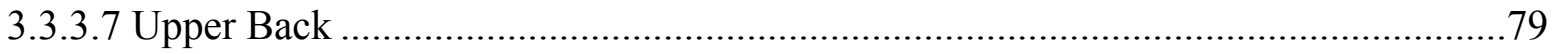




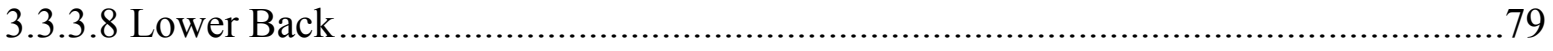

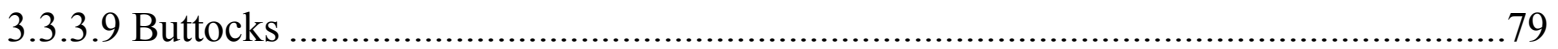

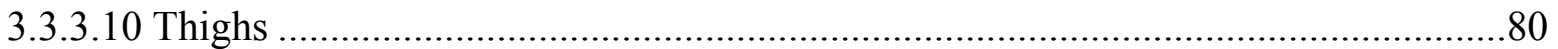

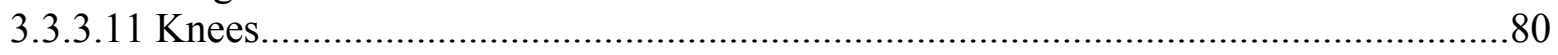

3.3.4 Relationship Between Posture and Discomfort …………................................................83

\section{CHAPTER 4}

\section{Interpretation of Findings}

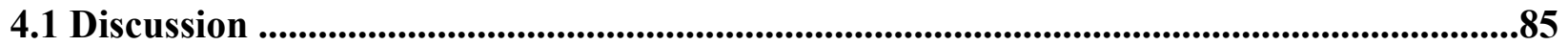

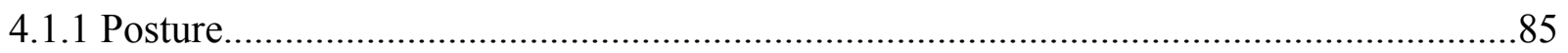

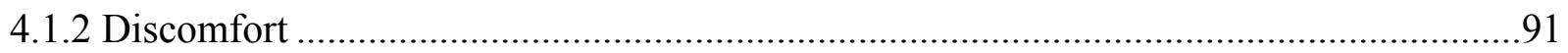

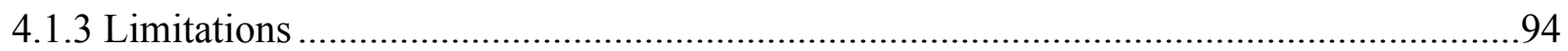

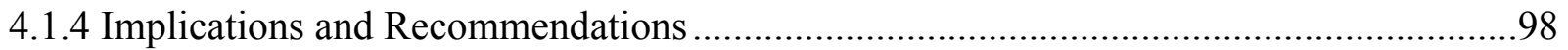

4.2 Conclusions...............................................................................................................................102

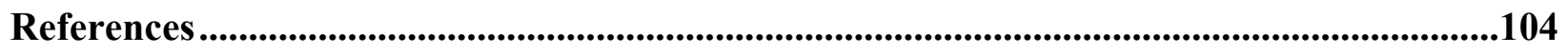

Appendix A .......................................................................................................................112

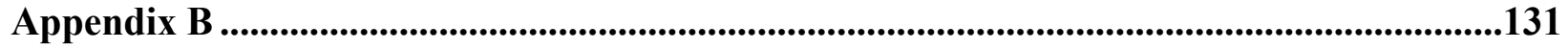

Appendix C .............................................................................................................................133

Appendix D ...............................................................................................................................135

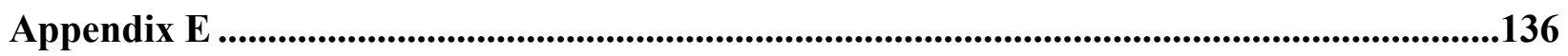

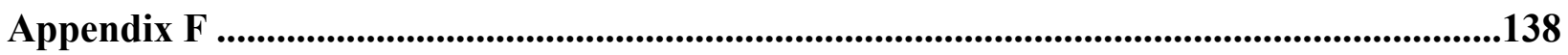

Appendix G .........................................................................................................................................139 


\section{LIST OF ABBREVIATIONS}

\begin{tabular}{|c|l|}
\hline LS & $\begin{array}{l}\text { Configuration where individual is sitting on a bed, leaning back against a wall or } \\
\text { headboard, legs straight, laptop resting on his/her lap. }\end{array}$ \\
\hline CL & $\begin{array}{l}\text { Configuration where individual is sitting on a bed with his/her legs crossed, laptop } \\
\text { resting on his/her lap. }\end{array}$ \\
\hline CB & $\begin{array}{l}\text { Configuration where individual is sitting on a bed with his/her legs crossed, laptop } \\
\text { resting on the bed in front of him/her. }\end{array}$ \\
\hline
\end{tabular}




\section{CHAPTER 1}

\section{INTRODUCTION}

\subsection{Literature Review}

In the midst of the technological age, computer use has become ubiquitous in the workplace, school, and home. Due to an emphasis on knowledge work and a shift towards "paperless offices", over half of the workforce in developed countries worldwide currently use a computer on a daily basis (Smith et al., 1999). The increased prevalence of computers is not only seen in the office, but in the home as well. As of 2011 , over $75 \%$ of households had a computer, compared with only 8\% in 1984 (United States Census Bureau, 2013). Sedentary work, as is performed by contemporary knowledge workers and facilitated by the use of computers, is linked to a number of health issues, such as cardiovascular disease, type 2 diabetes, and obesity (Hamilton et al., 2007). However, attention is only recently starting to be paid to the chronic musculoskeletal conditions that computer workers are developing due to the awkward postures that are commonly adopted during what is often intensive computer use. In addition to the physical and financial strain these injuries place on individuals, because computer use has become so widespread, even small risks associated with their use can have serious public health implications.

Musculoskeletal disorders are injuries that occur to a tissue because of repetitive and forceful exertions over time, usually combined with awkward postures and insufficient recovery time (Silverstein et al., 1986; Silverstein et al., 1996). These syndromes are characterized by discomfort, impairment, disability, or persistent pain in joints and soft tissues, most commonly in the muscles and tendons (Kroemer, 1989). Tendons and muscles become inflamed, which results in compression of peripheral nerves. This results in pain and/or numbness, which often leads to 
functional impairment (Carter \& Banister, 1994). Typing and computer mouse use are both highly repetitive motions that do not require an inordinate amount of force, however, when sustained and combined with static loading and uncomfortable or awkward postures, the operator is exposed to a risk of developing a musculoskeletal injury (Scalet, 1978). Deviated or nonneutral postures are a risk factor for the development of these injuries because of the stress and pressure placed on surrounding structures such as nerves or tendons. For example, in the wrist, deviations from neutral increase carpal tunnel pressure, which can lead to compression of the median nerve as well as reductions in blood flow (Bach et al., 1997; Gelberman et al, 1984). Contact stress between the wrist crease and a work surface also compresses the median nerve, which raises carpal tunnel pressure, and increases the risk of developing an injury (Rempel et al., 1998). Wrist extension and contact stress at the wrist crease are common during computer use, and over time, this can lead to serious and persistent injuries such as carpal tunnel syndrome. Along with these risk factors in the wrist, deviation and contact stress at the elbows, neck flexion and extension, trunk flexion/spinal kyphosis, and shoulder elevation often occur during computer use, and carry similarly adverse outcomes, particularly when combined with repetitive movements (Carter \& Banister, 1994; Turhan et al., 2008; Punnett and Bergqvist, 1997).

\subsubsection{Musculoskeletal Injuries Associated with Computer Use}

Musculoskeletal injuries are increasing in prevalence along with computer use in the United States (Amell \& Kumar, 1999; Gerr et al., 2006; Punnett \& Bergqvist, 1997). In 2011, $33 \%$ of workplace injuries requiring time off from work were due to musculoskeletal injuries, and the prevalence of musculoskeletal pain or discomfort due to computer use is predicted to be much higher (Bureau of Labor Statistics, 2012a). Furthermore, Noack-Cooper et al. (2009) found that musculoskeletal complaints are more common in college students who use computers than 
in computer using professionals. Most commonly, computer-related musculoskeletal complaints occur in the neck, shoulder, and back, as well as in the wrists and hands (Bergqvist et al., 1995; Erdinc, 2011; Hunting et al., 1981). Symptoms often include soreness, aching, stiffness, fatigue, cramps, numbness, tingling, or tremors (Carter \& Banister, 1994). While it is difficult to know the overall prevalence of musculoskeletal discomfort related to computer work, in a survey of workers identified as intensive computer users, Bergqvist et al. (1995) found that $62 \%$ reported neck or shoulder pain or discomfort, and hand or arm pain or discomfort was reported by $30 \%$. Turhan et al. (2008) found a slightly lower prevalence of musculoskeletal pain in data entry operators, with $36 \%$ reporting pain, most frequently in the neck and shoulders.

Punnett and Bergqvist (1997) performed an extensive review of the literature, and identified several risk factors for upper extremity musculoskeletal disorders related to computer use. Risk factors include frequency and duration of computer use, time spent using the computer without a break, repetitive and forceful motions related to typing, as well as frequent or prolonged static muscle contraction related to mouse use. Awkward positions necessitated by the design of the workstation or computer itself can lead to the adoption of non-neutral postures. Turhan et al. (2008) revealed that data entry operators often exhibit excessive neck flexion, kyphotic back postures, wrist extension, ulnar deviation, and hyperextension of the thumbs when using a computer. Static work, such as is often seen in the neck and shoulders during computer use, also leads to fatigue and an increased risk of developing symptoms. Punnett and Bergqvist (1997) revealed that problems can also arise from the pressure exerted by the hands or forearms on hard surfaces, and insufficient lighting or glare, which can lead to eyestrain. In addition, seated work performed in an unadjustable or incorrectly adjusted chair often leads to kyphotic lumbar curvature because the user is more inclined to lean forwards (Carter \& Banister, 1994). 
Specifically, hard keystrokes are a risk factor for shoulder pain and ganglion formation, and ulnar deviation is also related to ganglion formation and finger pain (Turhan et al., 2008). Often it is the combination of multiple risk factors that eventually results in an injury. For example, when postural deviation is combined with highly repetitive movements and a long task, the user is at a greater risk of injury compared to if he or she was adopting the deviated posture for a shorter period of time (Punnett and Bergqvist, 1997).

Waersted et al. (2010) performed an extensive review of the literature pertaining to the link between physician-diagnosed upper extremity musculoskeletal disorders and computer work. By examining the results of prospective studies involving an objective medical exam, causal relationships can be inferred. This review revealed that in the neck, tension neck syndrome is the most common diagnosis, and there is some evidence for a relationship between this diagnosis and computer use in general, as well as with time spent using a mouse. The development of these injuries appears to be most closely tied to workstation design and individual differences in posture. Lack of forearm support, non-neutral forearm positions, and neck flexion are risk factors for neck injuries. In the shoulders and elbows, the most common diagnoses are shoulder tendonitis and lateral or medial epicondylitis respectively; however, there is insufficient evidence to infer causality. Shoulder and neck diagnoses show a tendency to overlap, which may account for some of the ambiguity between studies. There is some degree of evidence pointing to a causal relationship between forearm pain and computer use in general and with time spent using a mouse, however no relationship with time spent using a keyboard was revealed. Finally, there is evidence supporting a causal relationship between injury to the wrist/hand and computer use in general, time spent using a mouse, and time spent using a keyboard. The most commonly reported injury in the wrist/hands is wrist tendonitis (including 
extensor and flexor tendonopathy/tendonitis and De Quervains syndrome). These injuries are also tied to workstation design, and the risk can be reduced by forearm support, low keyboard placement, and vertical mouse design.

\subsubsection{Positional Factors that Moderate the Risk}

Many of the musculoskeletal injuries that result from computer use are due to incorrect workstation set up. The location of the keyboard is one of the most important components of a computer workstation from a postural standpoint. Moffet et al. (2002) found that positioning the keyboard at or above the elbow height of the user increases musculoskeletal complaints in the hands, arms, neck, and shoulders. Problems likely occur due to the fact that when the keyboard is elevated above the desk surface, the user is unable to relax his or her shoulders, and must extend his or her wrists. Improper placement of the keyboard is common due to the fact that standard desk height is 29.5 inches, which is above the seated elbow height of the majority of computer users. When a keyboard is placed in a higher position, such as on a desk or work surface, users often exhibit shoulder flexion and elbow extension, because the keyboard is too high, and often too far from the user (Liao \& Drury, 2000). Increased shoulder flexion and wrist extension have also been associated with placement of the keyboard at a greater distance from the user, although use of a palm support can be used to correct wrist position (Kotani et al., 2007). Turhan et al. (2008) has shown that resting the wrists on the keyboard or a desk is associated with elbow pain and extensor tenosynovitis of the wrist.

While there are issues associated with keyboard placement at a distance from the user, Moffet et al. (2002) also found that musculoskeletal complaints are also increased when the keyboard is positioned too close to the body, specifically when the inner elbow angle is less than 121 degrees. When the keyboard is too close to the user, awkward postures are necessitated such 
as ulnar deviation of the wrists and shoulder abduction (Kotani et al., 2007). Conventional computer keyboards slope upwards towards the back of the device at an angle of approximately 15 degrees to the horizontal. This can lead to excessive wrist extension when the keyboard is placed on a flat desk surface (Hedge et al., 1999). Because of the postural risks related to keyboard placement, there has been an interest in the use of keyboard trays that position the keyboard lower than the desk surface, particularly downward tilting trays that compensate for sloped keyboards and afford more neutral hand and wrist positions. Hedge et al. (1999) performed a field experiment aimed at assessing the effect the use of a lowered, downward tilting keyboard tray has on posture and musculoskeletal discomfort. The authors found that compared to positioning of the keyboard on the desktop, use of the keyboard tray decreased wrist extension and improved seated posture. Use of a keyboard tray led to a reduction in self-reported musculoskeletal discomfort, particularly in the lower back and left shoulder. These findings indicate that use of a lowered, downward tilting keyboard tray can facilitate neutral postures, and consequently reduce the risk of developing a musculoskeletal injury. This study did not measure neck or shoulder position, which is another body region that may potentially benefit from a lowered keyboard.

In addition to the placement of the keyboard, the position of the computer monitor is highly influential in determining the posture of the user. One challenge in attempting to determine the ideal screen height and viewing angle for computer use is the conflicting requirements between reducing strain on the musculoskeletal system and reducing strain on the eyes. The normal resting point of the eyes in regards to gaze is approximately 15 degrees below the horizontal line of sight, therefore to reduce visual strain, it is recommended that the computer screen is placed below this level (Seghers et al., 2003). In general, higher screen placement 
appears to be correlated with visual strain (Burgess-Limerick et al. 1998; Villanueva et al, 1996). It has been suggested that the least strain is placed on the visual system when the center of the display is between 30 and 45 degrees below the horizontal line of sight (Burgess-Limerick, 2000). Lower screen height is associated with lowered gaze direction and decrease in ocular surface area, which has been associated with improved eye comfort (Bergqvist \& Knave, 1994; Yaginuma et al., 1990). However, placing the computer screen at this height increases neck flexion and downward head tilt, which can lead to musculoskeletal problems in the neck and shoulders. Villanueva et al. (1997) found that increased neck flexion caused by lower screen heights was correlated with increased neck muscle activity. Particularly, increasing the viewing angle to the center of the display from 15 degrees to 35 or 40 degrees increased muscle activity in a variety of muscles in the neck and shoulders, particularly in the cervical erector spinae muscles. Low screen placement places strain on the musculoskeletal system, and is also associated with reductions in preference and comfort as reported by users (Sommerich et al., 2001; Turville et al., 1998). In addition, as screen height is lowered, the neck becomes more inclined, and the thoracic spine becomes more kyphotic, which places increased stress and loading on the spine (Villanueva et al., 1997).

In order to attempt to address the apparent incompatibility between the demands of the visual and musculoskeletal systems, Allie et al. (2005) have proposed screen height recommendations that take a "middle ground" approach, considering both systems as well as user preference. The authors suggest that the top of the display should be placed no higher than 5 degrees below the horizontal line, while the center of the display should be placed no lower than 25 degrees below the horizontal line of sight. These recommendations postulate that the bottom 
of the display should be no lower than 40 degrees below the horizontal line of sight in order to minimize excessive neck flexion.

\subsubsection{Risk Factors Associated with Laptop Computer Use}

A recent trend that has significant postural implications is the replacement of desktop computers with laptop computers. As of 2008, close to one half of American adults owned a laptop, and between 2006 and 2009, the proportion of college students who owned a laptop computer rose from $66 \%$ to $88 \%$, while desktop computer ownership decreased from $71 \%$ to 44\% during the same time period (Horrigan, 2009; Smith et al., 2009). This shift in device preference has important implications related to user health and safety, particularly in regards to musculoskeletal injury. One reason that laptops are increasing in popularity is because of an increasingly mobile workforce. According to the Bureau of Labor Statistics, over $20 \%$ of the American workforce engages in some degree of telecommuting (Bureau of Labor Statistics, 2012b). This proportion is much higher in other countries; for example, in India and Indonesia $50 \%$ and $32 \%$ of their respective workforces telecommute on a regular basis (Reuters, 2012). These workers are not only working from home where they may have an office or other arrangement with a desk and chair; the flexibility inherent in telecommuting allows individuals to work from any location that that is convenient to them. Telecommuters are not the only segment of the workforce who utilize laptops on a regular basis; within an office setting, laptops are beneficial in the sense that they require less desk space, and can easily transported for use during meetings or in different workstations.

Another population of individuals who take advantage of the portability of laptops is college students. Chang et al. (2008) found that up to $88 \%$ of college students own a laptop computer, with $82 \%$ using a laptop exclusively over a desktop. Laptop computers are ideal for 
student use because of their small size and portability. A questionnaire administered by Schlossberg et al. (2004) revealed that $34 \%$ of first year graduate students report using a computer for greater than 40 hours per week, and $80 \%$ use their computer for greater than 20 hours per week. The proportion of students using a computer to the same extent in their fifth year of graduate study increased to $56 \%$ and $95 \%$ respectively. While these statistics do not differentiate between desktop and laptop computer use, as mentioned, the majority of college students use laptop computers exclusively.

There is a deficiency of research pertaining to the relationship between laptop use and musculoskeletal injury, with the majority of previous work focusing on desktop computers. While there are many similarities between laptop and desktop computer use, laptop computers presents some unique challenges because of their size and lack of adjustability. Because the screen and keyboard are attached, there is an inherent lack of adjustability with these devices, which often leads to a trade-off between neck and wrist posture; users are often required to tilt their head and neck downwards in order to view the display, or elevate their wrists and/or arms to maintain proper screen height. When a laptop is placed on a standard desk, the resulting height of the keyboard is much higher than what is recommended to maintain a neutral posture, and often results in deviations of the wrists elbows, and/or shoulders (Asundi et al., 2010). In order to use a laptop effectively at a standard desk or workstation, implementation of an external keyboard and mouse is recommended in conjunction with a keyboard tray. These tools allow the user to adjust the keyboard and monitor positions independently, and achieve a configuration that is conducive to a neutral posture in both the neck and wrists. However, keyboard trays or other tools that may help to reduce the risky postures associated with laptop use such as a docking station, notebook holder, and footstool are rarely used (Malińska et al., 2012). Further 
exacerbating the postural issues associated with laptop computer use are the implications the introduction of portable computers has on their usage patterns, particularly the fact that that they are able, and encouraged, to be used away from a desk or table. The combination of a smaller and less adjustable device with the lack of an appropriate workstation often results in highly risky postures that can lead to the development of a musculoskeletal injury.

Laptop computer use is associated with many of the same postural risk factors as desktop computer use, with discomfort most commonly reported in the neck, shoulders, back, and wrists (Price \& Dowell, 1998). However, in addition to the problems already discussed, laptop computer users have a tendency to exhibit even more pronounced neck flexion and forward head tilt than do desktop computer users (Saito et al., 1997; Straker et al., 1997). Laptop computers are also available in a wide range of sizes, many of which are very small to afford portability. Due to the lower position of the monitor in these smaller computers, their use results in a substantial flexion in both the cervical and thoracic spine segments (Straker et al., 1997; Szeto \& Lee, 2002; Villanueva et al., 1998). During laptop use, particularly with those that are smaller, flexion is pronounced in the cervical segment of the spine, indicating that it is the upper spine and neck that is most commonly adjusted to compensate for a smaller screen size (Szeto \& Lee, 2002). Increased neck and shoulder flexion leads to an increase in biomechanical load on surrounding structures, which is associated with stiffness and pain and often the eventual development of musculoskeletal disorders (Grandjean, 1987). Specifically, cervical extensor muscle strain has been found to increase with head flexion (Straker et al., 2009a). Increased downward head tilt also increases user fatigue and diminishes endurance, and is related to musculoskeletal symptoms in the arm, hand, and neck (Chaffin, 1973; Heyer et al., 1990). Villanueva et al. (1998) found that as display size decreases, forward trunk inclination increases 
and there is increased static and median muscle activity in the neck extensor muscles, increasing as a function of display height and neck flexion. Saito et al. (1997) also found that laptop users have a tendency to change their head angle less frequently than desktop computer users, indicating a more static posture. Higher levels of musculoskeletal discomfort and eyestrain are reported during use of smaller laptops, primarily in the neck, shoulders, elbow, and wrist (Villanueva et al., 1998).

Overall, compared with desktop computers, the greatest postural differences that result from laptop use are found in the neck. Laptop use results in increased neck flexion and downward head tilt, a related increase in neck extensor activity, and reduced range of neck movement. Musculoskeletal discomfort is reported in similar areas as is seen with desktop computer use, mainly the neck and shoulders, and also the elbows and wrists. Because the screen and keyboard are not independently adjustable on a laptop computer, there is often a trade-off between head/neck posture and hand/wrist posture. In order to achieve a more neutral head and neck position, the screen height must be increased. This is often done by use of an external monitor, however this is not practical for individuals who use their laptop as a mobile device. Placing the entire laptop on a higher working surface in order to attempt to achieve a more neutral neck posture is not a viable solution, as this results in greater discomfort in all body parts, including the neck and shoulders (Price \& Dowell, 1998). This also has negative impacts on the wrists, as extension is increased. As an alternative, Asundi et al. (2012) examined the impact of placing the computer on an incline, which elevates the screen while maintaining the height of the keyboard. These authors found that placing the keyboard on an incline did reduce the non-neutral head and neck positions, minimizing downward head tilt and neck flexion. However, this was at 
the expense of wrist posture, as wrist extension was increased. The authors suggest that the tradeoffs are acceptable with a 12-degree incline.

\subsubsection{Laptop Use on the Lap}

Laptop use has been associated with non-neutral postures in numerous laboratory studies (Price \& Dowell, 1998; Sommerich et al., 2002; Szeto and Lee, 2002; Villanueva et al., 1998). However, despite the portability of laptop computers, these studies almost exclusively assume a traditional workstation set up consisting of a desk and chair. There are a small number of studies that have been performed investigating the postural differences between laptop use on a desk compared to laptop use when it is positioned on the user's lap. Moffet et al. (2002) identified a number of postural differences between these two configurations. As compared to when the laptop was placed on the desk, placement on the lap resulted in greater downward head tilt, backward trunk inclination, and wrist extension, as well as reduced shoulder flexion. These differences are intuitive based on the lower height of the keyboard and screen when placed on the lap, which necessitates that the user look downwards during viewing (Saito et al., 1997; Stracker et al., 1997; Villanueva et al., 1997). These differences in posture also corresponded to differences in muscle activity, with greater muscle load in the wrist extensors, and lower muscle load in the trapezius and deltoid muscles in the lap condition (Moffel et al., 2002). Because there was no significant difference in productivity between the two conditions, the changes in muscle activity can be related to posture with a greater degree of confidence. Participants reported a greater degree of neck discomfort when the laptop was placed on the lap compared to when it was placed on the desk, which is likely attributable to the increased neck flexion that was observed. Users compensated for the lower screen height by inclining the screen to a greater 
degree when it was positioned on the lap, however it is apparent that this did not correct their posture completely.

Asundi et al. (2010) performed a study that is in some ways comparable to Moffet et al. (2002), however this study introduced a third condition for comparison; the use of a lapdesk. A lapdesk is a commercially available product that provides the user with a raised surface to place his or her laptop on, which rests on top of the user's lap. The authors proposed that reduced postural variability is a risk factor that should be considered when evaluating the musculoskeletal implications of laptop use, therefore this variable was included in this study as a measure in addition to posture, discomfort, and productivity. Asundi et al. (2010) revealed that although the laptop was situated approximately $100 \mathrm{~mm}$ lower when on the lap compared to when on the desk or lapdesk, regardless of height, users maintained a relatively constant distance between the eyes and the screen. This may indicate that users are compensating to some degree with body position or posture. Consistent with Moffet et al.'s (2002) findings, the results of this analysis indicated that use of a laptop positioned on the lap increases downward head tilt, neck flexion, and wrist extension, and reduces shoulder elevation, protraction, flexion, and abduction. Arms were also positioned closer to the body when the laptop was on the lap. There was no difference in neck flexion between the two conditions, which is surprising, and possibly explained by the fact that users compensated for the vertical height difference of the screen by adjusting the horizontal position of the laptop. Use of a laptop situated on the lap decreased postural variability in the shoulder and elbow, although there was an increase in variability in wrist position.

Compared to the lap condition, use of a lapdesk elevated the head, reducing downward head tilt and neck flexion. Arms remained close to the body, resulting in a compensatory elbow flexion, although there was a reduction in wrist flexion. The lapdesk did not increase postural 
variability when compared to the lap position. A greater degree of discomfort was reported in the lap position than the desk position, which was alleviated to some degree by the lapdesk, although the difference was not statistically significant. Overall, both the lap and desk positions resulted in some undesirable positions, with the lapdesk reducing the negative postures adopted in the lap position. Regardless of placement of the laptop, there were body segments in deviated positions, which increases the risk of injury, especially when sustained.

The above-mentioned studies are two of a small number of experiments that have been published investigating postural differences resulting from differential laptop use. The results of these studies are consistent, finding similar eye-to-screen distances regardless of whether the laptop is positioned on the lap or on a desk, and that productivity is not affected by computer location. Postural differences between laptop positions were also found to be consistent, with laptop use on the lap increasing downward head tilt and wrist extension, and reducing shoulder flexion. The condition in which the laptop was positioned on the users lap reliably resulted in the highest subjective reports of discomfort.

In a recent study, Werth and Babski-Reeves (2012) compared laptop, netbook, and slate computer use under two conditions: in a traditional workplace set-up consisting of an adjustable desk and chair, and when the user is sitting on a sofa with the device positioned on his/her lap. Wrist extension and neck flexion increased when participants were seated on the sofa, compared with when working at the desk. This is consistent with Asundi et al. (2010) and Moffet et al. (2002), who found that participants adopted similarly deviated postures when working on a laptop that was positioned on their lap, when seated in an office lounge chairs or adjustable office chairs. This indicates that regardless of the type of furniture they are sitting on, participants adopt similarly adverse postures when using a laptop positioned on the lap. 
However, only Moffet et al. (2002) measured back and trunk position, which is an area that would likely be affected by the type of chair because of differences in support.

\subsubsection{Laptop Use in Alternative Configurations}

The literature that exists relating to the postures adopted during laptop use almost exclusively focuses on work that is performed while the subject is sitting at a desk. Laptop computers are designed to be transportable and easily used on the go and in any environment. Consequently, it can be expected, and easily observed, that laptop owners use their computers not only in a wide variety of environments, but also in a diverse number of positions and configurations. As described in the previous section, a small number of studies exist examining the postures that result from using a laptop positioned on an individual's lap, however the musculoskeletal impacts of laptop use in non-seated positions have not been investigated sufficiently. The way in which consumers physically use their products, and the related health and safety consequences, are aspects that need to be addressed and incorporated in future laptop computer designs.

Sommerich and Korkmaz (2008) surveyed high school students who had been issued tablet PCs about the different positions in which they use the device. The questionnaire revealed a wide variety of locations of use, as well as numerous different positions and postures adopted. The most frequently reported positions include sitting on a chair, bed, couch, the floor, and lying down. Similarly, the tablet PCs were commonly stationed on a desk, lap, table, bed, or the floor. Unfortunately, there was no quantifiable analysis performed on any of these positions. It can be inferred that these positions are adopted with a similar frequency during laptop use, as the function of portability is constant between the two types of device. 
In a pilot study aimed at identifying and examining popular workstation configurations utilized by college students, Chang et al. (2008) performed a postural analysis on photographs of students using laptop computers in various self-selected set ups including: sitting at a table in a chair, sitting on a bed with a laptop on the lap, lying on a bed with a laptop on the bed, sitting on a chair with a laptop on the lap, and sitting on a lounge-style couch with a laptop on the lap. The authors distinguished between traditional (desk and chair) and non-traditional configurations, observing increased shoulder flexion and abduction in the traditional configurations, and increased neck flexion in the non-traditional arrangements. Some degree of neck flexion, head tilt, trunk flexion, shoulder flexion and abduction, and elbow flexion was observed in all configurations. Especially problematic with laptop use in non-traditional configurations is that fact that the majority of work surfaces and seating arrangements utilized are unadjustable, thereby often requiring postural compensation. Coupled with lack of ergonomic knowledge and/or practice, risky postures often ensue. Excessive shoulder flexion was the most commonly observed problematic posture, which was often exacerbated by trunk flexion, and the related depression of the shoulders. One limitation of this study is that the authors broadly classified positions as traditional or non-traditional, which raises some issues with the specificity of their analysis. The non-traditional positions vary greatly, from lying down to sitting on a couch. Consequently, there are likely to be significant differences between the postures assumed in the different positions within this category. These specific differences are of interest and warrant further investigation.

Gold et al. (2012) carried out the only other laboratory-based study that has been performed to date investigating laptop use in positions other than when the laptop is placed on a desk or lap. This study compared different positions that students commonly adopt when using 
laptop computers, including sitting on a couch with the participant's feet resting on the floor, sitting on a couch with the participant's feet resting on an ottoman, and with the participant lying on his/her stomach. A postural analysis was performed on these three positions, as well as on an additional three configurations that were selected by each participant. The authors found statistically different mean joint angles for each of the three above-mentioned positions for all joints measured (trunk flexion/extension, neck flexion/extension, shoulder elevation, shoulder horizontal abduction/adduction, shoulder external/internal rotation, elbow flexion/ extension, and wrist flexion/extension) except for shoulder rotation and trunk flexion/extension. The most notable differences existed between the prone position and the two sitting positions. This supports the suggestion that non-traditional positions cannot be analyzed as a single homogeneous group. When using a laptop in a seated position, users experience neck flexion, shoulder abduction, shoulder extension, elbow flexion of greater than 90 degrees, and a relatively neutral wrist posture. When using a laptop in the prone position, users exhibit neck extension, pronounced shoulder flexion, a degree of elbow flexion less than 90 degrees, and pronounced wrist flexion. The shoulder experienced a similar degree of internal rotation in all three positions.

The additional body positions that were analyzed in this study were the three most frequently identified positions by the participants. First of all, a cross-legged position resulted in marked neck flexion, shoulder abduction, internal shoulder rotation, and wrist extension. Second, sitting with the knees flexed at 90 degrees or greater resulted in shoulder abduction, internal shoulder rotation, and elbow flexion. Third, lying on the bed slightly propped up and with the legs straight out was a relatively neutral posture for the shoulders, elbows, and wrists.

The trunk was extended in all six conditions. Joint range of motion was the greatest in the prone position, and a greater degree of discomfort was reported in this position. In all positions 
tested, the greatest range of motion was in the wrist, and the least in the trunk sagittal plane. The neutral wrist posture that was observed in the seated positions is surprising, and contrasts with previous studies that found a significant degree of wrist extension in similar configurations (Asundi et al., 2010; Moffet et al., 2002). The authors suggest that because the laptop used in the study provided a palm rest, this may have been used to facilitate a more neutral wrist posture. However, Moffet at al. (2002) compared laptops with and without a palm resting area, and found no significant difference in wrist motion or posture between conditions, with both laptops resulting in a significant degree of wrist extension.

While this study made a valiant attempt at capturing a diversity of different positions in which laptops are used, only three configurations were tested with every participant, and the attenuated sample size for the others makes comparisons difficult. In addition, the criteria upon which these configurations were selected by the researchers is unclear, so it is unknown how frequently individuals actually work in these positions.

\subsubsection{Current Direction}

Computer use is associated with significant risk factors for the development of musculoskeletal injury, especially in the neck, shoulders, and back. Problems often arise because of the repetitive and forceful exertions required by keyboard and mouse use, frequent and/or static muscle contraction, and the adoption of non-neutral postures. These adverse postures are exaggerated during laptop use, particularly in the neck, where pronounced flexion and increased muscle activity are typical. There is a deficit of research pertaining to the use of laptops in configurations other than at a desk with the user situated in an office chair. The few studies that have investigated the effects of laptop use when placed on the lap have found that this position further deteriorates posture; increasing downward head tilt, neck flexion, and wrist extension 
(Asundi et al., 2010; Moffet et al., 2002; Werth \& Babski-Reeves, 2012). It has been shown that individuals use these devices in a wide variety of settings and positions, particularly college students who frequently use their laptops on the go (Chang et al., 2008). Because the majority of college students own a laptop computer over a desktop computer, and they are using these devices in a transient fashion and in a number of settings, it is important to understand the risks associated with these patterns of use. College students are required to use computers frequently; consequently, musculoskeletal discomfort associated with computer use is widespread in college students, with over 50\% reporting some form of discomfort (Jenkins et al., 2007; Schlossberg et al., 2004). These factors make college students a particularly important population to examine in terms of understanding the risks and attempting to find solutions.

One variable of interest is gender, as it has previously been found that females have a tendency to report a higher prevalence of musculoskeletal discomfort associated with computer use than males, particularly in the neck (Bergqvist et al., 1995; Bernard et al., 1994; Rajagopal et al., 2012). However, Bernard et al. (1994) cautioned that this might be due to gender differences in the tasks performed by participants in their sample. Despite this qualification, males and females tend to adopt slightly different postures when performing seated computer work, which may affect their degree of comfort or discomfort (Dunk \& Callaghan, 2005; Straker et al., 2009b). Regardless of the chair used or task performed, males tend to exhibit greater trunk and lumber flexion, as well as greater posterior pelvic rotation than their female counterparts, who actually tend to show anterior pelvic rotation. These trends have been found in both adult and adolescent populations. Males are also more likely to utilize a backrest when one is provided, while females tend to perch towards the front of the seat pan. Because of anatomical differences, it is likely that males and females also adopt different postures in other contexts, such as when 
using a laptop away from a desk. Because of this, in order to understand and assess the postures adopted during laptop computer use, it is important to examine males and females separately.

One hypothesis that has not been investigated as an explanation for the finding that females are more likely to report musculoskeletal discomfort related to computer use than males is that they may be more likely than males to work in awkward or risky configurations. There are few studies that directly focus on gender differences in discomfort while using laptop computers, or on the mechanisms that may cause this.

In the current study, an initial a web survey was conducted to identify the configurations that college students use their laptop computers in most frequently and to reveal the prevalence of musculoskeletal discomfort associated with laptop use in general. This survey was also intended to identify any gender differences in patterns of laptop use and the prevalence of musculoskeletal discomfort associated with laptop use. It is hypothesized that there is a greater prevalence of musculoskeletal discomfort related to laptop computer use in females than males, as this trend has been shown in previous studies (Bergqvist et al., 1995; Bernard et al., 1994; Rajagopal et al., 2012).

H1: Females will report a higher prevalence of musculoskeletal discomfort associated with laptop use than males.

As an explanation for this, it is hypothesized that the configurations that females are more likely than males to utilize are associated with deviated postures. This hypothesis has three components.

$\mathrm{H} 2$ : Females will report using laptop computers in configurations that are associated with deviated postures more frequently than males.

H2a: Males and females will report different patterns of laptop use, in that some 
configurations are utilized by each gender more frequently than others.

$\mathrm{H} 2 \mathrm{~b}$ : The configurations of laptop use that females report utilizing more frequently than males will be those that are associated with risky or deviated upper-body postures.

H2c: Postural deviation will be positively correlated with musculoskeletal discomfort in a body region.

In order to test the second hypothesis, an experiment was conducted to examine participants' posture for some of the most commonly utilized configurations identified in the survey. Discomfort data was collected while participants used a laptop in each of three configurations that involve using a laptop computer on a bed.

Previous studies have found that males and females adopt different postures during seated computer work (Dunk \& Callaghan, 2005; Straker et al., 2009b). It is expected that postural differences will also exist when using a laptop away from a desk, and in the experiment it was hypothesized that females are more likely than males to adopt risky postures while using a laptop in each of the three configurations when lying or sitting on a bed. This hypothesis is offered as an alternative explanation for the finding that females have a higher prevalence of musculoskeletal discomfort associated with laptop use than males.

H3: Females will adopt more highly deviated postures than males when using a laptop computer on a bed.

By understanding the impact laptop computer use has on the musculoskeletal system in male and female college students, ergonomic interventions can be implemented and products designed to target problematic postures and reduce the risk of developing an injury. This study focuses on the context of computer use on a bed, which also has implications for individuals and 
professionals who telecommute or travel as part of their jobs and spend time working in hotel rooms and other non-office settings. 


\section{CHAPTER 2}

\section{PART I: SURVEY OF LAPTOP USE}

\subsection{Method}

\subsubsection{Participants}

A total of 191 students completed the online questionnaire, five of which were excluded from analysis because they did not meet the inclusion criteria (two respondents were staff members, two were alumni, and one did not own a laptop computer). Consequently, 186 participants were included in the final data analysis, 148 undergraduate students and 38 graduate students. A variety of majors were included in the sample. The final sample was comprised of 90 males and 96 females. Participants ranged in age from 18 to $50(M=21.41, S D=3.677)$. The sample of males was slightly older $(M=21.88, S D=4.717)$ than the sample of females $(M=$ 20.97, $S D=2.238), t(179)=1.667, p=.044$.

\subsubsection{Measures}

An online questionnaire was created using Qualtrics survey software. The survey asked questions to identify the configurations in which college students most frequently work on their laptop computers. In order to create the questionnaire, a list of the possible configurations in which a laptop can be used was brainstormed, resulting in a total of 31 possible configurations that students may use a laptop in for extended periods of time. The list included positions of working on a sofa, on a bed, on the floor, standing, and other possible configurations. Configurations that were not expected to be utilized frequently or for extended periods of time were not included, such as while standing and holding the laptop. A section for respondents to add positions that were missed or not included in the list was included at the end of the survey. 
Each question asked the participants to rate how often they use their laptop computer in the described configuration (never, occasionally (less than 1 hour per week), 1-5 hours per week, 5-10 hours per week, 10-15 hours per week, over 15 hours per week). A picture of a person demonstrating each configuration was provided with the verbal description in order to eliminate any ambiguity or confusion regarding the configuration being described.

Demographic questions and questions about any pain or discomfort experienced while using a laptop computer were also included in the questionnaire. The survey took approximately 10 to 20 minutes to complete. The full questionnaire can be found in Appendix A.

\subsubsection{Procedure}

Emails were sent out to all students in the departments of Design and Environmental Analysis, Computer Science, Psychology, Information Science, and Communication, inviting students to participate in a study examining the ways in which college students use their laptop computers. Flyers were also posted throughout campus inviting students to participate in the study, and the study was advertised on the department of Psychology's SUSAN online recruiting website. Recruitment and participation took place after the end of the spring semester, from the end of May to early September 2013. In order to be eligible to participate, one must be both a Cornell student and the owner of a laptop computer. Participants received entry in a draw for one of three $\$ 25$ visa gift cards for their participation. Because more females responded to the survey than males, the online description in SUSAN was changed partially through the recruitment process to specify the need for male subjects. The survey was closed once the number of males and females became more balanced.

A link to access the questionnaire was provided in the email that was distributed, on ripoff tags on the flyers that were posted, and online to participants who were recruited through 
SUSAN. Upon deciding to participate, each student visited the link independently to complete the questionnaire. The first page of the questionnaire outlined the purpose and goals of the research, eligibility requirements, and potential risks. Completion of the questionnaire was taken as informed consent. The questionnaire took approximately 10 to 20 minutes to complete, and there was no time limit enforced. The Institutional Review Board at Cornell University approved this research design.

\subsubsection{Analysis}

The results of the survey were exported from Qualtrics into IBM SPSS Statistics version 21. A Pearson chi-square test was used to determine if there were any gender differences in selfreported musculoskeletal discomfort in specific body areas, and in how frequently subjects reported using a laptop computer in each configuration listed. Because the response choices were ordinal, the median response for males, females, and the entire sample are presented to represent average responses.

\subsection{Results}

\subsubsection{Prevalence of Musculoskeletal Discomfort}

$53.76 \%$ of the students surveyed reported experiencing some form of pain or discomfort associated with laptop computer use, most frequently in the wrists, neck, and lower back (Table 1). $36.02 \%$ of the students surveyed reported experiencing pain or discomfort in the neck, $26.88 \%$ reported pain or discomfort in the wrists, and $24.19 \%$ reported pain or discomfort in the lower back. $17.20 \%$ and $16.67 \%$ of those surveyed reported experiencing pain or discomfort in the upper back and shoulders respectively. There was a lower prevalence of reported pain or discomfort in the fingers and arms/elbows (8.06\% and 3.23\% respectively). 
Table 1. Number of respondents who reported pain or discomfort in each body region

\begin{tabular}{|l|l|l|}
\hline \multicolumn{1}{|c|}{ Body Region } & $\begin{array}{c}\text { Number of Participants } \\
\text { Reporting Pain/Discomfort } \\
(\mathbf{N = 1 8 6 )}\end{array}$ & $\begin{array}{l}\text { Percentage of Participants } \\
\text { Reporting Pain/Discomfort }\end{array}$ \\
\hline Neck & 67 & 36.02 \\
\hline Wrists & 50 & 26.88 \\
\hline Lower Back & 45 & 24.19 \\
\hline Upper Back & 32 & 17.20 \\
\hline Shoulders & 31 & 16.67 \\
\hline Fingers & 15 & 8.06 \\
\hline Arms/elbows & 6 & 3.23 \\
\hline
\end{tabular}

There was no significant effect of gender on musculoskeletal discomfort, $\chi^{2}(1, N=186)$ $=0.013, p=.909 .53 .33 \%$ of males and $54.17 \%$ of females reported some degree of pain or discomfort associated with laptop computer use, and both genders were most likely to report discomfort in the wrists, neck, and lower back (Table 2). A significantly higher proportion of females $(23.96 \%)$ than males $(8.89 \%)$ reported pain/discomfort in the shoulders, $\chi^{2}(1, N=186)$ $=7.595, p=.006$. A significantly higher proportion of females $(42.71 \%)$ also reported pain or discomfort in the neck, as compared to their male counterparts $(28.89 \%), \chi^{2}(1, N=186)=3.849$, $p=.05$. There was no significant difference in the proportion of males and females reporting pain or discomfort in the wrists $\left(\chi^{2}(1, N=186)=0.527, p=.468\right)$, fingers $\left(\chi^{2}(1, N=186)=\right.$ $0.019, p=.889)$, arms/elbows $\left(\chi^{2}(1, N=186)=0.830, p=.362\right)$, upper back $\left(\chi^{2}(1, N=186)=\right.$ $0.035, p=.851)$, or lower back $\left(\chi^{2}(1, N=186)=0.903, p=.342\right)$. 
Table 2. Percentage of males and females who reported pain or discomfort in each body region

\begin{tabular}{|l|l|l|}
\hline \multicolumn{1}{|c|}{ Body Region } & $\begin{array}{c}\text { Percentage of Males } \\
\text { Reporting Pain/Discomfort }\end{array}$ & $\begin{array}{c}\text { Percentage of Females } \\
\text { Reporting Pain/Discomfort }\end{array}$ \\
\hline Neck & 28.89 & $42.71 *$ \\
\hline Wrists & 24.44 & 29.17 \\
\hline Lower Back & 21.11 & 27.08 \\
\hline Upper Back & 16.67 & 17.71 \\
\hline Shoulders & 8.89 & $23.96 * *$ \\
\hline Fingers & 7.78 & 8.33 \\
\hline Arms/elbows & 4.44 & 2.08 \\
\hline$* \boldsymbol{p}=\mathbf{. 0 5}, * * \boldsymbol{p}<\mathbf{. 0 5}$. &
\end{tabular}

\subsubsection{Time Spent Using a Laptop Computer in Various Configurations}

Overall, participants reported working in each configuration infrequently. Because the data was skewed towards the lower end of the scale of responses, the categories at the higher end of the scale were collapsed and combined into a single category. The categories "5-10 hours per week", "10-15 hours per week", and "greater than 15 hours per week" were combined into a single category labeled "greater than 5 hours per week". All analyses were done using the resulting four categories (“never”, "less than 1 hour per week”, “1-5 hours per week”, and "greater than 5 hours per week"). In addition, configurations for which greater than $50 \%$ of participants reported that they never work in were not included in the analysis. Because the focus of the study was to identify configurations that college students commonly work in, the configurations that a majority of students report never working in were not included. Based on this criterion, 11 configurations were not included in the analysis: "sitting on the floor, not leaning against anything, legs straight out, laptop resting on your lap", "sitting on the floor, not leaning against anything, knees bent, laptop resting on your lap", "sitting on the floor, leaning against a wall or piece of furniture, legs straight out, laptop resting on the floor to the side of 
you", "sitting on the floor, leaning against a wall or piece of furniture, knees bent, laptop resting on the floor to the side of you", "sitting on the floor, not leaning against anything, legs straight out, laptop resting on the floor to the side of you", "sitting on the floor with your legs spread out in front of you, laptop resting on the floor in front of you", "sitting on a bed, leaning back against wall or headboard, knees bent, laptop resting on the bed beside you", "sitting on a bed with your legs spread in front of you, laptop resting on the bed in front of you", "standing, while laptop is on a counter or raised desk in front of you", "standing, while laptop is on a standard desk in front of you", "sitting in a lounge chair, laptop resting on a table in front of you (i.e. chairs at a coffee shop)". See Table 3 for the frequency with which participants reported working in each configuration included in the analysis. Note that rows may not add up to $100 \%$ due to rounding. See Appendix B for a table showing the frequency with which participants reported working in each configuration, including those not included in the analysis.

The configurations that the participants reported working in most frequently included "sitting in an office chair at a desk" and "sitting in a straight-back chair at a desk", which had median responses of greater than 5 hours per week and 1-5 hours per week respectively. "Sitting on a bed, leaning back against a wall or headboard, legs straight out, laptop resting on your lap" also had a median response of 1-5 hours per week. All other positions had a median response of never or occasionally (less than 1 hour per week). Median responses for the average frequency of use of each position for males and females are presented in Table 4 . The median value is presented rather than the mean because the data is skewed and the response options were ordinal. This information is presented as purely descriptive, and gender differences in patterns of reporting are presented in Table 5 . 
Table 3. Percentage of participants who selected each response for each configuration of laptop use

\begin{tabular}{|c|c|c|c|c|}
\hline \multirow{2}{*}{ Configuration described in questionnaire } & \multicolumn{4}{|c|}{$\begin{array}{l}\text { Percentage of subjects who selected } \\
\text { each response }\end{array}$} \\
\hline & Never & $\begin{array}{c}<1 \\
\mathrm{hr} / \mathrm{wk}\end{array}$ & $\begin{array}{c}1-5 \\
\mathbf{h r} / \mathrm{wk}\end{array}$ & $\begin{array}{c}>5 \\
\text { hr/wk }\end{array}$ \\
\hline $\begin{array}{l}\text { Sitting on a sofa with your feet on the floor (knees at } 90^{\circ} \text { ), laptop resting } \\
\text { on your lap }\end{array}$ & 15.6 & 41.4 & 32.8 & 10.2 \\
\hline $\begin{array}{l}\text { Sitting on a sofa with your legs straight out, feet supported on a coffee } \\
\text { table or ottoman, laptop resting on your lap }\end{array}$ & 22.2 & 32.4 & 31.9 & 13.5 \\
\hline $\begin{array}{l}\text { Sitting on a sofa with legs bent, feet resting on a coffee table, laptop } \\
\text { resting on your lap }\end{array}$ & 22.6 & 37.1 & 28.5 & 11.8 \\
\hline $\begin{array}{l}\text { Sitting on a sofa with your feet on the floor (knees at } 90^{\circ} \text { ), bending over } \\
\text { to use laptop that is resting on a coffee table or ottoman in front of you }\end{array}$ & 41.6 & 38.9 & 11.4 & 8.1 \\
\hline $\begin{array}{l}\text { Sitting on the floor, leaning against a wall or piece of furniture, legs } \\
\text { straight out, laptop resting on your lap }\end{array}$ & 50.0 & 34.4 & 11.3 & 4.3 \\
\hline $\begin{array}{l}\text { Sitting on the floor, leaning against a wall or piece of furniture, knees } \\
\text { bent, laptop resting on your lap }\end{array}$ & 47.3 & 34.9 & 12.9 & 4.8 \\
\hline Sitting on the floor with your legs crossed, laptop resting on your lap & 43.5 & 37.6 & 17.2 & 1.6 \\
\hline $\begin{array}{l}\text { Sitting on the floor with your legs crossed, laptop resting on the floor in } \\
\text { front of you }\end{array}$ & 43.0 & 43.0 & 11.3 & 2.7 \\
\hline $\begin{array}{l}\text { Lying on your stomach on the floor, laptop resting on the floor in front } \\
\text { of you }\end{array}$ & 31.2 & 34.9 & 19.4 & 14.5 \\
\hline $\begin{array}{l}\text { Sitting on a bed, leaning back against a wall or headboard, legs straight } \\
\text { out, laptop resting on your lap }\end{array}$ & 16.7 & 20.4 & 34.9 & 28.0 \\
\hline $\begin{array}{l}\text { Sitting on a bed, leaning back against a wall or headboard, legs straight } \\
\text { out, laptop resting on the bed beside you }\end{array}$ & 54.3 & 19.4 & 17.7 & 8.6 \\
\hline $\begin{array}{l}\text { Sitting on a bed, leaning back against a wall or headboard, knees bent, } \\
\text { laptop resting on your lap }\end{array}$ & 26.9 & 28.5 & 30.1 & 14.5 \\
\hline Sitting on a bed with your legs crossed, laptop resting on your lap & 43.8 & 31.9 & 13.5 & 10.8 \\
\hline $\begin{array}{l}\text { Sitting on a bed with your legs crossed, laptop resting on the bed in front } \\
\text { of you }\end{array}$ & 41.9 & 33.3 & 16.7 & 8.1 \\
\hline $\begin{array}{l}\text { Lying on your stomach on a bed, laptop resting on the bed in front of } \\
\text { you }\end{array}$ & 22.0 & 31.2 & 23.7 & 23.1 \\
\hline Sitting in an office chair at a desk & 10.3 & 13.5 & 18.4 & 57.8 \\
\hline Sitting in a straight-back chair at a desk & 8.1 & 19.4 & 23.7 & 48.9 \\
\hline $\begin{array}{l}\text { Sitting in a straight-back chair that has an attached work surface on the } \\
\text { side (i.e. in a classroom) }\end{array}$ & 27.7 & 27.7 & 26.6 & 17.9 \\
\hline $\begin{array}{l}\text { Sitting on a stool at a counter, while the laptop is on the counter in front } \\
\text { of you }\end{array}$ & 44.3 & 33.9 & 14.8 & 7.1 \\
\hline $\begin{array}{l}\text { Sitting in a lounge chair, laptop resting on your lap (i.e. chairs at a } \\
\text { coffee shop) }\end{array}$ & 20.5 & 36.2 & 29.7 & 13.5 \\
\hline
\end{tabular}


Table 4. Median frequencies with which participants reported using their laptop computer in each configuration

\begin{tabular}{|c|c|c|c|}
\hline \multirow{2}{*}{ Configuration } & \multicolumn{3}{|c|}{ Median reported frequency } \\
\hline & Overall & Males & Females \\
\hline $\begin{array}{l}\text { Sitting on a sofa with your feet on the floor (knees at } 90^{\circ} \text { ), laptop resting on your } \\
\text { lap }\end{array}$ & 2.0 & 2.5 & 2.0 \\
\hline $\begin{array}{l}\text { Sitting on a sofa with your legs straight out, feet supported on a coffee table or } \\
\text { ottoman, laptop resting on your lap }\end{array}$ & 2.0 & 2.0 & 2.0 \\
\hline $\begin{array}{l}\text { Sitting on a sofa with legs bent, feet resting on a coffee table, laptop resting on } \\
\text { your lap }\end{array}$ & 2.0 & 2.0 & 2.0 \\
\hline $\begin{array}{l}\left.\text { Sitting on a sofa with your feet on the floor (knees at } 90^{\circ}\right) \text {, bending over to use } \\
\text { laptop that is resting on a coffee table or ottoman in front of you }\end{array}$ & 2.0 & 2.0 & 1.5 \\
\hline $\begin{array}{l}\text { Sitting on the floor, leaning against a wall or piece of furniture, legs straight out, } \\
\text { laptop resting on your lap }\end{array}$ & 1.5 & 1.0 & 2.0 \\
\hline $\begin{array}{l}\text { Sitting on the floor, leaning against a wall or piece of furniture, knees bent, } \\
\text { laptop resting on your lap }\end{array}$ & 2.0 & 1.0 & 2.0 \\
\hline Sitting on the floor with your legs crossed, laptop resting on your lap & 2.0 & 1.5 & 2.0 \\
\hline $\begin{array}{l}\text { Sitting on the floor with your legs crossed, laptop resting on the floor in front of } \\
\text { you }\end{array}$ & 2.0 & 1.0 & 2.0 \\
\hline Lying on your stomach on the floor, laptop resting on the floor in front of you & 2.0 & 2.0 & 2.0 \\
\hline $\begin{array}{l}\text { Sitting on a bed, leaning back against a wall or headboard, legs straight out, } \\
\text { laptop resting on your lap }\end{array}$ & 3.0 & 3.0 & 3.0 \\
\hline $\begin{array}{l}\text { Sitting on a bed, leaning back against a wall or headboard, legs straight out, } \\
\text { laptop resting on the bed beside you }\end{array}$ & 1.0 & 2.0 & 1.0 \\
\hline $\begin{array}{l}\text { Sitting on a bed, leaning back against a wall or headboard, knees bent, laptop } \\
\text { resting on your lap }\end{array}$ & 2.0 & 2.0 & 3.0 \\
\hline Sitting on a bed with your legs crossed, laptop resting on your lap & 2.0 & 1.0 & 2.0 \\
\hline Sitting on a bed with your legs crossed, laptop resting on the bed in front of you & 2.0 & 1.0 & 2.0 \\
\hline $\begin{array}{l}\text { Sitting on a bed with your legs spread in front of you, laptop resting on the bed in } \\
\text { front of you }\end{array}$ & 1.0 & 1.0 & 1.0 \\
\hline Lying on your stomach on a bed, laptop resting on the bed in front of you & 2.0 & 2.0 & 2.5 \\
\hline Sitting in an office chair at a desk & 4.0 & 4.0 & 4.0 \\
\hline Sitting in a straight-back chair at a desk & 3.0 & 4.0 & 3.0 \\
\hline $\begin{array}{l}\text { Sitting in a straight-back chair that has an attached work surface on the side (i.e. } \\
\text { in a classroom) }\end{array}$ & 2.0 & 2.0 & 2.0 \\
\hline Sitting on a stool at a counter, while the laptop is on the counter in front of you & 2.0 & 2.0 & 2.0 \\
\hline Sitting in a lounge chair, laptop resting on your lap (i.e. chairs at a coffee shop) & 2.0 & 2.0 & 2.0 \\
\hline
\end{tabular}

Notes: Numeric values were assigned to each response value. 1 = never; 2 = occasionally $(<1$ hour per week); $3=1-5$ hours per week; $4=>5$ hours per week. 
A Pearson chi-square test was performed in order to determine whether there was a significant difference in the frequency with which males and females reported working in each configuration. The proportion of males and females who report working in each configuration is presented in Table 5. Note that rows may not add up to $100 \%$ due to rounding. Configurations not included in the analyses due to a low proportion of subjects reporting working in the configuration are not included.

Females reported spending significantly more time than males "sitting on the floor, leaning against a wall or piece of furniture, legs straight out, laptop resting on your lap" ( $\chi^{2}(3, N$ $=186)=9.655, p=.022$ ), "sitting on the floor with your legs crossed, laptop resting on the floor in front of you" $\left(\chi^{2}(3, N=186)=11.497, p=.009\right)$, "sitting on a bed, leaning back against a wall or headboard, knees bent, laptop resting on your lap" $\left(\chi^{2}(3, N=186)=8.554, p=.036\right)$, "sitting on a bed with your legs crossed, laptop resting on your lap" $\left(\chi^{2}(3, N=185)=14.597, p\right.$ $=.002)$, "sitting on a bed with your legs crossed, laptop resting on the bed in front of you" $\left(\chi^{2}(3\right.$, $N=186)=26.504, p=<.001$ ), and "sitting in a lounge chair, laptop resting on your lap (i.e. chairs at a coffee shop $) "\left(\chi^{2}(3, N=185)=8.048, p=.045\right)$.

Males reported spending significantly more time than females "sitting on a sofa with your feet on the floor (knees at $90^{\circ}$ ), bending over to use laptop that is resting on a coffee table or ottoman in front of you" $\left(\chi^{2}(3, N=185)=8.893, p=.031\right)$ and "sitting on a bed, leaning back against a wall or headboard, legs straight out, laptop resting on the bed beside you" $\left(\chi^{2}(3, N=\right.$ 186) $=8.887, p=.031)$.

There was no effect of gender on any of the other configurations included in the analysis: "sitting on a sofa with your feet on the floor (knees at $\left.90^{\circ}\right)$, laptop resting on your lap" $\left(\chi^{2}(3, N=\right.$ $186)=4.278, p=.233)$, "sitting on a sofa with your legs straight out, feet supported on a coffee 
Table 5. Percentage of males and females who selected each frequency for each configuration included in the analysis

\begin{tabular}{|c|c|c|c|c|c|}
\hline \multirow{2}{*}{ Configuration described in questionnaire } & \multirow{2}{*}{ Gender } & \multicolumn{4}{|c|}{$\begin{array}{c}\text { Percentage of subjects who } \\
\text { selected each response }\end{array}$} \\
\hline & & Never & $\begin{array}{c}<1 \\
\text { hr/wk }\end{array}$ & $\begin{array}{c}1-5 \\
\text { hr/wk }\end{array}$ & $\begin{array}{c}>5 \\
\mathrm{hr} / \mathrm{wk}\end{array}$ \\
\hline \multirow{2}{*}{$\begin{array}{l}\text { Sitting on a sofa with your feet on the floor (knees at } 90^{\circ} \text { ), laptop } \\
\text { resting on your lap }\end{array}$} & Males & 12.2 & 37.8 & 36.7 & 13.3 \\
\hline & Females & 18.8 & 44.8 & 29.2 & 7.3 \\
\hline \multirow{2}{*}{$\begin{array}{l}\text { Sitting on a sofa with your legs straight out, feet supported on a } \\
\text { coffee table or ottoman, laptop resting on your lap }\end{array}$} & Males & 21.1 & 36.7 & 30 & 12.2 \\
\hline & Females & 23.2 & 28.4 & 33.7 & 14.7 \\
\hline \multirow{2}{*}{$\begin{array}{l}\text { Sitting on a sofa with legs bent, feet resting on a coffee table, laptop } \\
\text { resting on your lap }\end{array}$} & Males & 30 & 33.3 & 26.7 & 10 \\
\hline & Females & 15.6 & 40.6 & 30.2 & 13.5 \\
\hline \multirow{2}{*}{$\begin{array}{l}\left.\text { * Sitting on a sofa with your feet on the floor (knees at } 90^{\circ}\right) \text {, } \\
\text { bending over to use laptop that is resting on a coffee table or } \\
\text { ottoman in front of you }\end{array}$} & Males & 32.6 & 40.4 & 14.6 & 12.4 \\
\hline & Females & 50 & 37.5 & 8.3 & 4.2 \\
\hline \multirow{2}{*}{$\begin{array}{l}\text { * Sitting on the floor, leaning against a wall or piece of furniture, } \\
\text { legs straight out, laptop resting on your lap }\end{array}$} & Males & 60 & 27.8 & 6.7 & 5.6 \\
\hline & Females & 40.6 & 40.6 & 15.6 & 3.1 \\
\hline \multirow{2}{*}{$\begin{array}{l}\text { Sitting on the floor, leaning against a wall or piece of furniture, } \\
\text { knees bent, laptop resting on your lap }\end{array}$} & Males & 54.4 & 28.9 & 11.1 & 5.6 \\
\hline & Females & 40.6 & 40.6 & 14.6 & 4.2 \\
\hline \multirow{2}{*}{$\begin{array}{l}\text { Sitting on the floor with your legs crossed, laptop resting on your } \\
\text { lap }\end{array}$} & Males & 50 & 33.3 & 14.4 & 2.2 \\
\hline & Females & 37.5 & 41.7 & 19.8 & 1 \\
\hline \multirow{2}{*}{$\begin{array}{l}\text { ** Sitting on the floor with your legs crossed, laptop resting on the } \\
\text { floor in front of you }\end{array}$} & Males & 55.6 & 32.2 & 10.0 & 2.2 \\
\hline & Females & 31.3 & 53.1 & 12.5 & 3.1 \\
\hline \multirow{2}{*}{$\begin{array}{l}\text { Lying on your stomach on the floor, laptop resting on the floor in } \\
\text { front of you }\end{array}$} & Males & 36.7 & 33.3 & 16.7 & 13.3 \\
\hline & Females & 26 & 36.5 & 21.9 & 15.6 \\
\hline \multirow{2}{*}{$\begin{array}{l}\text { * Sitting on a bed, leaning back against a wall or headboard, legs } \\
\text { straight out, laptop resting on your lap }\end{array}$} & Males & 22.2 & 21.1 & 32.2 & 24.4 \\
\hline & Females & 11.5 & 19.8 & 37.5 & 31.3 \\
\hline \multirow{2}{*}{$\begin{array}{l}\text { * Sitting on a bed, leaning back against a wall or headboard, legs } \\
\text { straight out, laptop resting on the bed beside you }\end{array}$} & Males & 44.4 & 20 & 23.3 & 12.2 \\
\hline & Females & 63.5 & 18.8 & 12.5 & 5.2 \\
\hline \multirow{2}{*}{$\begin{array}{l}\text { * Sitting on a bed, leaning back against a wall or headboard, knees } \\
\text { bent, laptop resting on your lap }\end{array}$} & Males & 33.3 & 32.2 & 25.6 & 8.9 \\
\hline & Females & 20.8 & 25 & 34.4 & 19.8 \\
\hline \multirow{2}{*}{$\begin{array}{l}* * \text { Sitting on a bed with your legs crossed, laptop resting on your } \\
\text { lap }\end{array}$} & Males & 56.2 & 30.3 & 6.7 & 6.7 \\
\hline & Females & 32.3 & 33.3 & 19.8 & 14.6 \\
\hline \multirow{2}{*}{$\begin{array}{l}\text { ** Sitting on a bed with your legs crossed, laptop resting on the bed } \\
\text { in front of you }\end{array}$} & Males & 60 & 22.2 & 8.9 & 8.9 \\
\hline & Females & 25 & 43.8 & 24 & 7.3 \\
\hline \multirow{2}{*}{$\begin{array}{l}\text { Lying on your stomach on a bed, laptop resting on the bed in front } \\
\text { of you }\end{array}$} & Males & 26.7 & 30 & 18.9 & 24.4 \\
\hline & Females & 17.7 & 32.3 & 28.1 & 21.9 \\
\hline \multirow{2}{*}{ Sitting in an office chair at a desk } & Males & 11.1 & 8.9 & 18.9 & 61.1 \\
\hline & Females & 9.5 & 17.9 & 17.9 & 54.7 \\
\hline \multirow{2}{*}{ Sitting in a straight-back chair at a desk } & Males & 6.7 & 17.8 & 23.3 & 52.2 \\
\hline & Females & 9.4 & 20.8 & 24 & 45.8 \\
\hline \multirow{2}{*}{$\begin{array}{l}\text { Sitting in a straight-back chair that has an attached work surface on } \\
\text { the side (i.e. in a classroom) }\end{array}$} & Males & 23.3 & 27.8 & 26.7 & 22.2 \\
\hline & Females & 31.9 & 27.7 & 26.6 & 13.8 \\
\hline \multirow{2}{*}{$\begin{array}{l}\text { Sitting on a stool at a counter, while the laptop is on the counter in } \\
\text { front of you }\end{array}$} & Males & 41.6 & 29.2 & 21.3 & 7.9 \\
\hline & Females & 46.8 & 38.3 & 8.5 & 6.4 \\
\hline \multirow{2}{*}{$\begin{array}{l}\text { * Sitting in a lounge chair, laptop resting on your lap (i.e. chairs at a } \\
\text { coffee shop) }\end{array}$} & Males & 24.4 & 36.7 & 21.1 & 17.8 \\
\hline & Females & 16.8 & 35.8 & 37.9 & 9.5 \\
\hline
\end{tabular}
$* p<.05, * * p<.01$.

table or ottoman, laptop resting on your lap" $\left(\chi^{2}(3, N=185)=1.469, p=.689\right)$, "sitting on a sofa

with legs bent, feet resting on a coffee table, laptop resting on your lap" $\left(\chi^{2}(3, N=186)=5.614\right.$, 
$p=.132)$, "sitting on the floor, leaning against a wall or piece of furniture, knees bent, laptop resting on your lap" $\left(\chi^{2}(3, N=186)=4.325, p=.228\right)$, "sitting on the floor with your legs crossed, laptop resting on your lap" $\left(\chi^{2}(3, N=186)=3.697, p=.296\right)$, "lying on your stomach on the floor, laptop resting on the floor in front of you" $\left(\chi^{2}(3, N=186)=2.631, p=.452\right)$, "sitting on a bed, leaning back against a wall or headboard, legs straight out, laptop resting on your lap" $\left(\chi^{2}(3, N=186)=4.409, p=.221\right)$, "lying on your stomach on a bed, laptop resting on the bed in front of you" $\left(\chi^{2}(3, N=186)=3.577, p=.311\right)$, "sitting in an office chair at a desk" $\left(\chi^{2}(3, N=185)=3.244, p=.356\right)$, "sitting in a straight-back chair at a desk" $\left(\chi^{2}(3, N=186)=\right.$ $1.042, p=.791)$, "sitting in a straight-back chair that has an attached work surface on the side (i.e. in a classroom)" $\left(\chi^{2}(3, N=184)=3.028, p=.387\right)$, and "sitting on a stool at a counter, while the laptop is on the counter in front of you" $\left(\chi^{2}(3, N=183)=6.645, p=.084\right)$.

\subsection{Discussion}

A slight majority, $53.76 \%$, of the college students surveyed in this study reported experiencing some degree of pain or discomfort associated with laptop computer use. This is consistent with the prevalence of musculoskeletal discomfort that has been found in previous studies involving college students, with the number of students reporting discomfort generally falling around 50\% (Hupert et al., 2004; Jenkins et al., 2007; Schlossberg et al., 2004). In the current study, pain/discomfort was most commonly reported in the neck, wrists, and lower back, followed by the upper back and shoulders. The results of this survey also indicate that there is no difference in the prevalence of laptop-related musculoskeletal discomfort between males and females, which does not support Hypothesis 1 . However, there is a greater prevalence of discomfort in the neck and shoulders in females compared to males, which suggests that although men and women are equally likely to experience musculoskeletal discomfort associated 
with laptop use, the location of the discomfort differs. A possible explanation for the fact that women are more likely than men to experience discomfort in the neck and shoulders is that females generally have a smaller skeletal system and less muscle mass than males, which may require females to adopt more deviated postures (i.e. reaching) while interacting with technologies such as laptop computers. In addition, because of these reasons, females generally have less protection around soft tissues such as tendons and ligaments, which may result in a greater likelihood of developing an injury. It has also been suggested in previous studies that differences in levels of reported musculoskeletal discomfort may be due to differences in the tasks performed by each gender. Because we did not ask participants to report how many total hours per week they use a laptop computer, it cannot be inferred whether the differences are due to differences in time spent using a laptop, or differences in the tasks performed on a laptop. To investigate whether this may be a relevant variable, data about the total amount of time subjects spend using a laptop computer per week regardless of configuration will be collected in Part II. In addition, the study will directly capture discomfort data as subjects work in various configurations included in the questionnaire. It is also possible that although the overall prevalence of discomfort is the same for males or females, the severity of discomfort is greater for females. This will be investigated for the postures tested in the experiment described in Part II.

Males and females were equally likely to report experiencing discomfort in the wrists, fingers, arms/elbows, upper back, and lower back. Respondents were also given the opportunity to report areas of discomfort not included in this list of body areas provided in the survey. Seven respondents reported that they experience visual strain or discomfort in the eyes while using laptop computers. This was not included in the initial survey because the eyes are not considered 
to be part of the musculoskeletal system, which is the focus of this study. In addition, the areas of the body that were provided as options were included because they are areas where a joint angle can be measured. Although only $3.76 \%$ of the respondents took the time to physically write that they experience visual discomfort while using a laptop computer, it can be inferred that the proportion of individuals experiencing visual discomfort is much higher. Previous studies have shown that visual strain or discomfort is the most common complaint associated with computer use (Blehm et al., 2005; Thomson, 1998). In addition, two subjects reported pain/discomfort in the buttocks, one subject reported pain/discomfort in the back of the hands, one subject reported pain/discomfort in the lap or thighs, and one subject reported experiencing headaches. Again, it is likely that the number of students actually experiencing discomfort in these areas is slightly higher than what was reported in this survey, but due to the very low number of subjects who reported complaints in these areas, it can be assumed that the prevalence is also relatively low.

Females reported spending significantly more time than males "sitting on the floor, leaning against a wall or piece of furniture, legs straight out, laptop resting on your lap", "sitting on the floor with your legs crossed, laptop resting on the floor in front of you", "sitting on a bed, leaning back against a wall or headboard, knees bent, laptop resting on your lap", "sitting on a bed with your legs crossed, laptop resting on your lap", "sitting on a bed with your legs crossed, laptop resting on the bed in front of you", and "sitting in a lounge chair, laptop resting on your lap (i.e. chairs at a coffee shop) when using a laptop". Males reported spending significantly more time than females "sitting on a sofa with your feet on the floor (knees at $90^{\circ}$ ), bending over to use laptop that is resting on a coffee table or ottoman in front of you" and "sitting on a bed, leaning back against a wall or headboard, legs straight out, laptop resting on the bed beside you" 
when using a computer. These findings lend support to Hypothesis 2a, which stated that there are gender differences in patterns of laptop use in regards to preferred configurations of use.

In general, females tend to spend more time than males in positions where the laptop is resting on the lap, and also in positions where they are sitting with their legs crossed. Males had a tendency to work more frequently in positions that required large deviations of the trunk, including leaning to bend over a coffee table while sitting, and sitting while the laptop is positioned to the side of the body (requiring twisting of the trunk and/or neck). The finding that females report spending more time using a laptop while it is positioned on the lap may give some insight into the increased prevalence of musculoskeletal discomfort in the neck reported by females as compared to males. Placement of a laptop on the lap often results in pronounced neck flexion, and when sustained this can lead to pain or discomfort (Asundi et al., 2010; Moffet et al., 2002; Werth \& Babski-Reeves, 2012). It is intuitive that males report working with a laptop on the lap or with the legs crossed less frequently than females do, due to anatomical differences. This likely contributes to the finding that males are more likely to work with the laptop positioned to the side of the body, as this is the obvious alternative to placement on the lap. Similarly, the finding that males are more likely to bend over a table or ottoman while using a laptop could also be because this is an alternative to placement of the laptop on the lap.

The results of this survey indicate that college students spend the greatest amount of time using their laptop computers while working at a desk. However, participants did report spending time working in other configurations, most frequently while sitting on a couch or lounge chair, and sitting or lying on a bed. One limitation of the data collected from this survey is that we did not include a question asking the subjects to report how many hours per week they use their laptop computer in general, regardless of configuration. Most participants reported that they 
work in each configuration less than 5 hours per week, which, spread over 7 days, does not sound like an inordinate amount of time. However, without a baseline to compare it to, we do not know whether subjects are working these ways for a large or small proportion of the time they use their laptop. We also did not capture data on how long they work in these configurations continuously, whether they are altering their position frequently, etc. For example, subjects may work on their computer while on their bed for hours at a time, but may alternate between lying down and various seated postures. Static postures are associated with increased loading on the musculoskeletal system and associated discomfort. Postural variation would decrease the risk of injury (Punnett \& Bergqvist, 1997).

Another limitation of this survey is that responses are subjective and rely on memory; participants may not be able to give an accurate estimate about how many hours per week they work in each position, especially if they change their posture frequently. Despite this, participants are likely able to give an estimate of which positions they work in more than others, especially the ones that are utilized most often. Another constraint in interpreting the responses is that the list of configurations included in the questionnaire is not exhaustive. It is unknown if during the construction of the questionnaire popular configurations were left out. Participants were given the opportunity to write-in configurations that were missed, however even when this done, it was not quantified in terms of frequency of use. Because of this, and the small number of participants who mentioned additional positions, this data was not considered in the analysis. In addition, other variations of the configurations included in the questionnaire may exist (i.e. crossed legs with laptop raised on pillow in front versus crossed legs with laptop on bed in front), which may affect the interpretation of the questions and subsequent responses of the participants. 
Because of these limitations, we are restricted in the assumptions we can make about the patterns of laptop computer use exhibited by the students in our sample. However, we were able to identify configurations that college students spend some time working in, and generally which configurations are the most common. One of the main contexts in which college students use laptop computers is while sitting or lying on a bed. Part II of this study examines three configurations that are utilized by college students when using a laptop computer on a bed. 


\section{CHAPTER 3}

\section{PART II: POSTURAL ANALYSIS OF LAPTOP USE ON A BED}

\subsection{Introduction}

An experiment was conducted to further investigate the survey findings from Part I, and the sources of musculoskeletal discomfort in males and females. The hypothesis that there is a higher prevalence of reported musculoskeletal discomfort associated with laptop use in females than males was not fully supported by the results of the survey. However, females were significantly more likely than males to report discomfort in the neck and shoulders. The experiment tested whether females experience greater neck and shoulder musculoskeletal discomfort than males because they use laptop computers more frequently in configurations that are associated with deviated postures that increase discomfort. The experiment investigated a subset of the configurations that females reported utilizing more frequently than men in the survey. Discomfort and upper-body posture were analyzed to determine whether these configurations are significantly associated with musculoskeletal discomfort, especially in the neck and shoulders. This analysis also examined any postural differences between males and females. Three configurations were chosen for testing: "sitting on a bed, leaning back against a wall or headboard, legs straight, laptop resting on your lap", "sitting on a bed with your legs crossed, laptop resting on your lap", and "sitting on a bed with your legs crossed, laptop resting on the bed in front of you".

Previous research has found postural differences between males and females while using a computer at a desk (Dunk \& Callaghan, 2005; Straker et al., 2009b), however, postural differences between males and females while using a laptop computer on a bed have not previously been quantified. 


\subsection{Method}

\subsubsection{Participants}

Participants in this study included 18 male and 18 female right-handed undergraduate students at Cornell University. All participants were between the ages of 18 and 21 years old ( $M$ $=19.86, S D=.93)$, and all were the owners of a laptop computer. Participants were recruited through flyers that were posted throughout Cornell University’s campus, and received \$20 compensation for their participation in the study. The Institutional Review Board at Cornell University approved the research design.

\subsubsection{Measures}

3.2.2.1 Demographics. A paper-based demographic questionnaire was used in order to collect data regarding age, gender, level of activity, student status and major, and handedness. The questionnaire also collected data regarding any existing physical impairments, discomfort associated with laptop computer use, and frequency of laptop computer use. The demographic questionnaire can be found in Appendix C.

3.2.2.2 Anthropometrics. The following measurements were taken using a standard measuring tape: overall height, height to tragus (ear), height to acromion process (shoulder), height to the top of iliac crest in line with the lateral epicondyle (hip), height to patella (knee). Measurements were taken with the participant's shoes off.

3.2.2.3 Posture. Flexion, extension, radial deviation, and ulnar deviation of the right wrist was measured using an electrogoniometer. The right side of the body was measured because all participants were right-handed. Abduction and adduction of the shoulder was measured using a combination of body markers (stickers and tape) and photographs taken from the front of the participant. Flexion and extension of the neck; flexion and extension of the right 
shoulder, extension of the right elbow; and flexion and extension of the trunk were measured using a combination of body markers (stickers and tape) and photographs taken perpendicular to the right side of the participant. Body markers were attached to the tragus, C7 vertebrae of the spine, L5 vertebrae of the spine, top of iliac crest in line with the lateral epicondyle, acromion process, lateral epicondyle, ulnar styloid process, patella, and calcaneus. Joint angles were calculated from the photographs based on lines drawn between two or three body markers, depending on the joint in question.

In order to measure the angle of deviation of the neck, lines connecting the body markers positioned on the tragus, C7 vertebrae of the spine, and L5 vertebrae of the spine were drawn on photographs taken from the side of each participant. A calibration photograph was taken with each participant sitting straight up and looking forward in a neutral neck posture, and again in the same posture while standing, in order to capture his or her neutral neck position. The deviation from this neutral position was calculated from each photograph to determine the position of the neck.

In order to measure the angle of flexion or extension of the elbow, lines were drawn connecting the ulnar styloid process, lateral epicondyle, and acromion process. Flexion or extension of the shoulder was measured from lines connecting the acromion process, lateral epicondyle, and top iliac crest in line with the lateral epicondyle. Flexion or extension of the trunk was measured from lines connecting the $\mathrm{C} 7$ vertebrae of the spine to the top of iliac crest, and a line extending from the top of iliac crest to the horizontal. The angle at the intersection of these lines was measured to indicate deviation of the trunk. The photographs were straightened to ensure an accurate horizontal line by using a strip of metal on the wall that runs parallel to the floor. 
Abduction or adduction of the shoulder was measured from photographs taken of the participant straight on. The photographs were straightened in Photoshop using the headboard of the bed as a horizontal landmark, and a line was drawn from the lateral epicondyle to the acromion process, and another line was drawn vertical downwards from the acromion process. The resulting angle was used as the angle of abduction or adduction. Figure 1 shows examples of the photographs taken to obtain posture measurements. Detailed diagrams and descriptions of the landmarks used to take each specific measurement can be viewed in Appendix D.
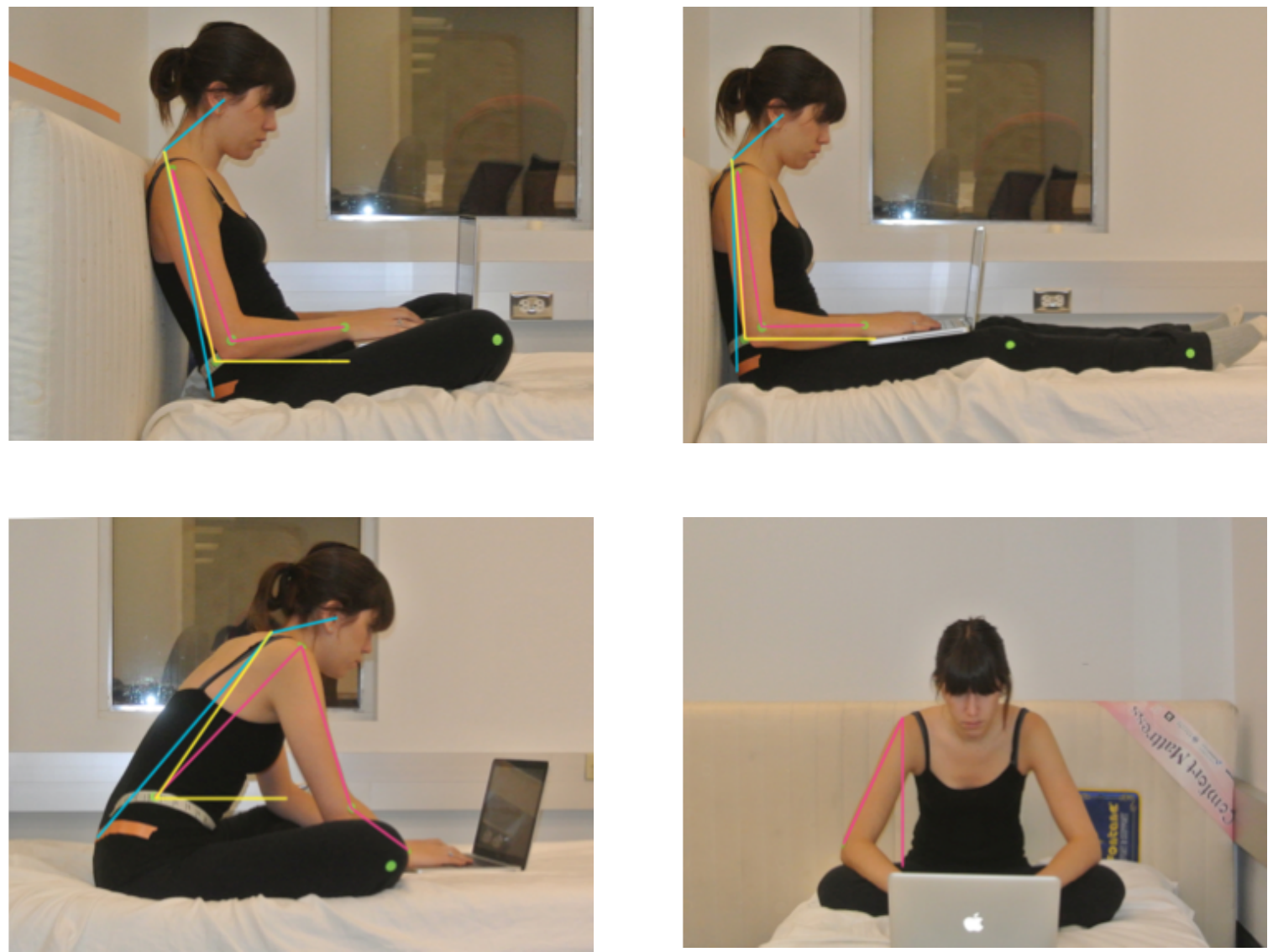

Figure 1. Illustration of three configurations tested and method of posture measurement. Top left $=\mathrm{CL}$, top right $=\mathrm{LS}$, bottom left $=\mathrm{CB}$, bottom right $=$ front view of $\mathrm{CB}$. Blue line represents measurement of neck flexion/extension, pink line represents measurement of shoulder flexion/extension or abduction/adduction and measurement of elbow angle. Yellow line represents measurement of trunk angle.

3.2.2.4 Discomfort. 11 separate visual analog scales were used to measure self-reported discomfort in the hands, wrists, forearms, elbows, neck, shoulders, upper back, lower back, 
buttocks, thighs, and knees. Each scale was $10 \mathrm{~cm}$ long, with an anchor labeled "no discomfort" on the left end, and an anchor labeled "extreme discomfort" on the right end. The discomfort questionnaire was filled out on paper, and can be found in Appendix E.

\subsubsection{Equipment}

3.2.3.1 Mattress. The mattress used in this study was a Serta iComfort twin XL, model number 500821318. The mattress was covered with a white sheet. A four-inch thick, twin-sized (30" x 72") A-Fontane comfort mattress was propped up on its side against the wall behind Serta mattress, and was used as a headboard the participants could lean against. An image of the set-up can be seen in Figure 3.

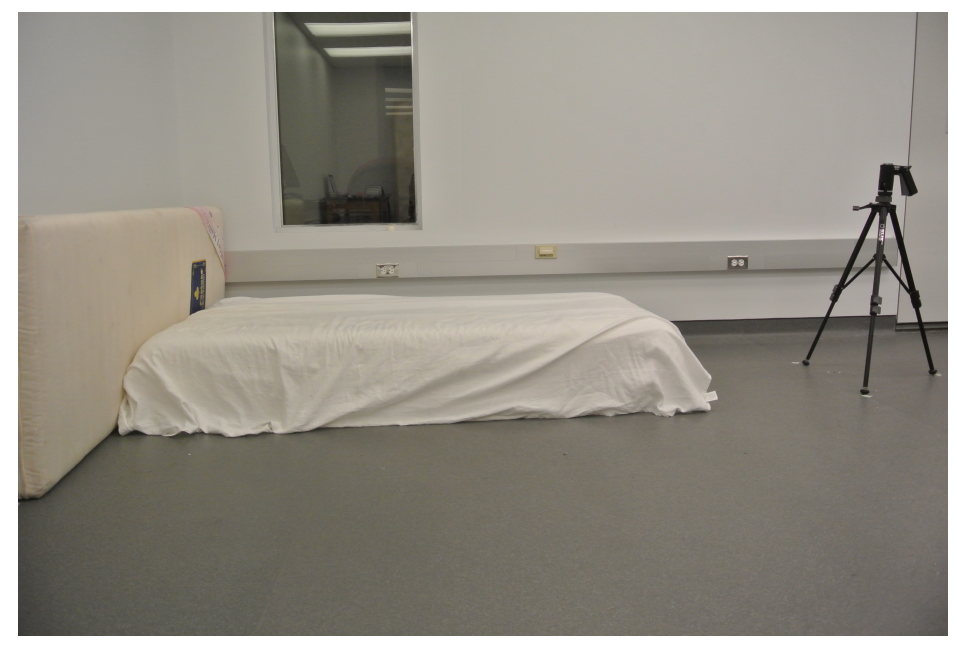

Figure 3. Laboratory set-up with mattress and camera

3.2.3.2 Electrogoniometer. A Biometrics Ltd. SG65 twin axis goniometer was used to measure flexion, extension, ulnar deviation, and radial deviation of the right wrist. Upon attaching the electrogoniometer to the back of the participant's hand and forearm, neutral wrist position was calibrated to zero using the DataLINK software. All data provided the deviation from this neutral position. 
3.2.3.3 DataLINK software. Biometrics Ltd. DataLINK acquisition system was used in conjunction with the electrogoniometer. Data was collected at a rate of 20 data points per second, and was exported using raw values. These raw values were translated into degrees of deviation using the following formula, as per the instructions contained within the software's manual: (raw value $/ 4000) \times 180$ degrees $=$ value in degrees.

3.2.3.4 Cameras. A Nikon $1 \mathrm{~J} 2$ digital camera was used to capture all photographs taken from the side of the body. The camera was set up on a tripod approximately eight feet away from the side of the mattress, perpendicular to the mattress and direction the participant was facing. A Canon PowerShot SD790 IS digital camera was used to capture all photographs taken from the front of the body. The camera was set up on a tripod approximately three feet away from the end of the mattress opposite from the headboard, in line with and facing the participant.

3.2.3.5 Body markers. $3 / 4$ inch diameter circular "neon dot stickers" were used to mark the position of the relevant joints (depicted in Figure 1). In cases where the body markers would not be visible on camera due to obstructions (i.e. arm in the way, body marker on back of participant), tape was used to extend the location of the marker into view. For example, the marker on the hip was often occluded by the participant's arm, so a strip of tape with numbered lines one inch apart was placed in line with the marker, so that the position of the marker could be extrapolated when not directly visible in the photographs.

3.2.3.6 Laptop. A 13-inch MacBook Pro was used by all participants in the study. The trackpad was set with a "natural" scroll direction where the content movement matches finger movement. Participants were instructed to change the brightness and angle of the screen, and the text size so that they could read the text clearly. 
3.2.3.7 Typing task. A PDF version of "Life of Pi" by Yann Martel was obtained from the Internet to be used in this study. The task required participants to type out the text from the PDF into a blank document in Microsoft Word. For the first condition, participants typed out the text starting from chapter one. Regardless of how far he or she got, condition two started at the beginning of chapter four, and condition three started at the beginning of chapter seven. Participants were instructed to change the size of the PDF document (and font size) and the size of the font in Microsoft Word so that they could read the text clearly.

3.2.3.8 Photoshop. Adobe Photoshop CS6 was used during the analysis to straighten the photographs and draw lines between body markers in order to measure the joint angles.

3.2.3.9 Manual goniometer. A plastic 12-inch manual goniometer was used to measure the joint angles from the lines drawn on the photographs in Photoshop. The screen was projected on a 32-inch Daytek LCD TV in order to magnify the image.

\subsubsection{Procedure}

The experiment was conducted in a climate-controlled room in the Human Ecology Building on Cornell University's campus. The temperature of the room was set to 74 degrees Fahrenheit and humidity was set at $60 \%$. These values are slightly above normal room temperature, but were used because participants performed a stationary task wearing a sleeveless shirt. The temperature was deemed to be comfortable for the task. It was important that participants were not too cold, as this might increase reported discomfort levels. Participants responded to posted advertisements via email, and upon scheduling an appointment, were instructed to wear a dark colored tank top or form-fitted t-shirt so that the position of their arms, neck, and torso could be seen clearly. If participants did not dress this way, a tank top was provided, or their clothing was taped so that it was tight to their body. 
Upon arriving in the laboratory, participants read and signed the consent form, and then filled out the demographic questionnaire and an initial discomfort survey. A discomfort survey was filled out before the experiment began in order to assess any existing discomfort and to establish a baseline to which discomfort resulting from each task could be compared. Following the completion of these documents, the researcher reiterated the information contained on the consent form regarding the tasks involved in the study, and explained that the participant would be completing a typing task in three configurations while sitting on the bed, and that he or she would be photographed while doing this. The researcher also explained that before the experiment could begin, body markers and sensors would need to be attached to the participant. Upon receiving verbal agreement from the participant, the researcher went on to attach body markers to the tragus, C7 vertebrae of the spine, L5 vertebrae of the spine, top iliac crest in line with the lateral epicondyle, acromion process, lateral epicondyle, ulnar styloid process, patella, and calcaneus. Next, the researcher instructed the participant to remove his or her shoes, and then measured the overall height of the participant, as well as the height to tragus, height to acromion process, height to the top of the ilium (hip - in line with elbow), and height to patella (knee).

Following these measurements, the electrogoniometer was attached to the participant's right wrist, with one sensor affixed to the back of the hand, and the other attached to the top of the forearm. The electrogoniometer was attached using a double-sided tape, and secured using medical tape. Once the electrogoniometer was in place, the participant was instructed to place his or her forearm flat on a table and hold his or her arm in place with the wrist straight. The researcher then calibrated the sensors to the "zero" or neutral position.

The participant was then instructed to stand beside the mattress and look at the wall in front of him or her, holding the neck in a neutral position. The researcher photographed the participant 
in this position, and this was then repeated with the participant sitting on the mattress. The participant was then instructed to sit on the mattress in one of three configurations: sitting with legs straight out, laptop on lap (LS); sitting with legs crossed, laptop on lap (CL); or sitting with legs crossed, laptop on bed in front of him/her (CB). The order in which the participant completed these three conditions was randomly assigned. The participant was instructed that he or she could sit up straight, lean back, or sit however they would like as long as the position fit the criteria of the configuration. It was emphasized that the participant was welcome to shift his or her position during the task, but had to stay in the general configuration. Participants were encouraged to sit as they would at home, as naturally as possible. Once the participant was settled, the researcher explained that the task was to type the text that was presented on the left side of the screen into the blank word document that was presented on the right side of the screen. The participant was instructed to type everything that he or she sees as quickly as possible, but to still go back and fix any mistakes. In addition, the participant was instructed to change the brightness of the screen or font size of the documents so that he or she could see the text clearly. The researcher then answered any questions.

Once the instructions were given, the researcher ensured that all body markers could be seen from the position of both cameras, and additional pieces of tape were added where needed so that the position of the markers could be extrapolated from the images later in the case that they were occluded during the task. Once this was done, the researcher started a timer and instructed the participant to begin typing.

During the task, the researcher took pictures of the participant after $5,10,15,20$, and 25 minutes of typing. The photograph of the participant from the side was taken first, and then the researcher walked to the other camera and took the photograph of the participant from the front. 
Consequently, all photographs were taken within 15 seconds of these predetermined times. The researcher manually instructed the electrogoniometer to collect data from the 7-minute mark to 8-minute mark, the 12-minute mark to the 13-minute mark, and the 17-minute mark to the 18 minute mark, for a total of 3 minutes of data per configuration. After the participant had been typing for 25 minutes and the final photographs were taken, he or she was instructed to stop typing. The researcher then gave the participant a copy of the discomfort questionnaire to complete while still sitting in the position on the mattress. The participant was then instructed to take a break, and to take as long as he or she would like, but to make sure that he or she waited until any discomfort subsided. While the participant took a break, the researcher saved and closed the document that was being used for the typing task, and opened a blank document to be used in the next condition. The next section of text was also presented on the screen.

Once the participant signaled that he or she was ready to continue, the researcher instructed him or her of the next configuration, and the above-described procedure was repeated. This occurred a third time for the final configuration. Upon completion of the third condition and third discomfort questionnaire, the participant was instructed to remove the body markers and electrogoniometer. The researcher then answered any questions about the experiment and paid the participant.

\subsubsection{Analysis}

3.2.5.1 Average postural deviation. Multivariate statistical software (IBM SPSS Statistics version 21) was used for all analyses. A linear mixed model was run in order to determine if there was a main effect of gender or condition on neck flexion, neck extension, shoulder flexion, shoulder extension, shoulder abduction, shoulder adduction, trunk position, elbow position, wrist flexion, wrist extension, wrist ulnar deviation, and wrist radial deviation. 
This analysis was also used to determine if any interactions were present. In the case that a significant interaction was present, pair wise comparisons were performed in order to determine whether differences between genders were significant in each body region, in each condition. A Bonferroni correction was applied to all analyses to adjust for multiple comparisons. The analyses for all body parts except the wrist included five data points per participant for each of the three conditions, which equals 90 data points for each gender in each condition for each body segment tested. When there were values in a category for only one condition (i.e. shoulder adduction only existed in the $\mathrm{CB}$ condition), an independent samples t-test was performed to determine if there was a gender difference. The analyses for the wrist included data points taken 20 times per second, for three minutes, in each condition.

3.2.5.2 Distribution of postural deviation. A Pearson chi square test was performed in order to determine whether there was a gender difference in the distribution of postures across the sample for the postures exhibited in the neck, shoulders, elbow, trunk, and wrists. The angles of deviation in each body part were categorized into four or five categories of differing magnitudes of deviation, which are described in the results section.

3.2.5.3 Discomfort. Self-reported discomfort was translated from a position on a visual analogue scale into a number that represents the distance from the zero point on the scale in centimeters. A linear mixed model was run to determine if there was a main effect of gender or condition on self-reported discomfort in the hands, wrists, forearms, elbows, neck, shoulders, upper back, lower back, buttocks, thighs, and knees. This analysis was also used to determine if any interactions were present. In the case that a significant interaction was present, pair wise comparisons were performed in order to determine whether differences between genders were 
significant in each body part, in each condition. A Bonferroni correction was applied to all analyses to adjust for multiple comparisons.

3.2.5.4 Relationship between posture and discomfort. In order to determine whether there was a relationship between postural deviation and self-reported discomfort, in each condition, a Pearson product-moment correlation was used to see if there was a correlation between the average angle of a participant's deviation in a body part (regardless of direction) and the discomfort score on related body parts.

\subsection{Results}

Upon removing two male and one female outliers who reported values greater than two standard deviations above or below the mean, it was revealed that females $(M=40.00, S D=$ 11.04) spent a significantly greater number of hours per week using a laptop than did males $(M=$ $22.88, S D=9.46), t(31)=-4.771, p<.001$. Upon removing one male and one female outlier, it was revealed that females $(M=14.38, S D=13.26)$ spent a significantly greater number of hours per week using a laptop on a bed than did males $(M=5.76, S D=7.62), t(32)=-2.324, p=.027$. Statistics for this analysis including outliers can be found in Appendix F.

\subsubsection{Average Postural Deviation}

3.3.1.1 Neck flexion. Regarding neck flexion, there was a significant main effect of gender, with males exhibited a greater degree of neck flexion than females in all three conditions, $F(1,34)=5.179, p=.029$ (Figure 4). Males were in some degree of neck flexion (neck angle was greater than zero) for $100 \%$ of the time spent in each condition. Females were in some degree of neck flexion for $100 \%$ of the time spent in the LS and CL conditions, and $77.89 \%$ of the time spent in the CB condition. In the LS condition, males were observed to exhibit a mean angle of flexion of 26.23 degrees $(S E=1.85)$, while the mean angle of flexion for 
females in this condition was 19.41 degrees $(S E=1.85), t(39.573)=2.615, p=.013$. The mean angle of flexion in the CL condition was 25.28 degrees $(S E=1.85)$ for males and 19.36 degrees $(S E=1.85)$ for females, $t(39.573)=2.270, p=.029$. In the CB condition, the mean angle of flexion was 18.04 degrees $(S E=1.85)$ for males and 13.64 degrees $(S E=1.88)$ for females, $t(41.228)=1.671, p=.102$.

There was a main effect of condition in regards to neck flexion, $F(2,408.712)=69.840$, $p<.001$. The average magnitude of neck flexion in the LS condition $(M=22.82, S E=1.31)$ was not significantly different than in the CL condition $(M=22.32, S E=1.31), t(479.973)=.815, p$ $=1.00$. However, the average neck flexion in the $\mathrm{CB}(M=15.84, S E=1.32)$ condition was significantly lower than in both the LS $(t(481.117)=10.74, p<.001)$ and CL conditions $(t(481.117)=9.962, p<.001)$.

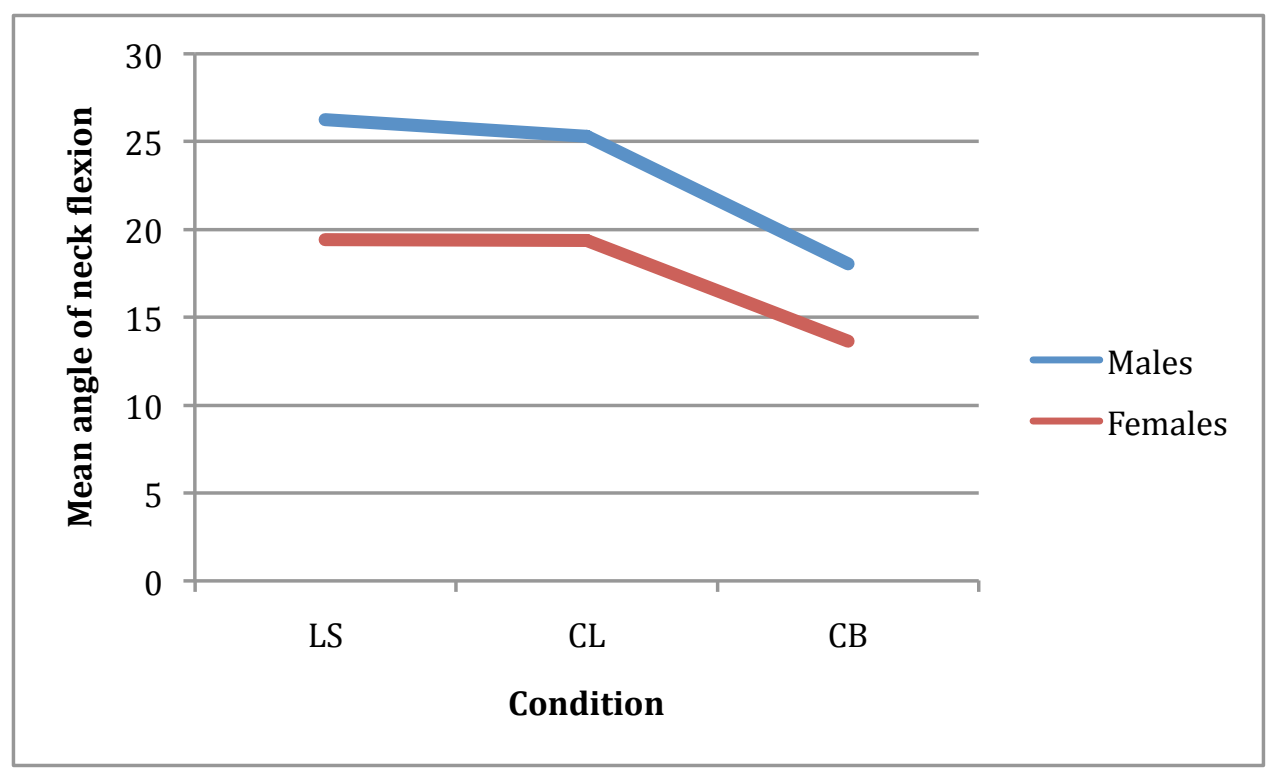

Figure 4: Average neck flexion for males and females in each condition

3.3.1.2 Neck extension. The only condition where neck extension was observed was in the $\mathrm{CB}$ condition. Females exhibited neck extension for $22.22 \%$ of the time sampled. The 
average degree of neck extension in these participants was 6.90 degrees, with a standard deviation of 5.08. Males did not exhibit neck extension in any of the three configurations.

3.3.1.3 Shoulder flexion. A significant gender $x$ condition interaction was observed regarding shoulder flexion, $F(2,405.903)=13.320, p<.001$ (Figure 5). In the LS condition, males spent $78.89 \%$ of the time and females spent $86.67 \%$ of the time in some degree of shoulder flexion. In this condition there was no significant gender difference; males exhibited an average shoulder flexion of 8.49 degrees $(S E=1.76)$ and females exhibited an average shoulder flexion of 6.88 degrees $(S E=1.73), t(43.284)=.652, p=.518$. In the CL condition, males spent $70 \%$ of the time and females spent $55.56 \%$ of the time in shoulder flexion. In the CL condition, there was no significant gender difference; the average shoulder flexion was 9.33 degrees $(S E=$ $1.79)$ in males and 5.11 degrees $(S E=1.87)$ in females, $t(51.915)=1.632, p=.109$.In the $\mathrm{CB}$ condition, males and females both spent $100 \%$ of the time in some degree of shoulder flexion. In this condition, there was no significant gender difference; the average shoulder flexion was 56.03 $(S E=1.70)$ for males, and $60.19(S E=1.70)$ for females, $t(39.328)=.65, p=.092$.

A main effect of condition was observed for shoulder flexion, $F(2,405.903)=2699.67, p$ $<.001$. There was no significant difference in the average deviation between the $\operatorname{LS}(M=7.68$, $S E=1.23)$ and CL $(M=7.22, S E=1.29)$ conditions, $t(404.416)=.504, p=1.00$. However, the average magnitude of shoulder flexion observed in the CB condition $(M=58.11, S E=1.20)$ was significantly greater than the magnitude of shoulder flexion observed in both the LS (t(404.210) $=65.068, p<.001)$ and $\mathrm{CL}(t(409.403)=58.566, p<.001)$ conditions. 


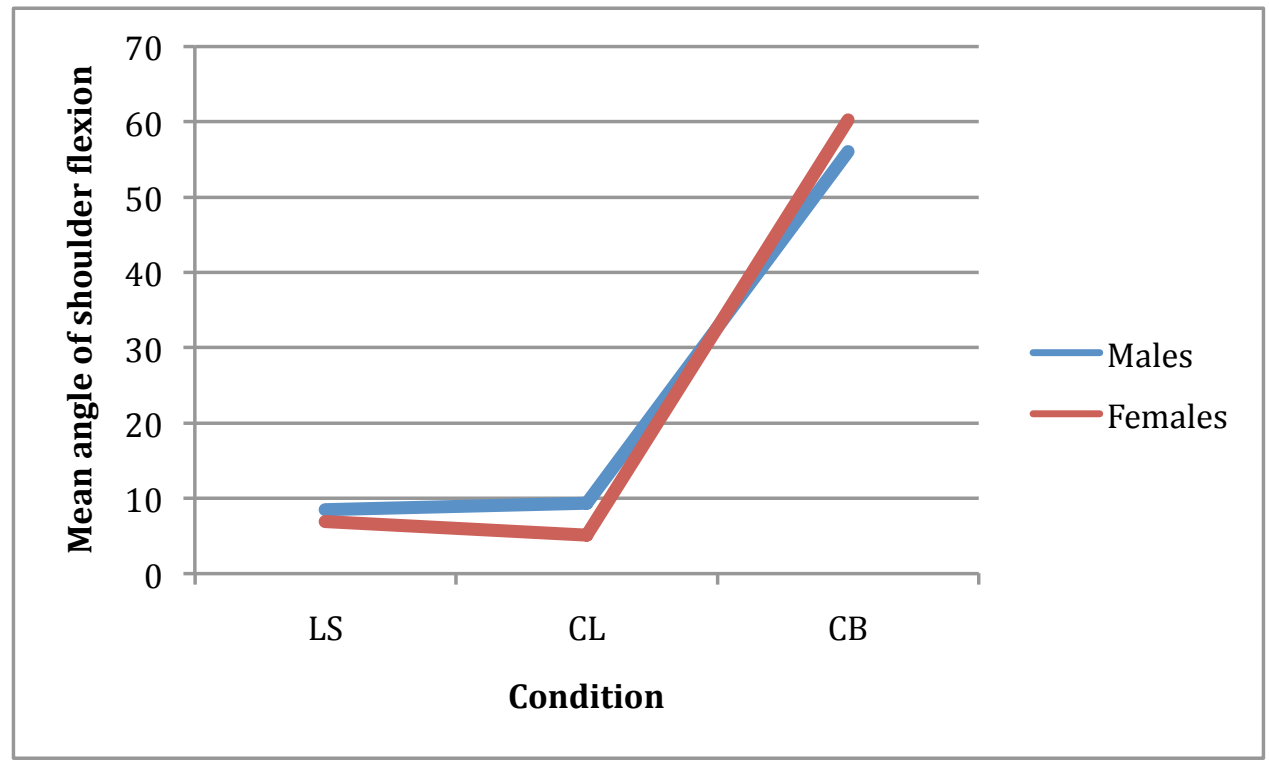

Figure 5. Average shoulder flexion for males and females in each condition

3.3.1.4 Shoulder extension. Shoulder extension was observed in the CL and LS conditions, but not in the CB condition (Figure 6). In the LS condition, males spent $18.89 \%$ of the time and females spent $8.89 \%$ of the time in some degree of shoulder extension. In this condition, there was no significant gender difference; males exhibited an average shoulder extension of 2.63 degrees $(S E=1.31)$ while females exhibited an average shoulder extension of 1.92 degrees $(S E=1.64), t(45.137)=.342, p=.734$. In the CL condition, males spent $27.78 \%$ of the time and females spent $44.44 \%$ of the time in shoulder extension. In this condition, there was no significant gender difference; the average shoulder extension for males was 6.37 degrees ( $S E$ $=1.23)$ and the average shoulder extension for females was 7.00 degrees $(S E=1.14), t(20.891)=$ $.376, p=.710$. In the LS condition, males spent $2.22 \%$ of the time and females spent $4.44 \%$ of the time in neither flexion or extension of the shoulder (zero degrees of deviation). In the CL condition, males also spent $2.22 \%$ of the time in zero degrees of shoulder flexion or extension. 
A main effect of condition was observed for shoulder extension, $F(1,79.136)=22.640, p$ $<.001$. A significantly greater degree of deviation was observed in the CL condition $(M=6.69$, $S E=.84)$ compared to the LS condition $(\mathrm{M}=2.27, S E=1.05), t(79.136)=4.759, p<.001$. No shoulder extension was observed in the $\mathrm{CB}$ condition.

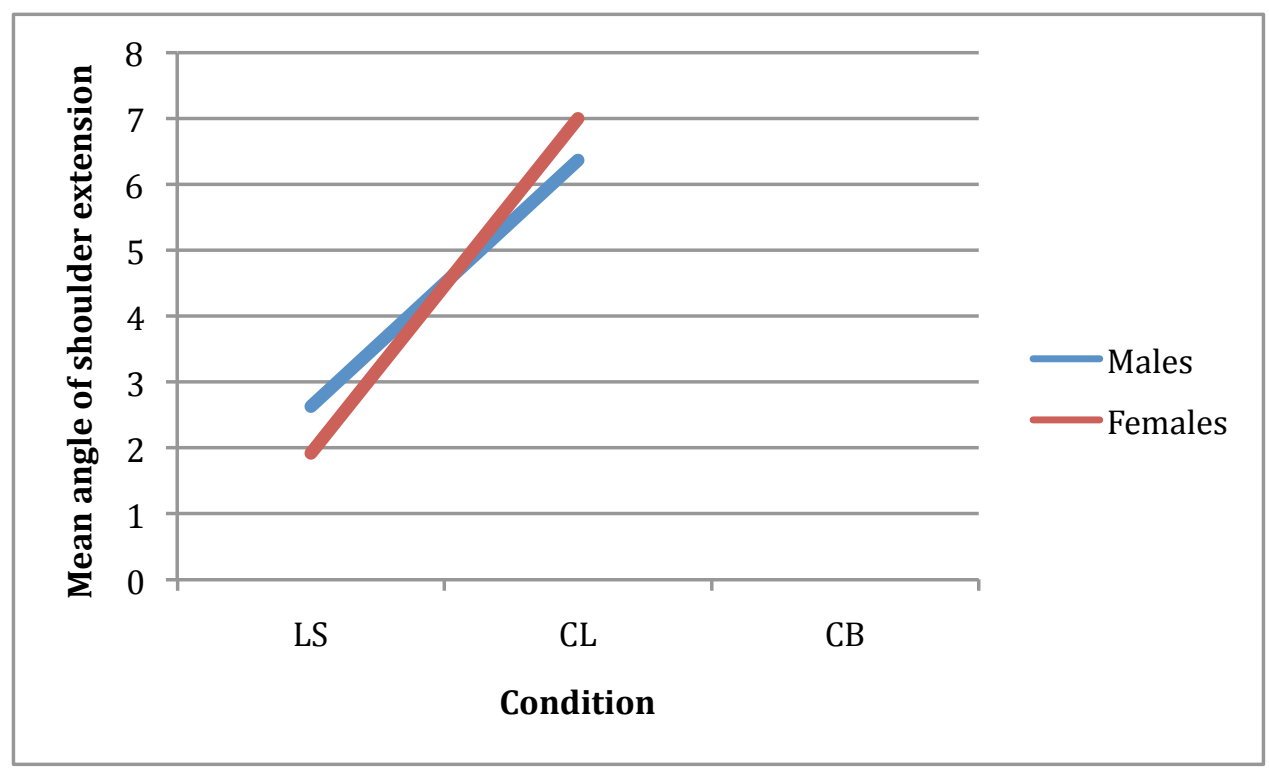

Figure 6. Average shoulder extension for males and females in each condition

3.3.1.5 Shoulder abduction. A significant gender $\mathrm{x}$ condition interaction was observed for shoulder abduction, $F(2,482.826)=5.695, p<.001$ (Figure 7). In the LS condition, both males and females spent $100 \%$ of the time in some degree of shoulder abduction. In this condition, males exhibited an average shoulder abduction of 13.50 degrees $(S E=1.03)$ and females exhibited an average shoulder abduction of 13.09 degrees $(S E=1.03), t(50.469)=.282$, $p=.779$. In the CL condition, males and females both spent $100 \%$ of the time in shoulder abduction. In the CL condition, the average shoulder abduction in males was 15.41 degrees ( $S E$ $=1.03)$ and 14.03 degrees $(S E=1.03)$ in females, $t(50.469)=.946, p=.349$. In the CB condition, males spent $92.22 \%$ and females spent $87.78 \%$ of the time in some degree of shoulder 
abduction. In this condition, males had an average shoulder abduction of 12.70 degrees $(S E=$ 1.05), and females had a mean shoulder abduction of 14.98 degrees $(S E=1.05), t(53.973)=$ $1.543, p=.129$.

There was a main effect of condition, $F(2,482.826)=3.535, p=.030$. The average degree of shoulder abduction was significantly higher in the CL $(M=14.72, S E=.741)$ than LS $(M=13.29, S E=.728)$ condition, $t(482.012)=2.635, p=.026$. No other significant differences between conditions were present.

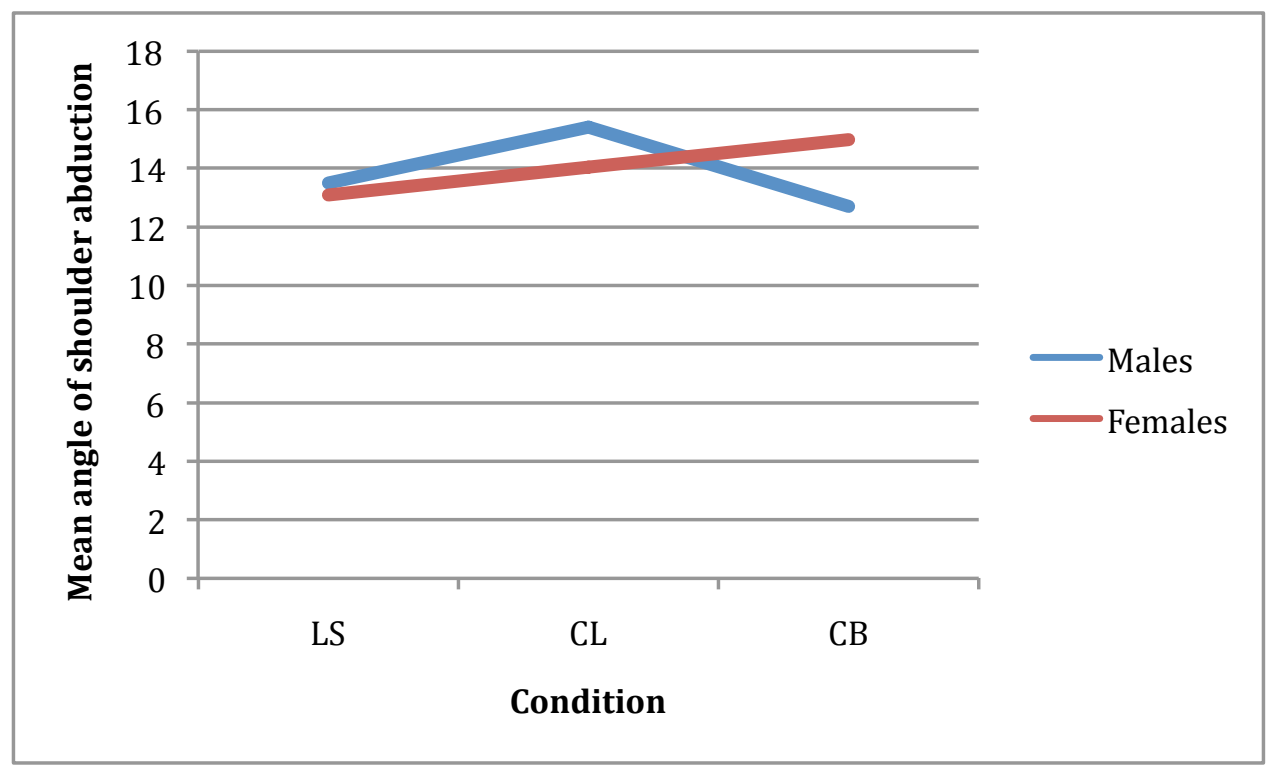

Figure 7. Average shoulder abduction for males and females in each condition

3.3.1.6 Shoulder adduction. The only condition where shoulder adduction was observed was in the $\mathrm{CB}$ condition. Females exhibited shoulder adduction for $7.78 \%$ of the time sampled and males exhibited shoulder adduction for $5.56 \%$ of the time sampled. There was no significant difference in average degree of shoulder adduction between males $(M=1.80, S D=.84)$ and females $(M=2.14, S D=1.68), t(10)=.418, p=.685$. In the CB condition, males spent $2.22 \%$ of 
the time and females spent $4.44 \%$ of the time in neither adduction or abduction of the shoulder (zero degrees of deviation).

3.3.1.7 Trunk position. A significant gender $\mathrm{x}$ condition interaction was observed in the position of the trunk, $F(2,500)=3.492, p=.031$ (Figure 8 ). There was no significant difference in the average trunk angle for males and females in the LS and CL conditions. In the LS condition, males exhibited an average trunk angle of 104.87 degrees $(S E=1.45)$ and females exhibited an average trunk angle of 102.72 degrees $(S E=1.45), t(54.225)=1.04, p=.301$. In the CL condition, the average trunk angle was 101.86 degrees $(S E=1.45)$ for males and 100.11 degrees $(S E=1.45)$ for females, $t(54.225)=.850, p=.399$. In the CB condition, males had a significantly greater mean trunk angle $(M=70.84, S E=1.45)$ than females $(M=65.19, S E=$ $1.45), t(54.225)=2.756, p=.008$.

There was also a main effect of condition present, $F(2,500)=1193.799, p<.001$. The average trunk angle was significantly greater in the $\operatorname{LS}(M=103.79, S E=1.03)$ than CL $(M=$ $100.98, S E=1.03)$ condition, $t(500)=3.453, p=.002$. The average trunk angle in the LS condition was also significantly greater than the average trunk angle in the $\mathrm{CB}(M=68.02, S D=$ 1.03 ) condition, $t(500)=43.953, p<.001$. The mean trunk angle in the CL condition was significantly greater than the mean trunk angle in the CB condition as well, $t(500)=40.500, p<$ .001 . 


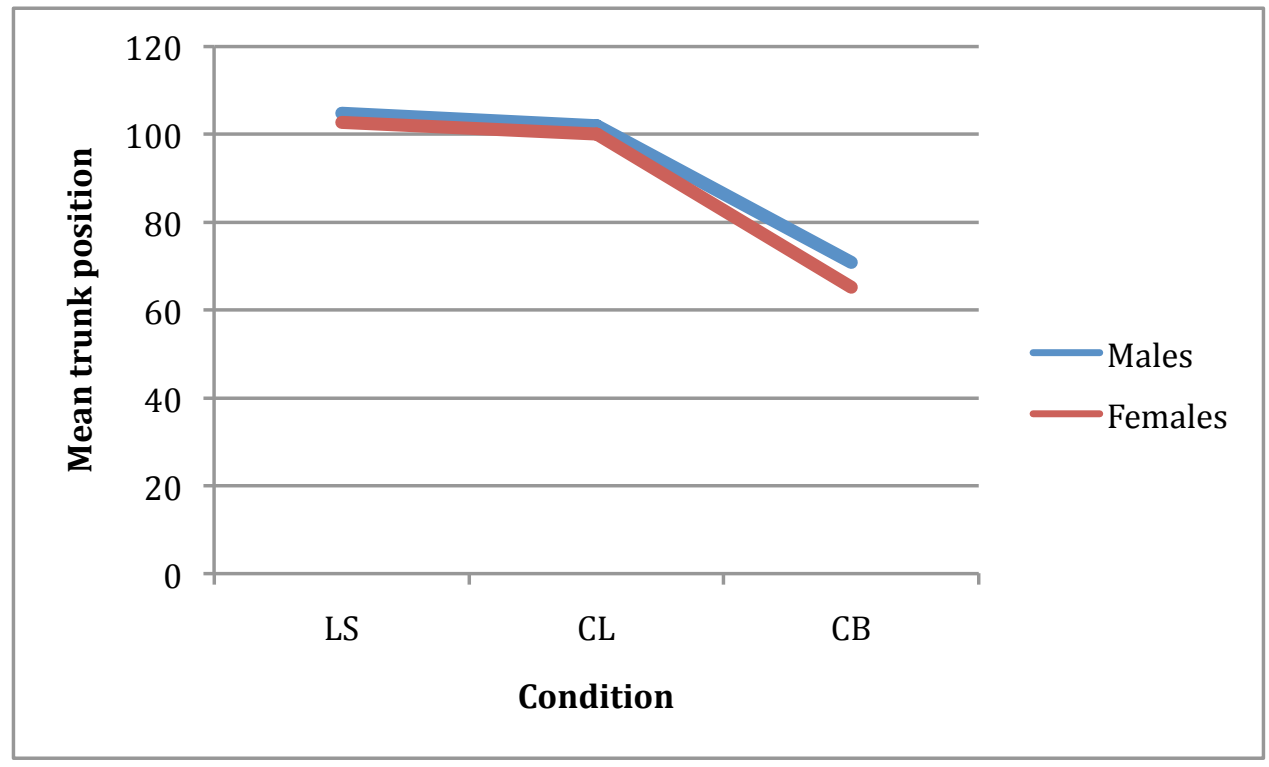

Figure 8: Average trunk angle for males and females in each condition

3.3.1.8 Elbow position. A significant gender $\mathrm{x}$ condition interaction was observed in elbow position, $F(2,500)=4.337, p=.014$ (Figure 9). In the LS condition, males exhibited an average elbow angle of 89.93 degrees $(S E=2.08)$ and females exhibited an average elbow angle of 92.20 degrees $(S E=2.08), t(66.017)=.771, p=.443$. In the CL condition, males had an average elbow angle of 90.02 degrees $(S E=2.08)$ and females had an average elbow angle of 86.09 degrees $(S E=2.08), t(66.017)=1.338, p=.186$. In the $\mathrm{CB}$ condition, males had a mean elbow angle of 129.32 degrees $(S E=2.08)$, while females had a mean elbow angle of 132.90 degrees $(S E=2.08), t(66.017)=1.217, p=.228$.

There was also a main effect of condition, $F(2,500)=622.738, p<.001$. The elbow angle was significantly greater in the $\mathrm{CB}(M=131.11, S E=1.47)$ than $\mathrm{LS}(M=91.07, S E=$ 1.47) condition, $t(500)=29.401, p<.001$. The average elbow angle was also significantly greater in the CB condition than the CL $(M=88.06, S D=1.47)$ condition, $t(500)=31.612, p<$ 
.001 . There was no significant difference between the LS and CL conditions, $t(500)=2.211, p=$ .083 .

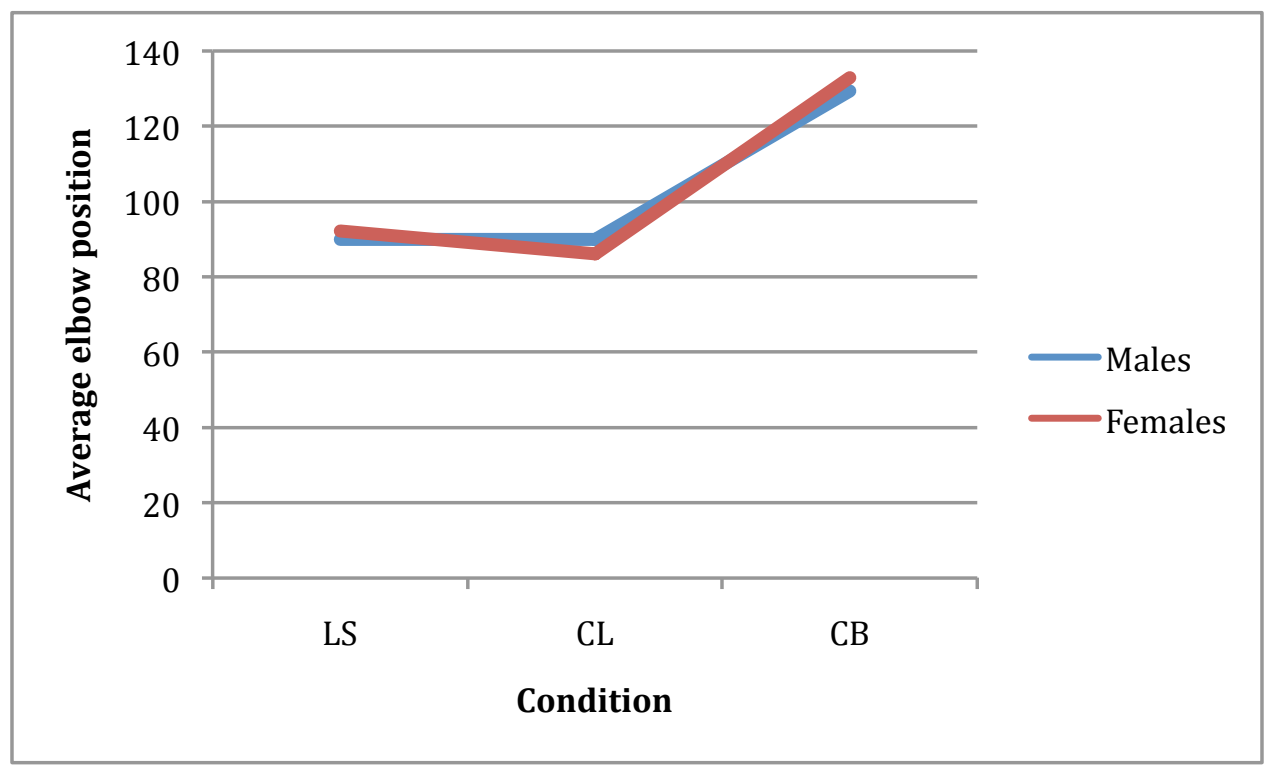

Figure 9: Average elbow angle for males and females in each condition

3.3.1.9 Wrist flexion. A significant gender $\mathrm{x}$ condition interaction was observed for average wrist flexion, $F(2,50281.558)=1220.346, p<.001$ (Figure 10). In the LS condition, males spent $18.58 \%$ of the time and females spent $11.35 \%$ of the time in some degree of wrist flexion. In this condition, males exhibited an average wrist flexion of 7.08 degrees $(S E=.93)$ and females exhibited an average wrist flexion of 5.64 degrees $(S E=.97), t(32.791)=1.076, p=$ .290. In the CL condition, males spent $18.65 \%$ of the time and females spent $7.74 \%$ of the time in wrist flexion. In the CL condition, the average wrist flexion in males was significantly greater in magnitude for males $(M=10.88, S E=.93)$ than females $(M=6.08, S E=.97), t(33.002)=$ $3.571, p=.001$. In the $\mathrm{CB}$ condition, males spent $12.49 \%$ of the time and females spent $8.52 \%$ of the time in some degree of wrist flexion. In this condition, females had a mean wrist flexion of 
10.12 degrees $(S E=.97)$, which was significantly greater than the average wrist flexion for males $(M=4.09, S E=.93), t(33.397)=4.467, p<.001$.

There was also a main effect of condition, $F(2,50281.558)=308.332, p<.001$. The average degree of wrist flexion was significantly higher in the CL $(M=8.48, S E=.67)$ than the $\mathrm{CB}(M=7.10, S E=.67)$ condition, $t(50264.616)=12.518, p<.001$ and the $\operatorname{LS}(M=6.36, S E=$ .67) condition, $t(50321.921)=24.674, p<.001$. The difference between the CB and LS conditions was also significant, $t(50252.598)=7.163, p<.001$.

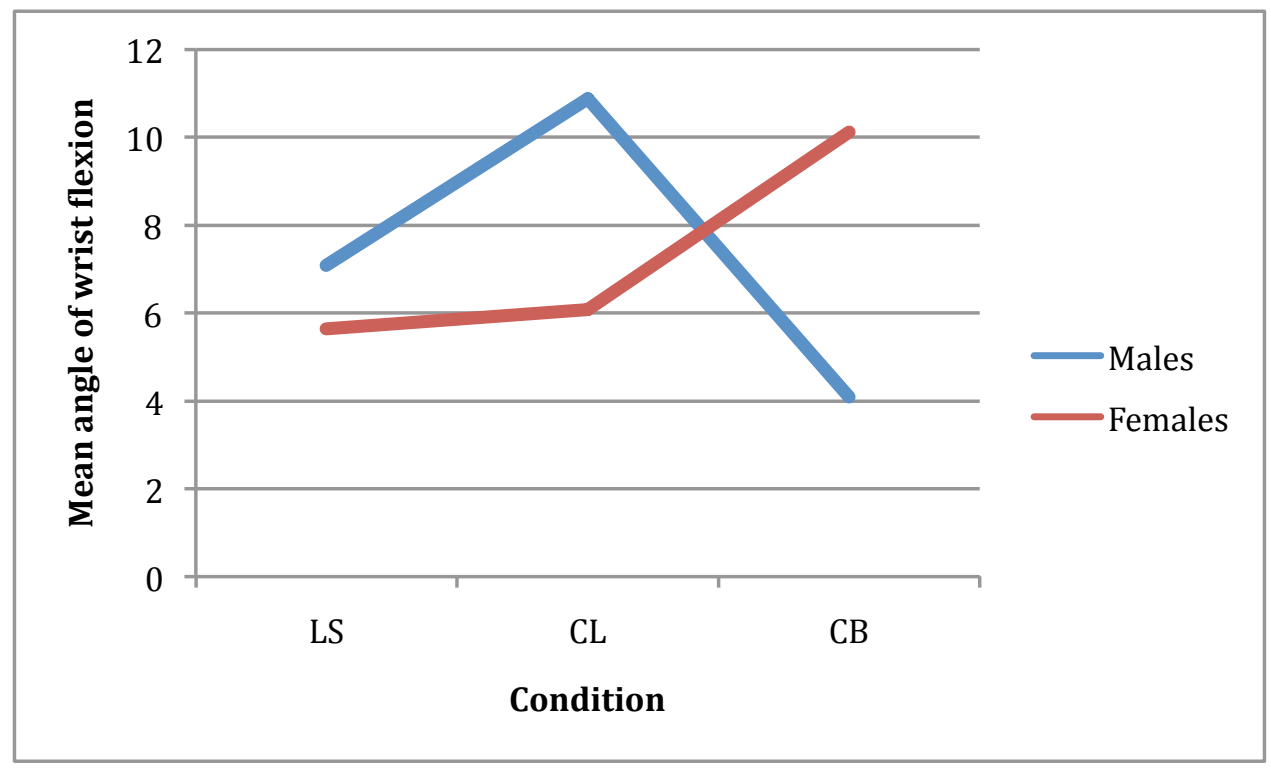

Figure 10: Average wrist flexion for males and females in each condition

3.3.1.10 Wrist extension. A significant gender $\mathrm{x}$ condition interaction was observed for wrist extension, $F(2,339343.759)=1840.548, p<.001$ (Figure 11). In the LS condition, males spent $81.11 \%$ of the time and females spent $88.45 \%$ of the time in some degree of wrist extension. In this condition, males exhibited an average wrist extension of 17.64 degrees $(S E=$ $1.96)$ and females exhibited an average wrist extension of 20.698 degrees $(S E=1.96), t(34.026)$ $=1.103, p=.278$. In the CL condition, males spent $81.20 \%$ of the time and females spent 
$92.14 \%$ of the time in wrist extension. In the CL condition, the average wrist extension in males was 18.25 degrees $(S E=1.96)$ and 23.01 degrees $(S E=1.96)$ in females, $t(34.026)=1.717, p=$ .095. In the CB condition, males spent $87.39 \%$ of the time and females spent $91.38 \%$ of the time in some degree of wrist extension. In this condition, females had a mean wrist extension of 34.22 degrees $(S E=1.96)$, which was significantly greater than the average angle of wrist extension for males $(M=25.65, S E=1.96), t(34.024)=3.087, p=.004$.

There was a main effect of condition for wrist extension, $F(2,339343.759)=31693.206$, $p<.001$. The average degree of wrist extension was significantly higher in the CB $(M=29.94$, $S E=1.39)$ than the $C L(M=20.63, S E=1.39)$ condition, $t(339344.772)=202.283, p<.001$ and the LS $(M=19.17, S E=1.39)$ condition, $t(339343.971)=229.128, p<.001$. The difference between the CL and LS conditions was also significant, $t(339342.539)=31.149, p<.001$. In each of the three conditions, both males and females spent less than $1 \%$ of the time in neither flexion or extension of the wrist (zero degrees of deviation).

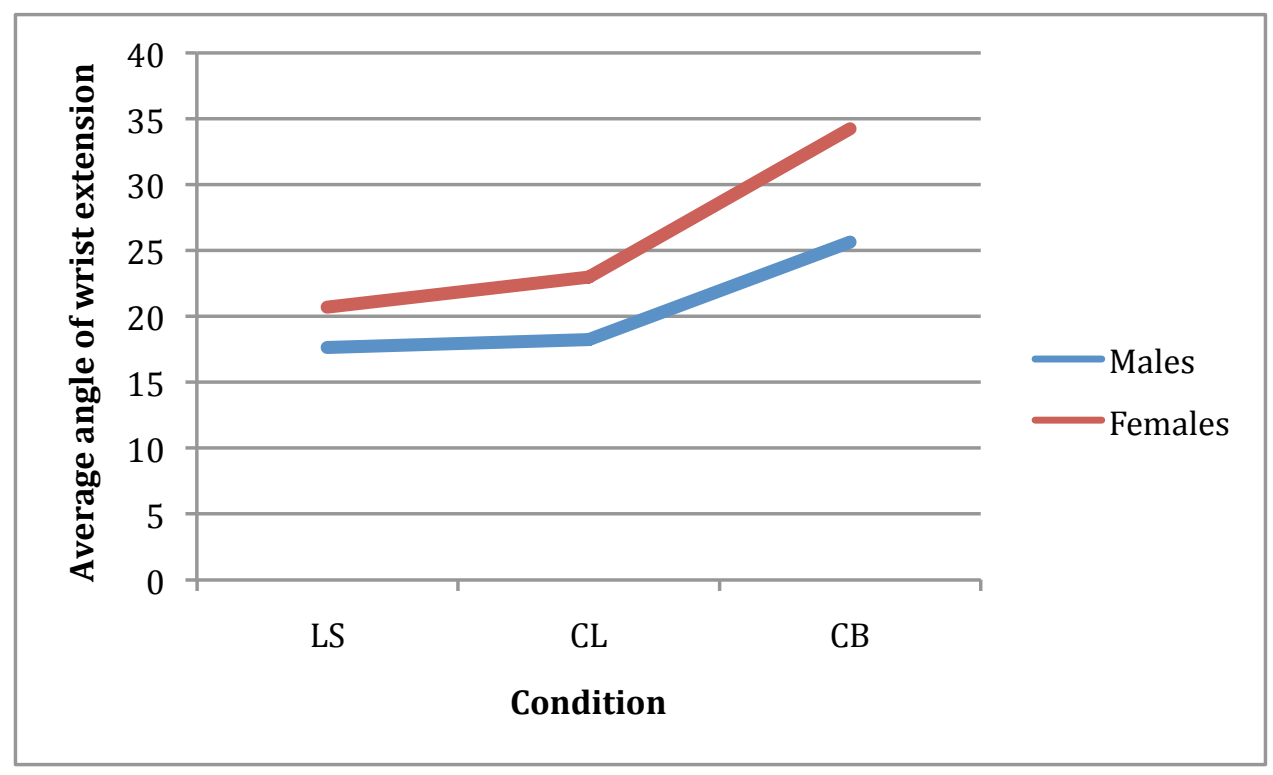

Figure 11: Average wrist extension for males and females in each condition 
3.3.1.11 Wrist ulnar deviation. A significant gender $\mathrm{x}$ condition interaction was observed for ulnar deviation of the wrist, $F(2,254807.399)=51.975, p<.001$ (Figure 12). In the LS condition, males spent $71.46 \%$ of the time and females spent $70.33 \%$ of the time in some degree of ulnar deviation. In this condition, males exhibited an average ulnar deviation of 12.45 degrees $(S E=.81)$ and females exhibited an average ulnar deviation of 12.18 degrees $(S E=.81)$, $t(34.083)=.229, p=.820$. In the CL condition, males spent $72.37 \%$ of the time and females spent $76.72 \%$ of the time in ulnar deviation. In the CL condition, the average ulnar deviation in males was 13.15 degrees $(S E=.81)$ and 12.71 degrees $(S E=.81)$ in females, $t(34.072)=.383, p$ $=.704$. In the $\mathrm{CB}$ condition, males spent $52.06 \%$ of the time and females spent $48.74 \%$ of the time in some degree of ulnar deviation. In this condition, males had an average ulnar deviation of 7.65 degrees $(S E=.81)$, and females had a mean ulnar deviation of 8.02 degrees $(S E=.81)$, $t(34.152)=.319, p=.752$.

There was a main effect of condition for wrist ulnar deviation, $F(2,254807.399)=$ 8856.682, $p<.001$. The average degree of ulnar deviation was significantly higher in the CL ( $M$ $=12.93, S E=.58)$ than the $\operatorname{LS}(M=12.32, S E=.58)$ condition, $t(254801.928 .772)=17.111, p<$ .001 and the $\mathrm{CB}(M=7.83, S E=.58)$ condition, $t(254816.262)=124.366, p<.001$. The average ulnar deviation in the LS condition was also higher than the average ulnar deviation in the CB condition, $t(254804.676)=112.075, p<.001$. 


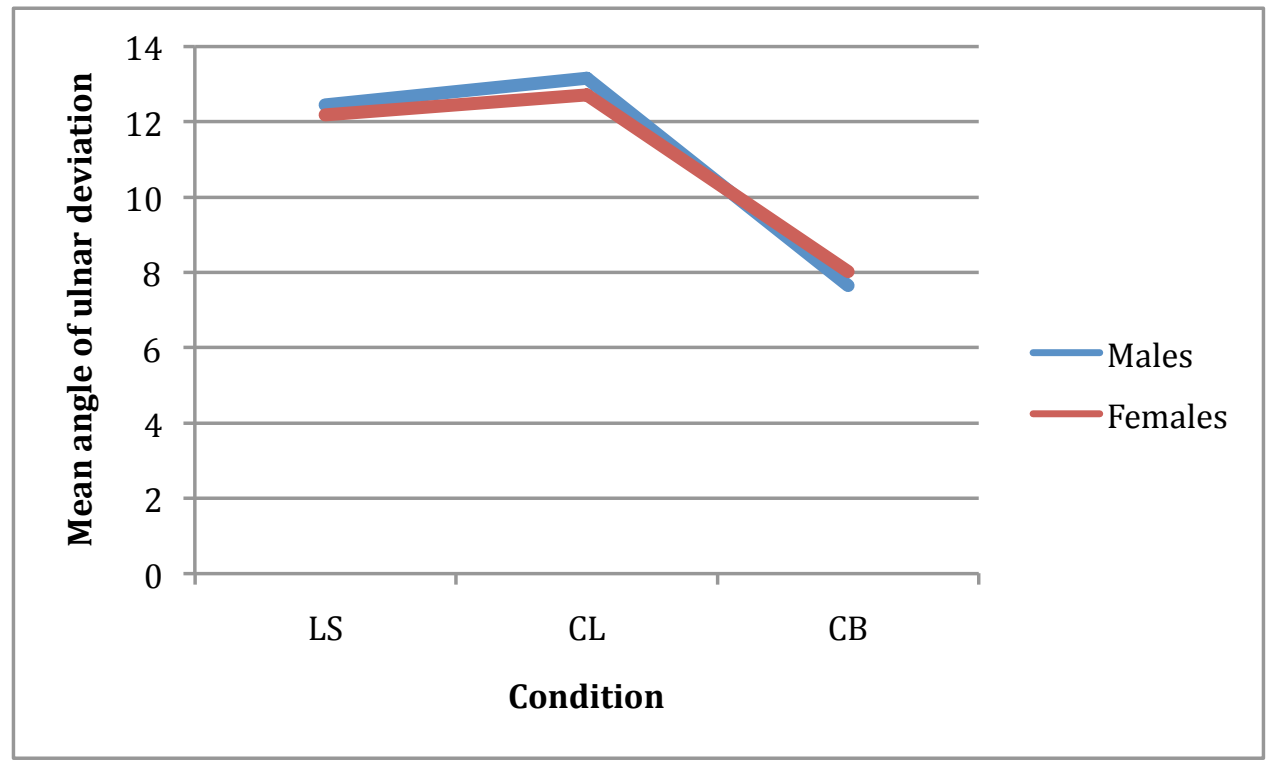

Figure 12: Average wrist ulnar deviation for males and females in each condition

3.3.1.12 Wrist radial deviation. A significant gender $\mathrm{x}$ condition interaction was observed for radial deviation of the wrist, $F(2,134038.575)=104.213, p<.001$ (Figure 13). In the LS condition, males spent $28.20 \%$ of the time and females spent $29.36 \%$ of the time in some degree of radial deviation. In this condition, males exhibited an average radial deviation of 6.78 degrees $(S E=.71)$ and females exhibited an average radial deviation of 6.76 degrees $(S E=.71)$, $t(34.224)=.024, p=.981$. In the CL condition, males spent $27.23 \%$ of the time and females spent $22.90 \%$ of the time in radial deviation. In the CL condition, the average radial deviation in males was 6.81 degrees $(S E=.71)$ and 6.07 degrees $(S E=.71)$ in females, $t(34.274)=.740, p=$ 465. In the $\mathrm{CB}$ condition, males spent $47.51 \%$ of the time and females spent $50.82 \%$ of the time in some degree of radial deviation. In this condition, males had an average radial deviation of 8.16 degrees $(S E=.71)$, and females had a mean radial deviation of 8.75 degrees $(S E=.71)$, $t(34.087)=.596, p=.555$. 
There was a main effect of condition, $F(2,134038.575)=1226.703, p<.001$. The average degree of radial deviation was significantly higher in the $\mathrm{CB}(M=8.46, S E=.50)$ than the $\operatorname{LS}(M=6.77, S E=.50)$ condition, $t(134039.484)=39.279, p<.001$ and the CL $(M=6.44$, $S E=.50)$ condition, $t(134045.710)=42.830, p<.001$. The average radial deviation in the LS condition was also higher than in the CL condition, $t(134033.511)=6.500, p<.001$. In each of the three conditions, both males and females spent less than $1 \%$ of the time in neither radial or ulnar deviation of the wrist (zero degrees of deviation).

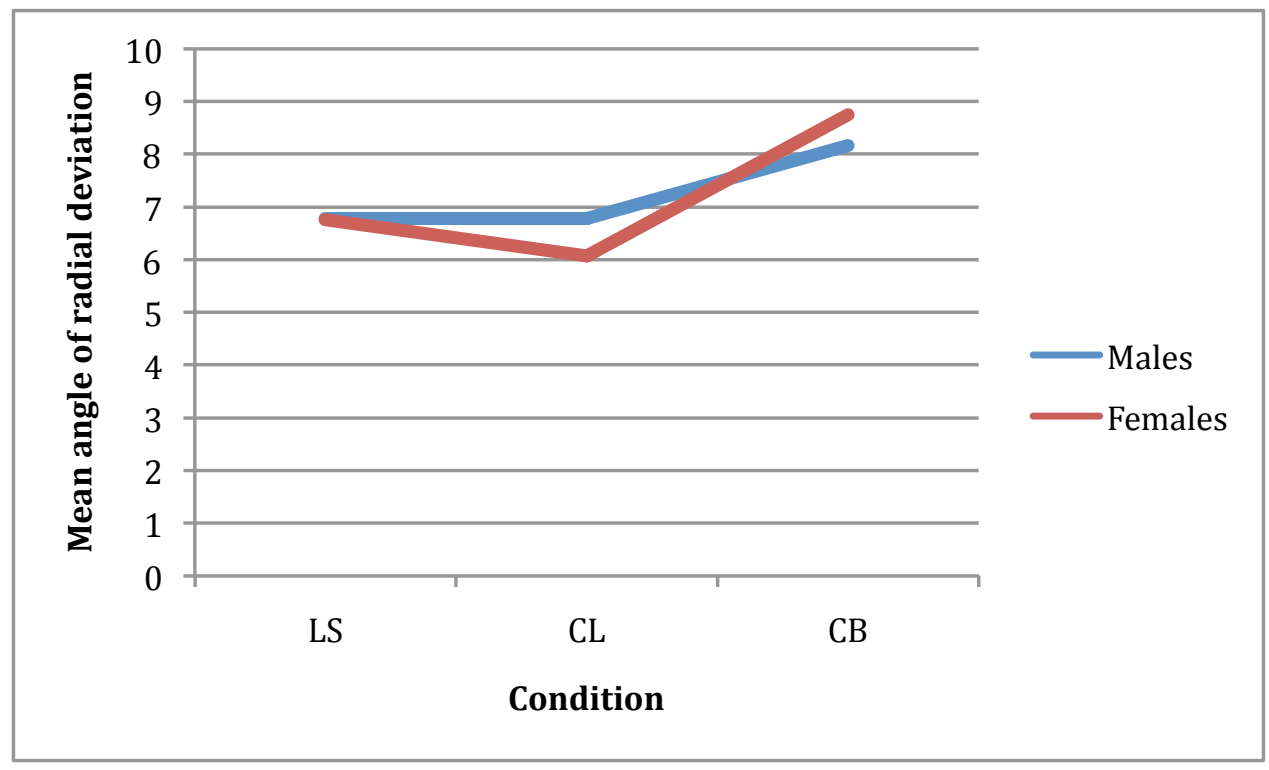

Figure 13: Average wrist radial deviation for males and females in each condition 
Table 6. Mean angles of deviation for males and females in the LS configuration

\begin{tabular}{|c|c|c|c|c|c|c|}
\hline \multirow[b]{2}{*}{ Measure } & \multicolumn{3}{|c|}{ Angle of Deviation - Males } & \multicolumn{3}{|c|}{ Angle of Deviation- Females } \\
\hline & $\begin{array}{l}\text { \% of time } \\
\text { in position }\end{array}$ & Mean & Std. Error & $\begin{array}{l}\text { \% of time } \\
\text { in position }\end{array}$ & Mean & Std. Error \\
\hline Neck Flexion & 100 & $26.23^{*}$ & 1.85 & 100 & 19.41 & 1.85 \\
\hline Neck Extension & 0 & - & - & 0 & - & - \\
\hline Shoulder Flexion & 78.89 & 8.49 & 1.76 & 86.67 & 6.88 & 1.73 \\
\hline Shoulder Extension & 18.89 & 2.63 & 1.31 & 8.89 & 1.92 & 1.64 \\
\hline Shoulder Abduction & 100 & 13.50 & 1.03 & 100 & 13.09 & 1.03 \\
\hline Shoulder Adduction & 0 & - & - & 0 & - & - \\
\hline Trunk Position & - & 104.87 & 1.45 & - & 102.72 & 1.45 \\
\hline Elbow Position & - & 89.93 & 2.08 & - & 92.20 & 2.08 \\
\hline Wrist Flexion & 18.58 & 7.08 & .93 & 11.35 & 5.64 & .97 \\
\hline Wrist Extension & 81.11 & 17.64 & 1.96 & 88.45 & 20.70 & 1.96 \\
\hline Wrist Ulnar Dev. & 71.46 & 12.45 & .81 & 70.32 & 12.18 & .81 \\
\hline Wrist Radial Dev. & 28.20 & 6.78 & .71 & 29.36 & 6.77 & .71 \\
\hline
\end{tabular}

$* p<.05$.

Table 7. Mean angles of deviation for males and females in the CL configuration.

\begin{tabular}{|c|c|c|c|c|c|c|}
\hline \multirow[b]{2}{*}{ Measure } & \multicolumn{3}{|c|}{ Angle of Deviation - Males } & \multicolumn{3}{|c|}{ Angle of Deviation- Females } \\
\hline & $\begin{array}{l}\text { \% of time } \\
\text { in position }\end{array}$ & Mean & Std. Error & $\begin{array}{l}\text { \% of time } \\
\text { in position }\end{array}$ & Mean & Std. Error \\
\hline Neck Flexion & 100 & $25.28^{*}$ & 1.85 & 100 & 19.36 & 1.85 \\
\hline Neck Extension & 0 & - & - & 0 & - & - \\
\hline Shoulder Flexion & 70 & 9.33 & 1.79 & 55.56 & 5.11 & 1.87 \\
\hline Shoulder Extension & 27.78 & 6.37 & 1.23 & 44.44 & 7.00 & 1.14 \\
\hline Shoulder Abduction & 100 & 15.41 & 1.03 & 100 & 14.03 & 1.03 \\
\hline Shoulder Adduction & 0 & - & - & 0 & - & - \\
\hline Trunk Position & - & 101.86 & 1.45 & - & 100.11 & 1.45 \\
\hline Elbow Position & - & 90.02 & 2.08 & - & 86.09 & 2.08 \\
\hline Wrist Flexion & 18.65 & $10.88^{*}$ & .93 & 7.74 & 6.08 & .96 \\
\hline Wrist Extension & 81.20 & 18.25 & 1.96 & 92.14 & 23.01 & 1.96 \\
\hline Wrist Ulnar Dev. & 72.37 & 13.15 & .81 & 76.72 & 12.71 & .81 \\
\hline Wrist Radial Dev. & 27.23 & 6.81 & .71 & 22.90 & 6.07 & .71 \\
\hline
\end{tabular}

${ }^{*} p<.05$. 
Table 8. Mean angles of deviation for males and females in the CB configuration

\begin{tabular}{|c|c|c|c|c|c|c|}
\hline \multirow[b]{2}{*}{ Measure } & \multicolumn{3}{|c|}{ Angle of Deviation - Males } & \multicolumn{3}{|c|}{ Angle of Deviation-Females } \\
\hline & $\begin{array}{l}\text { \% of time } \\
\text { in position }\end{array}$ & Mean & Std. Error & $\begin{array}{l}\text { \% of time } \\
\text { in position }\end{array}$ & Mean & Std. Error \\
\hline Neck Flexion & 100 & 18.04 & 1.85 & 77.78 & 13.64 & 1.88 \\
\hline Neck Extension & 0 & - & - & 22.22 & 6.90 & $5.08(\mathrm{SD})$ \\
\hline Shoulder Flexion & 100 & 56.03 & 1.70 & 100 & 60.19 & 1.70 \\
\hline Shoulder Extension & 0 & - & - & 0 & - & - \\
\hline Shoulder Abduction & 92.22 & 12.70 & 1.05 & 87.78 & 14.98 & 1.05 \\
\hline Shoulder Adduction & 5.56 & 1.80 & .84 & 77.78 & 2.14 & 1.68 \\
\hline Trunk Position & - & $70.84^{*}$ & 1.45 & - & 65.19 & 1.45 \\
\hline Elbow Position & - & 129.32 & 2.08 & - & 132.90 & 2.08 \\
\hline Wrist Flexion & 12.49 & 4.09 & .93 & 8.52 & $10.12^{*}$ & .97 \\
\hline Wrist Extension & 87.39 & 25.65 & 1.96 & 91.38 & $34.22^{*}$ & 1.96 \\
\hline Wrist Ulnar Dev. & 52.06 & 7.65 & .81 & 48.73 & 8.02 & .81 \\
\hline Wrist Radial Dev. & 47.51 & 8.16 & .71 & 50.82 & 8.75 & .71 \\
\hline
\end{tabular}

$* p<.05$.

Table 9. Angle of deviation in each configuration for males and females combined.

\begin{tabular}{|l|l|l|l|l|l|l|}
\hline \multirow{2}{*}{ Measure } & \multicolumn{2}{c|}{ Angle of Deviation - LS } & \multicolumn{2}{c|}{ Angle of Deviation - CL } & \multicolumn{2}{c|}{ Angle of Deviation - CB } \\
\cline { 2 - 8 } & \multicolumn{1}{|c|}{ Mean } & \multicolumn{1}{c|}{ Std. Error } & \multicolumn{1}{c|}{ Mean } & \multicolumn{1}{c|}{ Std. Error } & \multicolumn{1}{c|}{ Mean } & \multicolumn{1}{c|}{ Std. Error } \\
\hline Neck Flexion & $22.82^{\mathrm{a}}$ & 1.31 & $22.32^{\mathrm{a}}$ & 1.31 & $15.84^{\mathrm{b}}$ & 1.32 \\
\hline Neck Extension & - & - & - & - & 6.90 & $5.08(\mathrm{SD})$ \\
\hline Shoulder Flexion & $7.68^{\mathrm{a}}$ & 1.23 & $7.22^{\mathrm{a}}$ & 1.29 & $58.11^{\mathrm{b}}$ & 39.33 \\
\hline Shoulder Extension & $2.27^{\mathrm{a}}$ & 1.05 & $6.69^{\mathrm{b}}$ & .84 & - & - \\
\hline Shoulder Abduction & $13.29^{\mathrm{a}}$ & .73 & $14.72^{\mathrm{b}}$ & .73 & $13.84^{\mathrm{b}}$ & .74 \\
\hline Shoulder Adduction & - & - & - & - & 2.00 & $1.35(\mathrm{SD})$ \\
\hline Trunk Position & $103.79^{\mathrm{a}}$ & 1.03 & $100.98^{\mathrm{b}}$ & 1.03 & $68.02^{\mathrm{c}}$ & 1.03 \\
\hline Elbow Position & $91.07^{\mathrm{a}}$ & 1.47 & $88.06^{\mathrm{a}}$ & 1.47 & $131.11^{\mathrm{b}}$ & 1.47 \\
\hline Wrist Flexion & 6.36 & .67 & $8.48^{*, * * *}$ & .67 & $7.10^{*}$ & .67 \\
\hline Wrist Extension & $19.17^{\mathrm{a}}$ & 1.39 & $20.63^{\mathrm{b}}$ & 1.39 & $29.94^{\mathrm{c}}$ & 1.39 \\
\hline Wrist Ulnar Dev. & $12.32^{\mathrm{a}}$ & .58 & $12.93^{\mathrm{b}}$ & .58 & $7.83^{\mathrm{c}}$ & .58 \\
\hline Wrist Radial Dev. & $6.77^{\mathrm{a}}$ & .50 & $6.44^{\mathrm{b}}$ & .50 & $8.46^{\mathrm{c}}$ & .50 \\
\hline
\end{tabular}

${ }^{a}$ values with common superscripts were not significantly different, $p<.05$. 


\subsubsection{Distribution of Postural Deviation}

3.3.2.1 Neck. The position of the neck was coded into four different categories: neck extension (greater than one degree), neutral (0 to 10 degrees of flexion), flexion (11 to 20 degrees), and extreme flexion (21 degrees or greater). In the LS condition, there was a significant difference in the amount of time males and females spent in each of these categories of deviation, $\chi^{2}(2, N=180)=14.438, p=.001$ (Table 10). Males spent more time in extreme flexion, while females spent more time in flexion and neutral. In the CL condition, there was a significant difference in the amount of time males and females spent in each of these categories of deviation, $\chi^{2}(2, N=180)=17.880, p<.001$. Males spent more time in extreme flexion, and females spent more time in neutral. In the CB condition, there was a significant difference in the amount of time males and females spent in each of these categories of deviation, $\chi^{2}(2, N=180)$ $=28.037, p<.001$. Males spent more time in extreme flexion, and females spent more time in extension. When the three conditions were combined, there was a significant difference in the amount of time males and females spent in each of these categories of deviation, $\chi^{2}(3, N=540)$ $=44.769, p<.001$ (Figure 14). Females spent more time in neck extension, while males spent more time in extreme neck flexion. 


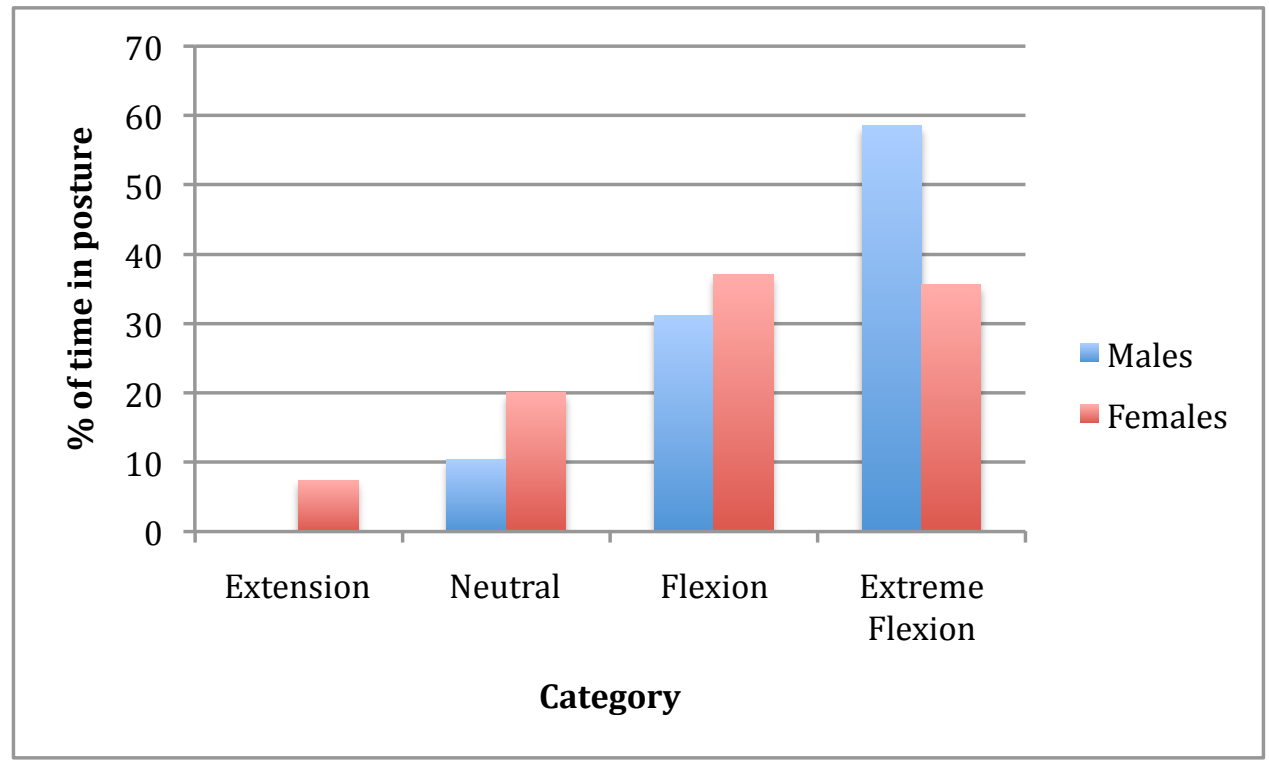

Figure 14. Distribution of neck position for males and females for the three configurations combined

Table 10. Percentage of time spent in each category of neck deviation

\begin{tabular}{|c|c|c|c|c|c|}
\hline \multirow{2}{*}{ Condition } & \multirow{2}{*}{ Gender } & \multicolumn{4}{|c|}{ Percentage of time sample spent in each category of neck deviation } \\
\hline & & Extension & Neutral & Flexion & Extreme Flexion \\
\hline \multirow{2}{*}{$\mathrm{LS}^{*}$} & Males & 0 & 2.2 & 28.9 & 68.9 \\
\hline & Females & 0 & 12.2 & 44.4 & 43.3 \\
\hline \multirow{2}{*}{$\mathrm{CL}^{*}$} & Males & 0 & 1.1 & 31.1 & 67.8 \\
\hline & Females & 0 & 18.9 & 34.4 & 46.7 \\
\hline \multirow{2}{*}{$\mathrm{CB}^{*}$} & Males & 0 & 27.8 & 33.3 & 38.9 \\
\hline & Females & 22.2 & 28.9 & 32.2 & 16.7 \\
\hline \multirow{2}{*}{ Total $^{*}$} & Males & 0 & 10.4 & 31.1 & 58.5 \\
\hline & Females & 7.4 & 20 & 37 & 35.6 \\
\hline
\end{tabular}

$* p<.05$.

3.3.2.2 Shoulder flexion/extension. The position of the shoulder was coded into four different categories: shoulder extension (greater than 11 degrees), neutral (10 degrees of extension to 10 degrees of flexion), flexion (11 to 45 degrees), and extreme flexion (46 degrees or greater). In the LS condition, there was no significant difference in the amount of time males 
and females spent in each of these categories of deviation, $\chi^{2}(2, N=180)=1.001, p=.606$ (Table 11). In the CL condition, there was no significant difference in the amount of time males and females spent in each of these categories of deviation, $\chi^{2}(2, N=180)=2.684, p=.261$. In the $\mathrm{CB}$ condition, there was no significant difference in the amount of time males and females spent in each of these categories of deviation, $\chi^{2}(2, N=180)=.418, p=.518$. When the three conditions were combined, there was no significant difference in the amount of time males and females spent in each of these categories of deviation, $\chi^{2}(3, N=540)=2.758, p=.430$ (Figure $15)$.

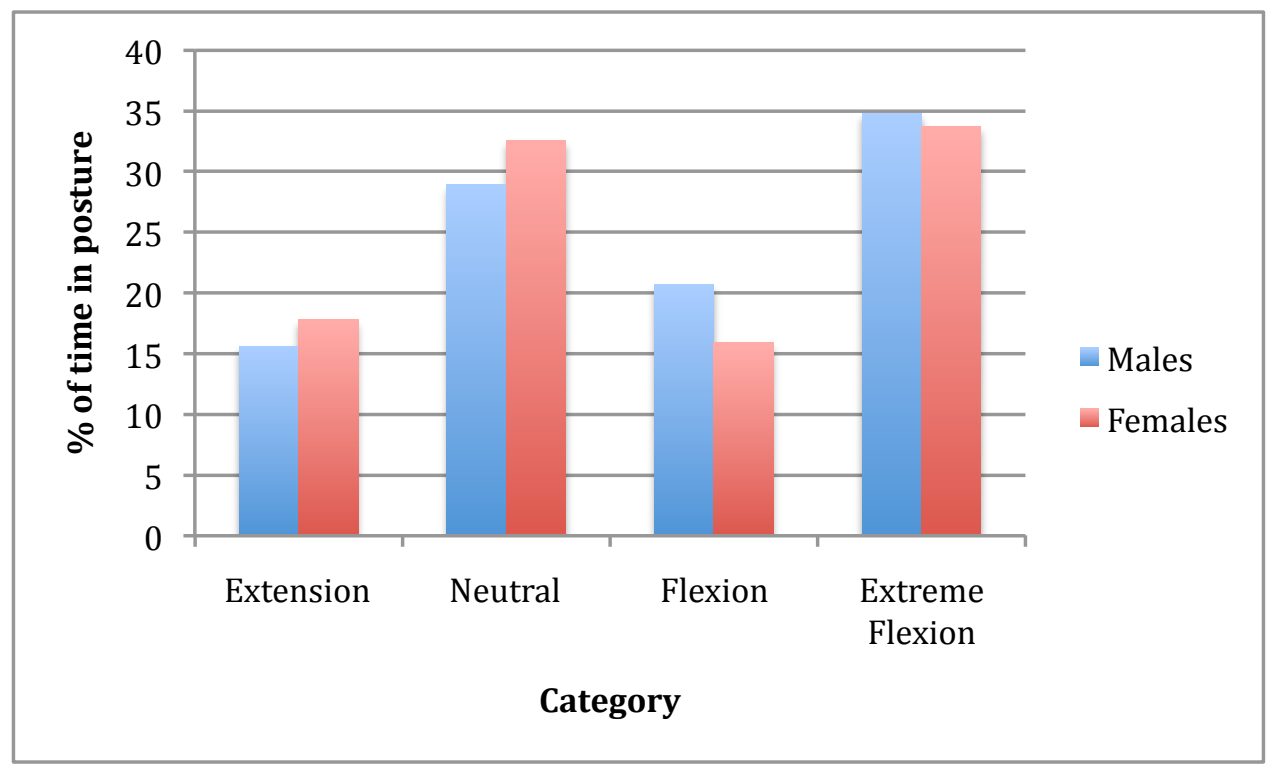

Figure 15. Distribution of shoulder position (flexion/extension) for males and females for the three configurations combined 
Table 11. Percentage of time males and females spent in each category of shoulder flexion or extension

\begin{tabular}{|l|l|l|l|l|l|}
\hline \multirow{2}{*}{ Condition } & \multirow{2}{*}{ Gender } & \multicolumn{6}{c|}{ Percentage of time sample spent in each category of shoulder deviation } \\
\cline { 3 - 6 } & & Extension & Neutral & Flexion & Extreme Flexion \\
\hline \multirow{2}{*}{ LS } & Males & 1.1 & 67.8 & 31.1 & 0 \\
\cline { 2 - 6 } & Females & 1.1 & 74.4 & 24.4 & 0 \\
\hline \multicolumn{5}{|l|}{} \\
\hline \multirow{2}{*}{ CL } & Males & 7.8 & 56.7 & 35.6 & 0 \\
\cline { 2 - 6 } & Females & 10.0 & 65.6 & 24.4 & 0 \\
\hline \multirow{2}{*}{ CB } & Males & 0 & 0 & 12.2 & 87.8 \\
\cline { 2 - 6 } & Females & 0 & 0 & 15.6 & 84.4 \\
\hline \multirow{2}{*}{ Total } & Males & 15.6 & 28.9 & 20.7 & 34.8 \\
\cline { 2 - 6 } & Females & 17.8 & 32.6 & 15.9 & 33.7 \\
\hline
\end{tabular}

3.3.2.3 Shoulder abduction/adduction. The position of the shoulder was coded into four different categories: shoulder adduction (greater than 1 degree), neutral (0 to 10 degrees of abduction), abduction (11 to 20 degrees), and extreme abduction (21 degrees or greater). In the LS condition there was no significant difference in the amount of time males and females spent in each of these categories of deviation, $\chi^{2}(2, N=180)=.028, p=.986$ (Table 12). In the CL condition, there was no significant difference in the amount of time males and females spent in each of these categories of deviation, $\chi^{2}(2, N=180)=4.974, p=.083$. In the CB condition, there was no significant difference in the amount of time males and females spent in each of these categories of deviation, $\chi^{2}(2, N=180)=3.262, p=.353$. When the three conditions were combined, there was no significant difference in the amount of time males and females spent in each of these categories of deviation, $\chi^{2}(3, N=540)=.682, p=.877$ (Figure 16). 


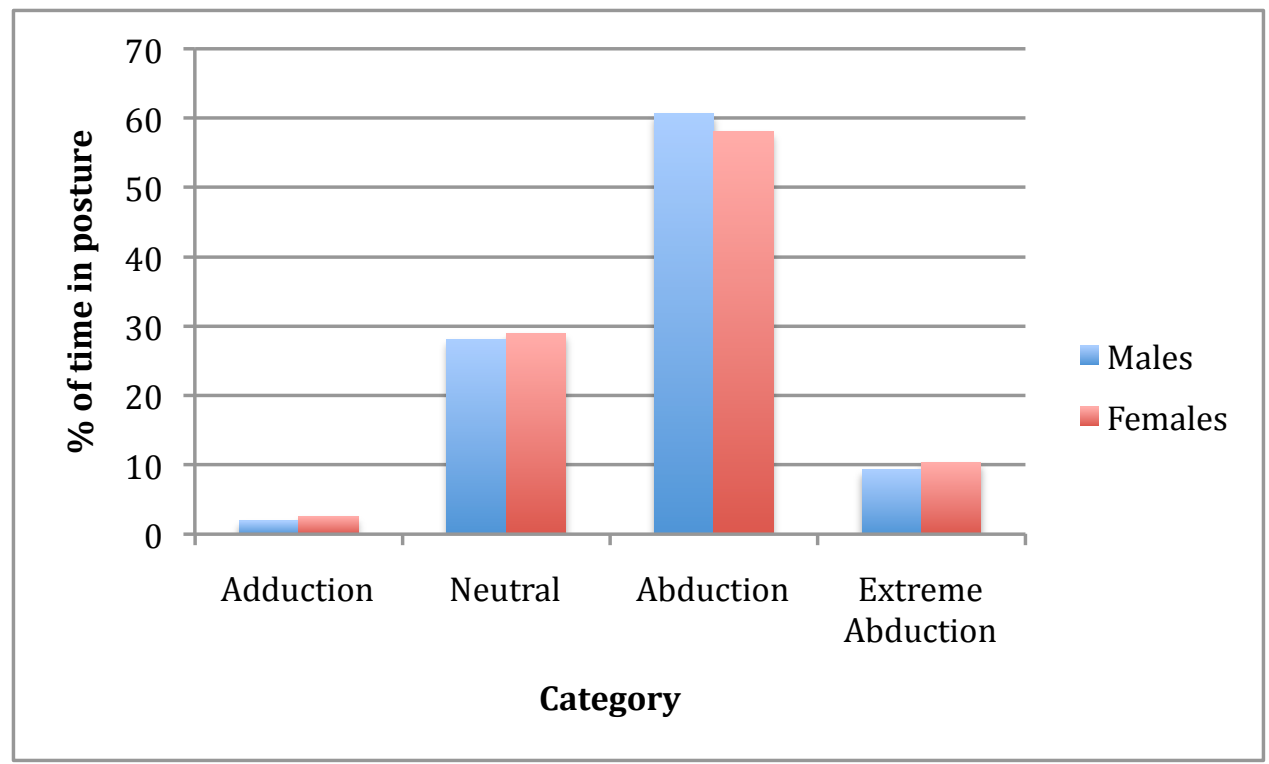

Figure 16. Distribution of shoulder position (abduction/adduction) for males and females for the three configurations combined

Table 12. Percentage of time males and females spent in each category of shoulder abduction or adduction

\begin{tabular}{|c|c|c|c|c|c|}
\hline \multirow[t]{2}{*}{ Condition } & \multirow[t]{2}{*}{ Gender } & \multicolumn{4}{|c|}{ Percentage of time sample spent in each category of shoulder deviation } \\
\hline & & Adduction & Neutral & Abduction & $\begin{array}{c}\text { Extreme } \\
\text { Abduction }\end{array}$ \\
\hline \multirow[t]{2}{*}{ LS } & Males & 0 & 26.7 & 70 & 3.3 \\
\hline & Females & 0 & 27.8 & 68.9 & 3.3 \\
\hline \multirow[t]{2}{*}{ CL } & Males & 0 & 13.3 & 76.7 & 10.0 \\
\hline & Females & 0 & 25.6 & 68.9 & 5.6 \\
\hline \multirow[t]{2}{*}{$\mathrm{CB}$} & Males & 5.6 & 44.4 & 35.6 & 14.4 \\
\hline & Females & 7.8 & 33.3 & 36.7 & 22.2 \\
\hline \multirow[t]{2}{*}{ Total } & Males & 1.9 & 28.1 & 60.7 & 9.3 \\
\hline & Females & 2.6 & 28.9 & 58.1 & 10.4 \\
\hline
\end{tabular}

3.3.2.4 Elbow position. The position of the elbow was coded into four different categories: less than 90 degrees, 91 to 120 degrees, 121 to 150 degrees, and 151 degrees and greater. In the LS condition, there was a significant difference in the amount of time males and females spent in each of these categories of deviation, $\chi^{2}(2, N=180)=13.151, p=.001$ (Table 
13). Males spent more time in the $<90$-degree range, while females spent more time in the $91-$ 120 degree range. In the CL condition, there was no significant difference in the amount of time males and females spent in each of these categories of deviation, $\chi^{2}(2, N=180)=4.640, p=$ .098. In the CB condition, there was no significant difference in the amount of time males and females spent in each of these categories of deviation, $\chi^{2}(2, N=180)=2.733, p=.435$. When the three conditions were combined, there was no significant difference in the amount of time males and females spent in each of these categories of deviation, $\chi^{2}(3, N=540)=2.383, p=$ .497 (Figure 17).

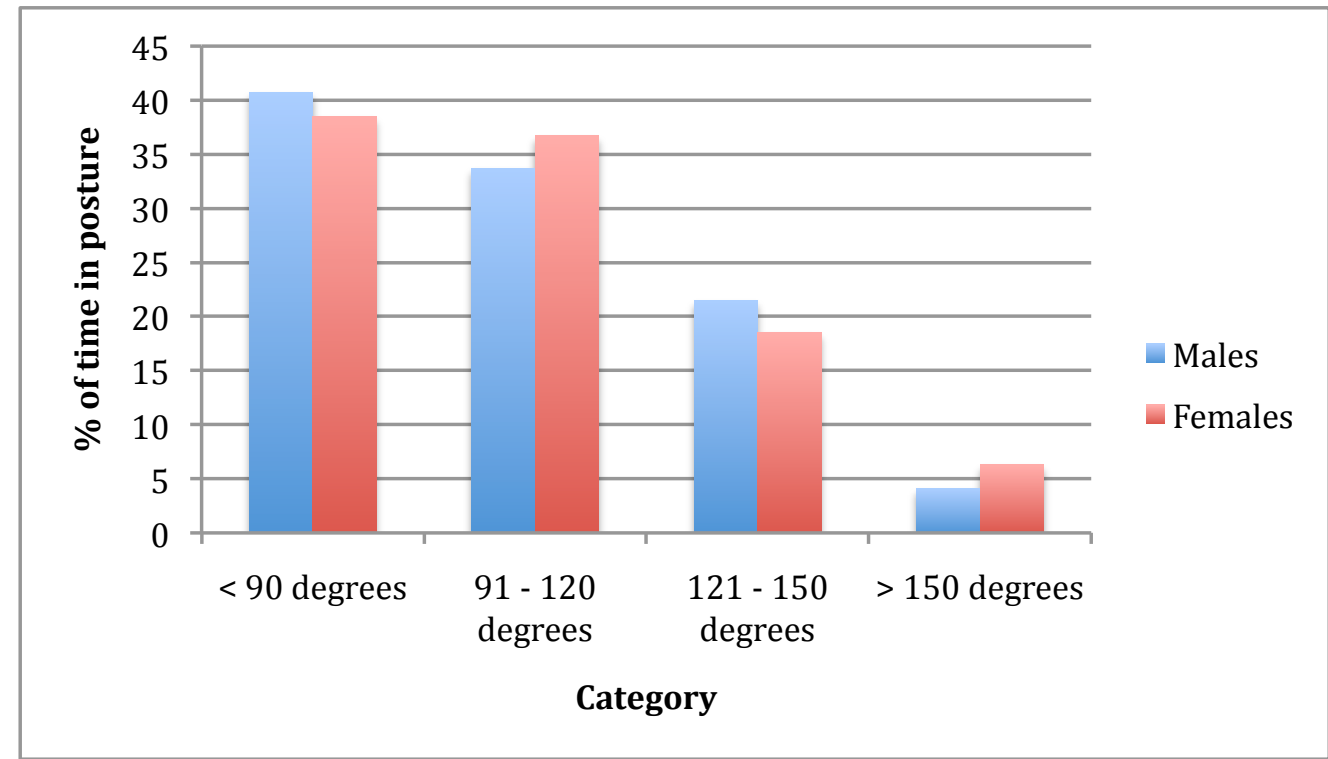

Figure 17. Distribution of elbow position for males and females for the three configurations combined 
Table 13. Percentage of time males and females spent in each category of elbow deviation

\begin{tabular}{|c|c|c|c|c|c|}
\hline \multirow[b]{2}{*}{ Condition } & \multirow[b]{2}{*}{ Gender } & \multicolumn{4}{|c|}{ Percentage of time sample spent in each category of elbow angle } \\
\hline & & $<90$ degrees & 91 - 120 degrees & $\begin{array}{c}121-150 \\
\text { degrees }\end{array}$ & $>151$ degrees \\
\hline \multirow{2}{*}{$\mathrm{LS}^{*}$} & Males & 66.7 & 31.1 & 2.2 & 0 \\
\hline & Females & 43.3 & 56.7 & 0 & 0 \\
\hline \multirow{2}{*}{$\mathrm{CL}$} & Males & 54.4 & 44.4 & 1.1 & 0 \\
\hline & Females & 68.9 & 31.1 & 0 & 0 \\
\hline \multirow{2}{*}{$\mathrm{CB}$} & Males & 1.1 & 25.6 & 61.1 & 12.2 \\
\hline & Females & 3.3 & 22.2 & 55.6 & 18.9 \\
\hline \multirow{2}{*}{ Total } & Males & 40.7 & 33.7 & 21.5 & 4.1 \\
\hline & Females & 38.5 & 36.7 & 18.5 & 6.3 \\
\hline
\end{tabular}

${ }^{*} p<.05$.

3.3.2.5 Trunk position. The position of the trunk was coded into four different categories: extreme flexion (less than 60 degrees), flexion (61 to 90 degrees), neutral (91 to 110 degrees), and extension (111 degrees and greater). In the LS condition, there was a significant difference in the amount of time males and females spent in each of these categories of deviation, $\chi^{2}(2, N=180)=9.786, p=.007$ (Table 14). Males spent more time in extension, and females spent more time in neutral. In the CL condition, there was a significant difference in the amount of time males and females spent in each of these categories of deviation, $\chi^{2}(2, N=180)$ $=11.116, p=.004$. Males spent more time in extension, while females spent more time in neutral. In the $\mathrm{CB}$ condition, there was a significant difference in the amount of time males and females spent in each of these categories of deviation, $\chi^{2}(2, N=180)=10.572, p=.005$.

Females spent more time in extreme flexion, while males spent more time in neutral and flexion. When the three conditions were combined, there was a significant difference in the amount of time males and females spent in each of these categories of deviation, $\chi^{2}(3, N=540)=23.571, p$ 
$<.001$ (Figure 18). Generally, males spent more time in extension, while females spent more time in both neutral and extreme flexion.

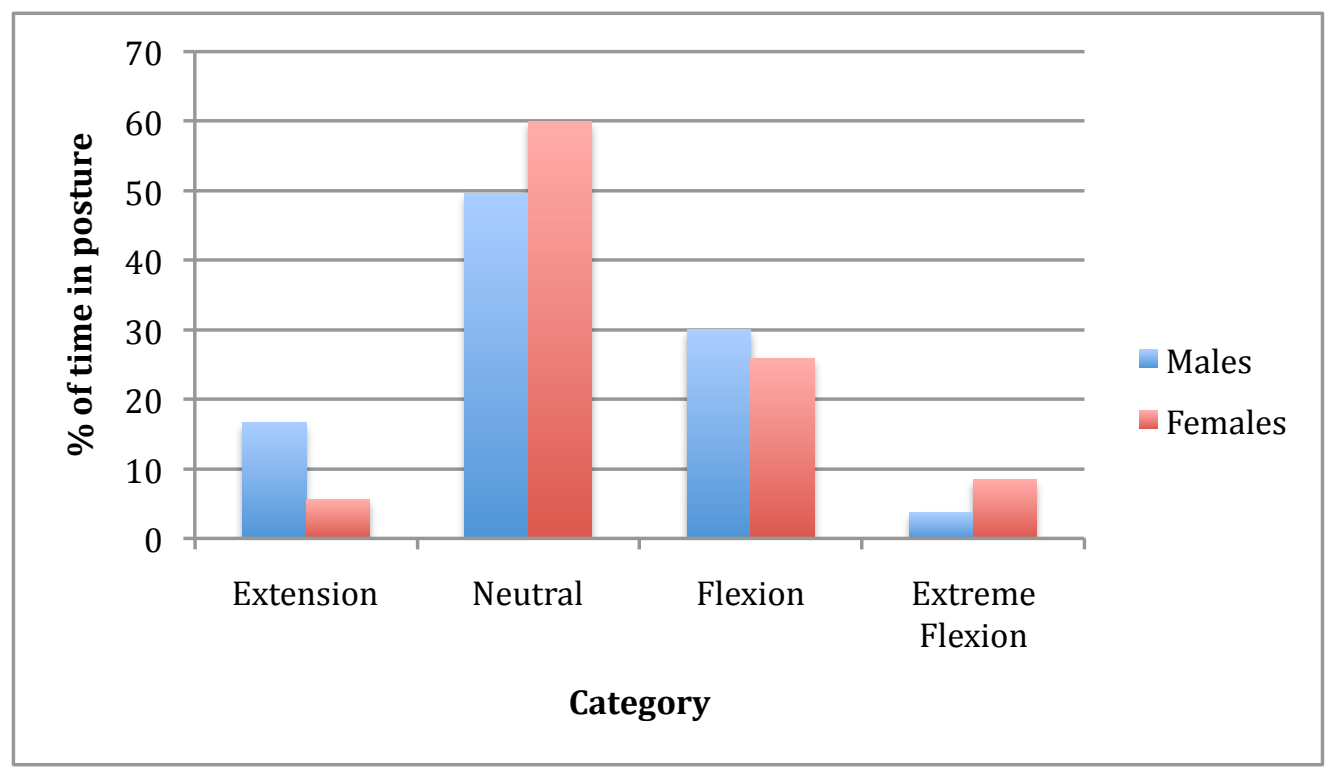

Figure 18. Distribution of trunk position for males and females for the three configurations combined

Table 14. Percentage of time males and females spent in each category of trunk deviation

\begin{tabular}{|c|c|c|c|c|c|}
\hline \multirow{2}{*}{ Condition } & \multirow{2}{*}{ Gender } & \multicolumn{4}{|c|}{ Percentage of time sample spent in each category of trunk deviation } \\
\hline & & Extreme flexion & Flexion & Neutral & Extension \\
\hline \multirow{2}{*}{$\mathrm{LS}^{*}$} & Males & 0 & 1.1 & 68.9 & 30.0 \\
\hline & Females & 0 & 0 & 87.8 & 12.2 \\
\hline \multirow{2}{*}{$\mathrm{CL}^{*}$} & Males & 0 & 5.6 & 74.4 & 20.0 \\
\hline & Females & 0 & 3.3 & 92.2 & 4.4 \\
\hline \multirow{2}{*}{$\mathrm{CB}^{*}$} & Males & 11.1 & 83.3 & 5.6 & 0 \\
\hline & Females & 25.6 & 74.4 & 0 & 0 \\
\hline \multirow{2}{*}{ Total $^{*}$} & Males & 3.7 & 30 & 49.6 & 16.7 \\
\hline & Females & 8.5 & 25.9 & 60 & 5.6 \\
\hline
\end{tabular}

${ }^{*} p<.05$.

3.3.2.6 Wrist flexion/extension. The position of the wrist was coded into five different categories: extreme flexion (greater than 15.001 degrees), flexion (5.001 to 15 degrees), neutral (5 degrees of flexion to 5 degrees of extension), extension (5.001 to 15 degrees) and extreme 
extension (greater than 15.001 degrees). In the LS condition, there was a significant difference in the amount of time males and females spent in each of these categories of deviation, $\chi^{2}(4, N=$ $130163)=2599.057, p<.001($ Table 15$)$. Females spent more time in extreme extension and less time in the other four categories than did males. In the CL condition, there was a significant difference in the amount of time males and females spent in each of these categories of deviation, $\chi^{2}(4, N=130059)=6089.052, p<.001$. Again, females spent more time in extreme extension and less time in the other four categories than did males. In the CB condition, there was a significant difference in the amount of time males and females spent in each of these categories of deviation, $\chi^{2}(4, N=130168)=1834.180, p<.001$. Females spent more time in extreme extension and less time in the other four categories than did males. When the three conditions were combined, there was a significant difference in the amount of time males and females spent in each of these categories of deviation, $\chi^{2}(4, N=390390)=9390.698, p<.001$ (Figure 19).

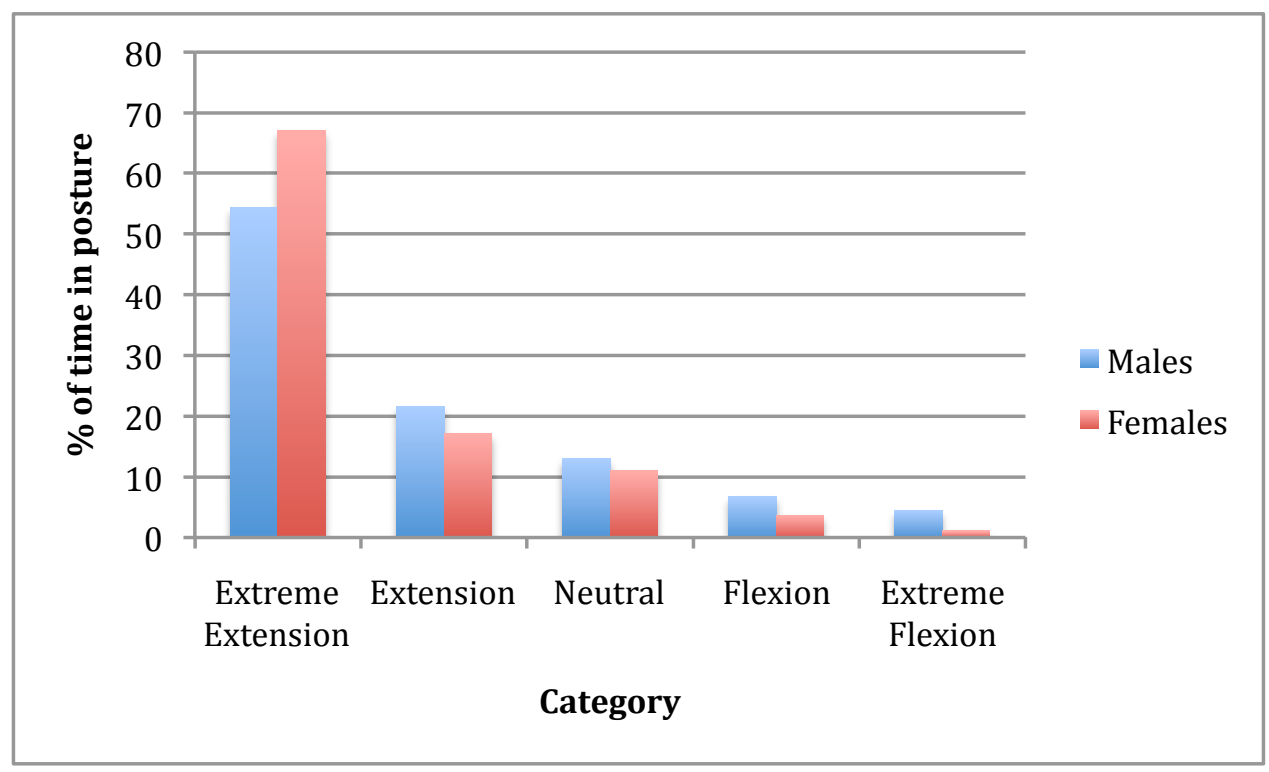

Figure 19. Distribution of wrist position (flexion/extension) for males and females for the three configurations combined 
Table 15. Percentage of time males and females spent in each category of wrist flexion or extension

\begin{tabular}{|c|c|c|c|c|c|c|}
\hline \multirow[b]{2}{*}{ Condition } & \multirow[b]{2}{*}{ Gender } & \multicolumn{5}{|c|}{ Percentage of time sample spent in each category of wrist deviation } \\
\hline & & $\begin{array}{l}\text { Extreme } \\
\text { Flexion }\end{array}$ & Flexion & Neutral & Extension & $\begin{array}{l}\text { Extreme } \\
\text { Extension }\end{array}$ \\
\hline \multirow{2}{*}{$\mathrm{LS}^{*}$} & Males & 2.7 & 8.0 & 18.4 & 26.4 & 44.4 \\
\hline & Females & 0.8 & 4.5 & 15.5 & 22.7 & 56.4 \\
\hline \multirow{2}{*}{$\mathrm{CL}^{*}$} & Males & 7.2 & 6.5 & 12.8 & 23.7 & 49.8 \\
\hline & Females & 0.8 & 3.3 & 9.9 & 19.3 & 66.7 \\
\hline \multirow{2}{*}{$\mathrm{CB}^{*}$} & Males & 3.5 & 5.5 & 7.7 & 14.5 & 68.8 \\
\hline & Females & 1.8 & 3.3 & 7.7 & 9.2 & 78.0 \\
\hline \multirow{2}{*}{ Total $^{*}$} & Males & 4.5 & 6.7 & 13.0 & 21.6 & 54.3 \\
\hline & Females & 1.1 & 3.7 & 11.0 & 17.1 & 67.0 \\
\hline
\end{tabular}

${ }^{*} p<.05$.

3.3.2.7 Wrist ulnar/radial deviation. The position of the wrist was coded into five different categories: extreme ulnar deviation (greater than 15.001 degrees), ulnar deviation (5.001 to 15 degrees), neutral (5 degrees of ulnar deviation to 5 degrees of radial deviation), radial deviation (5.001 to 15 degrees) and extreme radial deviation (greater than 15.001 degrees). In the LS condition, there was a significant difference in the amount of time males and females spent in each of these categories of deviation, $\chi^{2}(4, N=130163)=355.379, p<.001$ (Table 16). Men spent more time than females did in extreme ulnar deviation, while females spent more time in radial deviation than did males. In the CL condition, there was a significant difference in the amount of time males and females spent in each of these categories of deviation, $\chi^{2}(4, N=$ $130059)=856.069, p<.001$. Males spent more time in extreme ulnar deviation than did females, although females spent more time in ulnar deviation than did males. In the CB condition, there was a significant difference in the amount of time males and females spent in each of these categories of deviation, $\chi^{2}(4, N=130168)=2202.426, p<.001$. Males spent more time in both ulnar and extreme ulnar deviation than females did, while females spent more time in extreme 
radial deviation than males did. When the three conditions were combined, there was a significant difference in the amount of time males and females spent in each of these categories of deviation, $\chi^{2}(4, N=390390)=1619.433, p<.001($ Figure 20$)$.

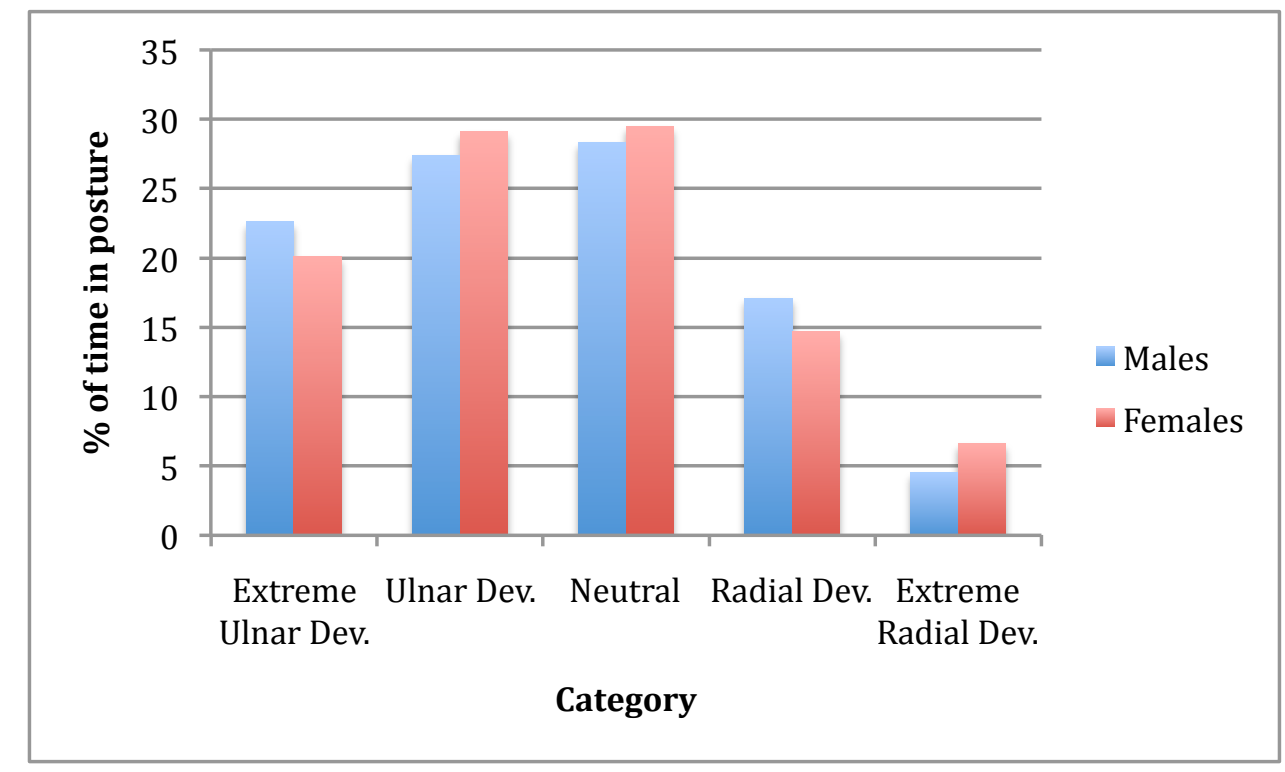

Figure 20. Distribution of wrist position (ulnar/radial deviation) for males and females for the three configurations combined

Table 16. Percentage of time males and females spent in each category of ulnar or radial deviation of the wrist

\begin{tabular}{|c|c|c|c|c|c|c|}
\hline \multirow[b]{2}{*}{ Condition } & \multirow[b]{2}{*}{ Gender } & \multicolumn{5}{|c|}{ Percentage of time sample spent in each category of wrist deviation } \\
\hline & & $\begin{array}{l}\text { Extreme } \\
\text { Ulnar Dev. }\end{array}$ & $\begin{array}{l}\text { Ulnar } \\
\text { Deviation } \\
\end{array}$ & Neutral & $\begin{array}{l}\text { Radial } \\
\text { Deviation } \\
\end{array}$ & $\begin{array}{l}\text { Extreme } \\
\text { Radial Dev. }\end{array}$ \\
\hline \multirow{2}{*}{$\mathrm{LS}^{*}$} & Males & 28.4 & 27.8 & 26.7 & 13.2 & 3.9 \\
\hline & Females & 24.6 & 30.5 & 26.0 & 13.9 & 5.0 \\
\hline \multirow{2}{*}{$\mathrm{CL}^{*}$} & Males & 29.3 & 28.4 & 27.1 & 12.3 & 3.0 \\
\hline & Females & 26.6 & 35.6 & 25.3 & 9.7 & 2.9 \\
\hline \multirow{2}{*}{$\mathrm{CB}^{*}$} & Males & 10.3 & 26.0 & 31.2 & 25.9 & 6.5 \\
\hline & Females & 9.0 & 21.2 & 37.2 & 20.5 & 12.1 \\
\hline \multirow{2}{*}{ Total $^{*}$} & Males & 22.6 & 27.4 & 28.3 & 17.1 & 4.5 \\
\hline & Females & 20.1 & 29.1 & 29.5 & 14.7 & 6.6 \\
\hline
\end{tabular}

\footnotetext{
$* p<.05$.
} 


\subsubsection{Discomfort}

3.3.3.1 Hands. There was no main effect of gender on the level of discomfort reported in the hands, $F(1,34)=.001, p=.970$. In the LS condition, the mean discomfort for males was 1.23 $(S E=.32)$ and the mean discomfort for females was .94 $(S E=.32), t(57.998)=.891, p=.377$. In the CL condition, males reported a mean discomfort of $1.19(S E=.32)$ and females reported a mean discomfort of $1.17(S E=.32), t(57.998)=1.043, p=.302$. In the CB condition males reported a mean discomfort of .71 $(S E=.32)$ and females reported a mean discomfort of 1.06 $(S E=.32), t(57.998)=1.537, p=.130$. There was no main effect of condition on the level of discomfort reported in the hands, $F(2,68)=1.371, p=.261$.

3.3.3.2 Wrists. There was no main effect of gender on the level of discomfort reported in the wrists, $F(1,34)=1.303, p=.262$. In the LS condition, the mean discomfort for males was $.90(S E=.31)$ and the mean discomfort for females was $1.24(S E=.31), t(65.593)=.787, p=$ .434. In the CL condition, males reported a mean discomfort of $.95(S E=.31)$ and females reported a mean discomfort of $1.23(S E=.31), t(63.593)=.630, p=.542$. In the $\mathrm{CB}$ condition males reported a mean discomfort of $.85(S E=.31)$ and females reported a mean discomfort of $1.49(S E=.31), t(63.593)=1.449, p=.153$. There was no main effect of condition on the level of discomfort in the wrists, $F(2,68)=.116, p=.660$.

3.3.3.3 Forearms. There was no main effect of gender on the level of discomfort reported in the forearms, $F(1,34)=.402, p=.530$. In the LS condition, the mean discomfort for males was $.79(S E=.33)$ and the mean discomfort for females was $1.10(S E=.33), t(59.080)=$ $.0659, p=.513$. In the CL condition, males reported a mean discomfort of $.95(S E=.33)$ and females reported a mean discomfort of $1.14(S E=.33), t(59.080)=.404, p=.687$. In the CB condition males reported a mean discomfort of $.84(S E=.33)$ and females reported a mean 
discomfort of $1.10(S E=.33), t(59.080)=.567, p=.572$. There was no main effect of condition on the level of discomfort reported in the forearms, $F(2,68)=.123, p=.885$.

3.3.3.4 Elbows. There was no main effect of gender on the level of discomfort reported in the elbows, $F(1,34)=.847, p=.364$. In the LS condition, the mean discomfort for males was $.43(S E=.22)$ and the mean discomfort for females was .64 $(S E=.22), t(47.809)=.714, p=$ .479. In the CL condition, males reported a mean discomfort of $.45(S E=.22)$ and females reported a mean discomfort of $.56(S E=.22), t(47.809)=.375, p=.709$. In the CB condition males reported a mean discomfort of $.36(S E=.22)$ and females reported a mean discomfort of $.79(S E=.22), t(47.809)=1.434, p=.158$. There was no main effect of condition on the level of discomfort reported in the elbows, $F(2,68)=.215, p=.807$.

3.3.3.5 Neck. There was no main effect of gender on the level of discomfort reported in the neck, $F(1,34)=1.799, p=.189$. In the LS condition, the mean discomfort for males was $1.98(S E=.38)$ and the mean discomfort for females was $2.45(S E=.38), t(57.998)=.891, p=$ .377. In the CL condition, males reported a mean discomfort of $1.84(S E=.38)$ and females reported a mean discomfort of $2.39(S E=.38), t(57.998)=1.043, p=.302$. In the CB condition males reported a mean discomfort of $2.03(S E=.38)$ and females reported a mean discomfort of $2.85(S E=.38), t(57.998)=1.537, p=.130$. There was no main effect of condition on the level of discomfort reported in the neck, $F(2,68)=1.013, p=.369$.

3.3.3.6 Shoulders. There was no main effect of gender on the level of discomfort reported in the shoulders, $F(1,34)=3.210, p=.082$. In the LS condition, the mean discomfort for males was $.79(S E=.36)$ and the mean discomfort for females was $1.60(S E=.36), t(65.213)$ $=1.572, p=.120$. In the CL condition, males reported a mean discomfort of $.85(S E=.36)$ and females reported a mean discomfort of $1.43(S E=.36), t(65.213)=1.134, p=.260$. In the CB 
condition males reported a mean discomfort of $.99(S E=.36)$ and females reported a mean discomfort of $1.89(S E=.36), t(65.213)=1.745, p=.085$. There was no main effect of condition on the level of discomfort reported in the shoulders, $F(2,68)=.212, p=.810$.

3.3.3.7 Upper back. A significant gender $\mathrm{x}$ condition interaction was observed in the pattern of reported discomfort in the upper back, $F(2,68)=3.930, p=.024$. In the LS condition, the mean discomfort for males was $2.52(S E=.42)$ and the mean discomfort for females was $1.56(S E=.42), t(70.752)=1.612, p=.111$. In the $\mathrm{CL}$ condition, males reported a mean discomfort of $1.60(S E=.42)$ and females reported a mean discomfort of $2.05(S E=.42)$, $t(70.752)=.750, p=.456$. In the $\mathrm{CB}$ condition males reported a mean discomfort of 1.77 (SE= $.42)$ and females reported a mean discomfort of $2.37(S E=.42), t(70.752)=1.007, p=.318$. There was no significant main effect of condition $F(2,68)=.381 p=.685$.

3.3.3.8 Lower back. There was no main effect of gender on the level of discomfort reported in the lower back, $F(1,34)=.037, p=.849$. In the LS condition, the mean discomfort for males was $2.95(S E=.48)$ and the mean discomfort for females was $2.42(S E=.48)$, $t(52.188)=.787, p=.435$. In the CL condition, males reported a mean discomfort of 2.73 (SE $=$ $.48)$ and females reported a mean discomfort of $2.54(S E=.48), t(52.188)=.278, p=.783$. In the $\mathrm{CB}$ condition males reported a mean discomfort of $2.59(S E=.48)$ and females reported a mean discomfort of $2.96(S E=.48), t(52.188)=.551, p=.584$. There was no main effect of condition on the level of discomfort reported in the lower back, $F(2,68)=.135, p=.874$.

3.3.3.9 Buttocks. There was no main effect of gender on the level of discomfort reported in the buttocks, $F(1,34)=1.367, p=.250$. In the LS condition, the mean discomfort for males was $.72(S E=.42)$ and the mean discomfort for females was $1.44(S E=.42), t(49.698)=1.203, p$ $=.235$. In the CL condition, males reported a mean discomfort of $.92(S E=.42)$ and females 
reported a mean discomfort of $1.25(S E=.42), t(49.698)=.555, p=.582$. In the CB condition males reported a mean discomfort of $1.23(S E=.42)$ and females reported a mean discomfort of $2.08(S E=.42), t(49.698)=1.413, p=.164$. A significant main effect of condition was observed, $F(2,68)=4.489, p=.015$. A significantly higher level of discomfort was consistently reported in the $\mathrm{CB}$ condition $(M=1.65, S E=.30)$ than the $\mathrm{LS}(M=1.08, S E=.30)$ condition, $t(68)=2.606$, $p=.033$. A significantly higher level of discomfort was also reported in the CB condition than the CL $(M=1.09, S E=.30)$ condition, $t(68)=2.575, p=.036$. There was no significant difference in the level of discomfort reported in the CL and LS conditions, $t(68)=.032, p=1.00$.

3.3.3.10 Thighs. A significant gender $\mathrm{x}$ condition interaction was observed in the level of discomfort reported in the thighs, $F(2,68)=3.365, p=.040$. In the LS condition, the mean discomfort for males was $.56(S E=.44)$ and the mean discomfort for females was $1.18(S E=$ $.44), t(62.923)=.986, p=.328$. In the CL condition, males reported a mean discomfort of 1.49 $(S E=.44)$ and females reported a mean discomfort of $1.06(S E=.44), t(62.923)=.682, p=.497$. In the $\mathrm{CB}$ condition males reported a mean discomfort of $1.70(S E=.44)$ and females reported a mean discomfort of $2.75(S E=.44), t(62.923)=1.695, p=.095$. There was also a main effect of condition present, $F(2,68)=11.305, p<.01$. A significantly higher level of discomfort was consistently reported in the $\mathrm{CB}(M=2.23, S E=.31)$ condition than in the $\operatorname{LS}(M=.87, S E=.31)$ condition, $t(68)=4.631, p<.01$. In addition, a significantly higher level of discomfort was reported in the $\mathrm{CB}(M=2.23, S E=.31)$ condition than in the $\mathrm{CL}(M=1.27, S E=.31)$ condition, $t(68)=3.246, p=.005$. There was no significant difference in the mean discomfort reported in the LS and CL conditions, $t(68)=1.386, p=.512$.

3.3.3.11 Knees. There was no main effect of gender on the level of discomfort reported in the knees, $F(1,34)=3.551, p=.068$. In the LS condition, the mean discomfort for males was 
$.45(S E=.44)$ and the mean discomfort for females was $.70(S E=.44), t(64.920)=.398, p=$ .692. In the CL condition, females $(M=2.29, S E=.44)$ reported a significantly higher level of discomfort than males $(M=.98, S E=.44), t(64.920)=2.121, p=.038$. In the CB condition, females $(M=2.78, S E=.44)$ also reported significantly higher levels of discomfort than did males $(M=1.43, S E=.44), t(64.920)=2.174, p=.033$. A significant main effect of condition was also observed, $F(2,68)=13.725, p<.01$. A significantly higher level of discomfort was reported in the CB $(M=2.11, S E=.31)$ condition than the $\operatorname{LS}(M=.58, S E=.31)$ condition. $t(68)=5.124, p<.01$. A significantly higher level of discomfort was also reported in the CL ( $M$ $=1.64, S E=.31)$ condition than in the LS condition, $t(68)=3.545, p=.002$. There was no significant difference in the mean discomfort reported between the CB and CL conditions, $t(68)$ $=1.579, p=.358$.

Table 17. Self-reported discomfort in each body part after completion of the LS condition.

\begin{tabular}{|l|l|l|l|l|}
\hline \multirow{2}{*}{ Body Part } & \multicolumn{2}{c|}{ Reported Discomfort - Males } & \multicolumn{2}{c|}{ Reported Discomfort - Females } \\
\cline { 2 - 5 } & \multicolumn{1}{|c|}{ Mean } & Std. Error & \multicolumn{1}{c|}{ Mean } & Std. Error \\
\hline Hands & 1.23 & .32 & .94 & .32 \\
\hline Wrists & .90 & .31 & 1.24 & .31 \\
\hline Forearms & .79 & .33 & 1.10 & .33 \\
\hline Elbows & .43 & .22 & .64 & .22 \\
\hline Neck & 1.98 & .38 & 2.45 & .38 \\
\hline Shoulders & .79 & .36 & 1.60 & .36 \\
\hline Upper Back & 2.52 & .42 & 1.56 & .42 \\
\hline Lower Back & 2.95 & .48 & 2.42 & .48 \\
\hline Buttocks & .72 & .42 & 1.44 & .42 \\
\hline Thighs & .56 & .44 & 1.18 & .44 \\
\hline Knees & .45 & .44 & .70 & .44 \\
\hline
\end{tabular}


Table 18. Self-reported discomfort in each body part after completion of the CL condition

\begin{tabular}{|l|l|l|l|l|}
\hline \multirow{2}{*}{ Body Part } & \multicolumn{2}{|c|}{ Reported Discomfort - Males } & \multicolumn{2}{c|}{ Reported Discomfort - Females } \\
\cline { 2 - 5 } & \multicolumn{1}{|c|}{ Mean } & \multicolumn{2}{c|}{ Std. Error } & \multicolumn{2}{c|}{ Mean } & .32 \\
\hline Hands & 1.19 & .32 & 1.17 & .31 \\
\hline Wrists & .95 & .31 & 1.23 & .33 \\
\hline Forearms & .95 & .33 & 1.14 & .22 \\
\hline Elbows & .45 & .22 & .56 & .38 \\
\hline Neck & 1.84 & .38 & 2.39 & .36 \\
\hline Shoulders & .85 & .36 & 1.43 & .42 \\
\hline Upper Back & 1.60 & .42 & 2.05 & .48 \\
\hline Lower Back & 2.73 & .48 & 2.54 & .42 \\
\hline Buttocks & .92 & .42 & 1.25 & .44 \\
\hline Thighs & 1.49 & .44 & 1.06 & .44 \\
\hline Knees & .98 & .44 & 2.29 & \\
\hline
\end{tabular}

$* p<.05$.

Table 19. Self-reported discomfort in each body part after completion of the CB condition.

\begin{tabular}{|l|l|l|l|l|}
\hline \multirow{2}{*}{ Body Part } & \multicolumn{2}{|l|}{ Reported Discomfort - Males } & \multicolumn{2}{l|}{ Reported Discomfort - Females } \\
\cline { 2 - 5 } & Mean & Std. Error & Mean & Std. Error \\
\hline Hands & .71 & .32 & 1.06 & .32 \\
\hline Wrists & .85 & .31 & 1.49 & .31 \\
\hline Forearms & .84 & .33 & 1.10 & .33 \\
\hline Elbows & .36 & .22 & .79 & .22 \\
\hline Neck & 2.03 & .38 & 2.85 & .38 \\
\hline Shoulders & .99 & .36 & 1.89 & .36 \\
\hline Upper Back & 1.77 & .42 & 2.37 & .42 \\
\hline Lower Back & 2.59 & .48 & 2.96 & .48 \\
\hline Buttocks & 1.23 & .42 & 2.08 & .42 \\
\hline Thighs & 1.70 & .44 & 2.75 & .44 \\
\hline Knees & 1.43 & .44 & $1.78 *$ & .44 \\
\hline
\end{tabular}

*p $<.05$. 
Table 20. Self-reported discomfort in each configuration for males and females combined

\begin{tabular}{|c|c|c|c|c|c|c|}
\hline \multirow{2}{*}{ Body Part } & \multicolumn{2}{|c|}{ Reported Discomfort - LS } & \multicolumn{2}{|c|}{ Reported Discomfort - CL } & \multicolumn{2}{|c|}{ Reported Discomfort - CB } \\
\hline & Mean & Std. Error & Mean & Std. Error & Mean & Std. Error \\
\hline Hands & $1.09^{\mathrm{a}}$ & .22 & $1.18^{\mathrm{a}}$ & .22 & $.89^{\mathrm{a}}$ & .22 \\
\hline Wrists & $1.07^{\mathrm{a}}$ & .22 & $1.09^{\mathrm{a}}$ & .22 & $1.17^{\mathrm{a}}$ & .22 \\
\hline Forearms & $.95^{\mathrm{a}}$ & .23 & $1.04^{\mathrm{a}}$ & .23 & $.97^{\mathrm{a}}$ & .23 \\
\hline Elbows & $.53^{\mathrm{a}}$ & .15 & $.51^{\mathrm{a}}$ & .15 & $.58^{\mathrm{a}}$ & .15 \\
\hline Neck & $2.21^{\mathrm{a}}$ & .27 & $2.12^{\mathrm{a}}$ & .27 & $2.44^{\mathrm{a}}$ & .27 \\
\hline Shoulders & $1.20^{\mathrm{a}}$ & .26 & $1.14^{\mathrm{a}}$ & .26 & $1.44^{\mathrm{a}}$ & .26 \\
\hline Upper Back & $2.04^{\mathrm{a}}$ & .30 & $1.82^{\mathrm{a}}$ & .30 & $2.07^{\mathrm{a}}$ & .30 \\
\hline Lower Back & $2.69^{\mathrm{a}}$ & .34 & $2.64^{\mathrm{a}}$ & .34 & $2.77^{\mathrm{a}}$ & .34 \\
\hline Buttocks & $1.08^{\mathrm{a}}$ & .30 & $1.09^{\mathrm{a}}$ & .30 & $1.65^{\mathrm{b}}$ & .30 \\
\hline Thighs & $.87^{\mathrm{a}}$ & .31 & $1.27^{\mathrm{a}}$ & .31 & $2.23^{\mathrm{b}}$ & .31 \\
\hline Knees & $.58^{\mathrm{a}}$ & .31 & $1.64^{\mathrm{b}}$ & .31 & $2.11^{b}$ & .31 \\
\hline
\end{tabular}

${ }^{\mathrm{a}}$ values with common superscripts were not significantly different, $p<.05$.

\subsubsection{Relationship Between Posture and Discomfort}

There was no significant relationship between discomfort and average degree of postural deviation in any of the body parts tested. Average neck deviation (flexion/extension) was not significantly correlated with the magnitude of discomfort reported in the neck $(r=.027, n=108$, $p=.781)$, shoulders $(r=-.164, n=108, p=.090)$, upper back $(r=-.159, n=108, p=.099)$, or lower back $(r=-.001, n=108, p=.990)$. Average shoulder deviation (flexion/extension) was not significantly correlated with the magnitude of discomfort reported in the neck $(r=.105, n=108$, $p=.279)$, shoulders $(r=.097, n=108, p=.319)$, upper back $(r=.035, n=108, p=.719)$, or lower back. $(r=.042, n=108, p=.666)$. Average shoulder deviation (abduction/adduction) was not significantly correlated with the magnitude of discomfort reported in the neck $(r=-.052, n=$ $108, p=.594)$, shoulders $(r=-.066, n=108, p=.497)$, upper back $(r=.002, n=108, p=.982)$, or lower back $(r=-.051, n=108, p=.602)$. Average trunk angle was not significantly correlated with the magnitude of discomfort reported in the upper back $(r=-.006, n=108, p=.949)$ or lower back $(r=-.038, n=108, p=.698)$, and average elbow angle was not significantly correlated with the magnitude of discomfort reported in the elbow $(r=.088, n=108, p=.364)$. 
Average wrist deviation (flexion/extension) was not significantly correlated with discomfort in the hands $(r=.052, n=108, p=.590)$, wrists $(r=.121, n=108, p=.213)$, forearms $(r=-.018, n$ $=108, p=.854)$, or elbows $(r=-.131, n=108, p=.176)$. Average wrist deviation (ulnar/radial deviation) was not significantly correlated with discomfort in the hands $(r=-.089, n=108, p=$ $.362)$, wrists $(r=.078, n=108, p=.419)$, forearms $(r=-.112, n=108, p=.250)$, or elbows $(r=$ $-.102, n=108, p=.292)$. 


\section{CHAPTER 4}

\section{INTERPRETATION OF FINDINGS}

\subsection{Discussion}

Both males and females exhibited highly deviated postures in the three configurations tested in this study, particularly in the neck, shoulders, and wrists. Because these configurations are utilized more frequently by females than males, it is possible that the reason that females report a higher prevalence of discomfort during laptop use than males is due to their choice of working configuration. The hypothesis that females would adopt more risky postures than males was not supported by the findings of this study. Although males and females experienced different patterns of risk in the neck, trunk, and wrists, both groups adopted undesirable postures for the majority of the time tested. Consequently, it cannot be said that one gender was more or less at risk of injury than the other.

The first hypothesis, that females would report higher levels of discomfort than males, was not supported by the findings of this study. In general, both males and females did not experience high levels of discomfort in any body region in any of the three configurations tested, indicating that these configurations may be acceptable for short periods of laptop use. The following chapter presents a discussion of the posture and discomfort findings in relation to the three proposed hypotheses, followed by suggestions for improvements, directions for future study, and implications of this work.

\subsubsection{Posture}

When comparing the average angles of deviation in each body region, very few postural differences were found between males and females. Because looking at an average angle can be misleading when trying to capture posture that may change over time, the data was grouped into categories of deviation in order to try and discern whether there were more subtle differences 
between males and females. Interesting differences started to emerge upon comparing the distributions of time spent in each category of postural deviation throughout the experiment.

The hypothesis that females would adopt more deviated postures than males was not supported by the results of this study. Females did not consistently exhibit a greater amount of postural deviation than males, and in some cases the opposite was found. There were few gender differences in regard to the position of the elbow and shoulders, which can likely be explained by the fact that the position of these body parts is due more to the configuration itself than can be adjusted by individual postural differences. For example, in the CB condition, the elbows and shoulders are required to be extended to reach the computer. Individuals have more control over how the trunk and neck are positioned based on how they are sitting. Males had greater average angles of wrist flexion than females in the CL condition, while females had greater average angles of both wrist flexion and extension than males in the $\mathrm{CB}$ condition. The distribution of wrist position over time was significantly different for males and females in all three conditions, however the overall trends were similar. In general, females spent more time in extreme wrist extension than males did, although both males and females spent the majority of time in some degree of extension. Any differences in the amount of time spent in each category of deviation were very small; consequently, although the difference was statistically significant, they might not be practically significant. Smaller differences were likely found to be statistically significant because of the large number of data points included in the analysis.

For both males and females, the majority of time was spent in either ulnar deviation or a neutral wrist position in this plane, which is characteristic of laptop and desktop computer use due to the shape and location of the keyboard (Turhan et al., 2008). Specifically, placement of the laptop on the lap of the participant may have necessitated these awkward wrist postures. 
Interestingly, in the $\mathrm{CB}$ condition, there was more time spent in radial deviation, which is somewhat uncommon during keyboard use. This may be related to the slightly higher proportion of time spent in extreme shoulder abduction; if the arms are bent out to the sides, this may result in different placement of the wrists compared to normal computer use where the arms are generally positioned more straight forward.

Males had an average angle of neck flexion that was significantly greater than the average angle for females in both the CL and LS conditions. In addition, males actually spent very little time in a neutral neck position, and the majority of their time in extreme flexion (over 20 degrees). This is problematic because sustained neck flexion places a substantial amount of strain on the tendons and other soft tissues in the neck. In the LS condition, males spent 17 of the 25 minutes in a position where the neck was flexed at an angle greater than 20 degrees. Females, on the other hand, exhibited extreme flexion during less than half the time in this configuration. There are several possible explanations for this. First of all, males may exhibit greater degrees of sustained neck flexion due to the placement of the laptop in a lower position, which could be due to their height. In order to test whether height may account for the gender difference in neck posture, a Pearson-product correlation was used. There was no significant correlation between height and neck deviation, and consequently no evidence to support the idea that males exhibited greater neck deviation than females due to their height (see Appendix G). Another explanation for the increased neck flexion in males could be that males are less proficient typists than females, which may have led them to spend more time looking at the keyboard. However, there was no significant difference between males and females in the number of words typed during the task, which could have been an indication of typing proficiency (see Appendix G). Females had a tendency to type more quickly, however as mentioned the difference was not significant. 
What may be the most likely explanation for the observed neck flexion in males could be the amount of time spent in a reclined position. Although there was no difference in the average trunk angle between males and females, an examination of the distribution of positions showed that in the LS and CL conditions, males spent more time than females with an extended trunk (angle greater than 110 degrees). Lying back in a more reclined position would require the neck to be flexed forward in order to view the screen to a greater degree than if the user was sitting in a more upright position. An adaptation of this configuration that may alleviate this neck position would be to raise the knees and prop the laptop up on the legs, however this position was not tested in this study. Males may be more likely to recline back on the bed because it is a more relaxed and comfortable position when using a laptop for a short period of time, although it is unclear why females would not adopt a similar posture. Previous work examining gender differences in seated posture indicate that females tend to sit in a slightly more vertically upright position than males, which is consistent with our findings (Dunk \& Callaghan, 2005).

Despite the finding that males showed higher degrees of and a greater amount of time spent in neck flexion, only female participants exhibited neck extension, which was found solely in the $\mathrm{CB}$ condition. It is likely that neck position is influenced by the position of the trunk. In the $\mathrm{CB}$ condition, females exhibited a significantly smaller trunk angle, indicating that they were leaning forward to a greater degree than males were. Because females were bending very far over in order to view the screen, they likely compensated with their neck by tilting the head back to view the computer screen. It is unclear why females displayed a greater degree of trunk flexion in this position, but it is possible that these participants chose to lean further forward in order to support their forearms or elbows on the bed. In future research, it would be valuable to measure how the tilt and horizontal distance of the screen impacted trunk and neck position in 
these configurations as well. In addition, position of the neck is likely compensated for with kyphotic spinal curve (to help keep neck straight). This was not quantified in this study, and because participants were generally hunched over their laptops, spinal curvature would be something to measure in the future. Trunk angle was used as a proxy for spinal curvature in this study.

In line with hypotheses $2 \mathrm{~b}$, regardless of gender, all three of these configurations placed participants in highly deviated and risky neck positions. The average angle of neck flexion was 13.64 degrees in the CB condition for females, and was greater in all other conditions for both genders. This means that the average angle is outside the recommended neutral range of 15 degrees of deviation in almost all conditions. Although females show a less risky average degree of flexion in the $\mathrm{CB}$ condition, they were still in some degree of flexion for over $72 \%$ of the time, and also displayed extension $22 \%$ of the time. It is difficult to generalize whether males or females are exhibiting more risky neck postures overall, however it can be said that they show different patterns of risk. These findings are in line with previous research that has shown deteriorated neck posture with placement of a laptop on the lap (Asundi et al., 2010; Werth \& Babski-Reeves, 2012).

In support of hypotheses $2 \mathrm{~b}$, each of the configurations tested resulted in large postural deviations from neutral, which place the users at risk of injury. The LS and CL conditions put participants in very similar upper extremity postures, putting participants at risk of injury primarily in the neck, shoulders, and wrists. Specifically, in both configurations the neck is in an average position of just over 20 degrees of flexion, with the shoulders in an average position approximately 14 degrees of abduction. In addition, the wrists were extended on average approximately 20 degrees and exhibited an average ulnar deviation of approximately 12 degrees. 
Despite these problems, the trunk and elbow are in acceptable positions, although these configurations lack appropriate lumbar support.

The $\mathrm{CB}$ condition differed from the other two in a number of ways. In addition to the substantial risk of injury to the neck, shoulders, and wrists, the trunk and elbow were also in unfavorable positions in this configuration. Although there was a smaller average angle of neck flexion than in the LS and CL conditions, the average angle of 16 degrees is still outside the recommended neutral range. In addition, females exhibited neck extension in this position, which places additional and more immediate strain on tendons in the neck. The average angle of shoulder abduction was similar in all three configurations, but the CB position was also characterized by extreme shoulder flexion and a largely extended elbow angle. This was related to the fact that participants were required to flex at the trunk and reach forward in order to view and type on the laptop. The average angle of the trunk was 68 degrees, placing a large amount of pressure on the unsupported lower back. There was also a large average angle of wrist extension in this position. In general, this position placed strain on the majority of the body.

These findings build off work performed by Chang et al. (2008), who tested a number of configurations of laptop use away from at a desk, finding that these positions were characterized by neck flexion, trunk tilt, shoulder flexion and abduction, elbow flexion. The authors reported their findings based on categories of configurations, rather than on each individual position tested. The current study starts to build off this by looking at a subset of configurations in greater detail. In general, the findings are similar, although this study shows that combining positions thought to be similar can result in a loss of information. The CB condition was characterized by very different postures than the LS and CL conditions, although at first glance one might assume 
the $\mathrm{CL}$ and $\mathrm{CB}$ conditions to be more similar. In addition to the gender differences uncovered, this highlights the importance of separating conditions and looking for individual differences.

\subsubsection{Discomfort}

There were no significant differences between males and females or between positions in terms of reported discomfort, with the exception of greater reported discomfort in the buttocks, thighs, and knees in the $\mathrm{CB}$ condition than the other two. The first hypothesis, that females are more likely to report musculoskeletal discomfort associated with laptop use than males was not supported. In general, levels of reported discomfort were very low, likely due to the short duration of the typing task. Because the reported values were low across the board, it is not surprising that statistical differences based on condition and/or gender were not found. Despite the risky and deviated postures exhibited during the tasks, the lack of reported discomfort may indicate that it is acceptable to work in these positions for short periods of time. It is generally recommended to take a break from seated computer work every 20 minutes, which is supported by these findings. However, because individuals often do not follow this rule in practice, it would be valuable to repeat this study or conduct a similar experiment testing longer durations of laptop use.

Because females did not report higher levels of discomfort following each task than males, it is likely that any differences in discomfort related to laptop computer use in reality are due to some factor other than gender-based postural differences, although it is difficult to draw many conclusions due to the limitations mentioned regarding the short duration of the task. In the initial demographic survey, females reported using a laptop in general and specifically on a bed for a greater number of hours per week than males. Although there was no difference in reported discomfort in this study, where all participants spent the same amount of time working in these 
positions, it may be the case that females experience greater discomfort related to laptop use in real life because they use laptops more frequently and/or for longer durations than males. While there was very little discomfort reported after 25 minutes, using a laptop for 40 hours a week (as females do) may result in higher levels of discomfort. It would be valuable to investigate the patterns with which males and females use laptops in terms of the duration of use without a break and break patterns in general. In addition, this study lends support to the hypothesis that females may experience discomfort due to the fact that they work in risky positions more frequently than males. It has been described that the three configurations tested place the individual at risk of injury due to the highly deviated postures exhibited when working these ways. Consequently, it can be suggested that because females work in these positions more frequently than males (see Part I), this may contribute to their higher levels of reported discomfort in self-report surveys. It is probable that the fact the females work in these risky configurations more frequently then males is exasperated by the finding that females report spending more hours per week than males using a laptop computer. Both of these factors (working in combination or independently) may contribute to greater musculoskeletal injury in females.

Although results from the Part I survey, as well as previous studies performed by Bergqvist et al. (1995), Bernard et al. (1994), and Rajagopal et al. (2012), have found that females are more likely to report discomfort associated with laptop use than are males, no gender difference was found in the Part II experiment. Part of this reason may be due to subtle differences in the question asked: there is a difference between presence and intensity of discomfort. The majority of questionnaires, including the one administered in the Part I survey, ask about presence of discomfort (i.e. do you experience discomfort associated with laptop use?), 
while the experiment in Part II asked about magnitude of discomfort (i.e. how much discomfort did you experience?). This difference in semantics may explain some of the discrepancy between previous self-report data and the current findings. In addition, if someone is working in a position for a long duration of time, some of the discomfort or pain may come the next day, and just the act of breaking the posture to fill out the questionnaire may alleviate some of the discomfort experienced during the task. Self-report measures also rely on honesty and memory, which may also account for the difference found between methods. Because Part II of this study measured intensity of discomfort and not prevalence, these findings do not contradict previous literature that indicate a higher prevalence of discomfort in females than males associated with laptop use (Bergqvist et al., 1995; Bernard et al., 1994; Rajagopal et al., 2012). Rather, this study may indicate that the higher prevalence of self-reported discomfort in females than males may be due to some factor other than differences in tolerance. Males and females did not differ in terms of the intensity of discomfort reported after working in the same configurations for the same duration of time, which suggests that the two groups do not differ in terms of their sensitivity to discomfort.

It was expected that there would be a relationship between posture and discomfort; specifically that angle of deviation in a body part would be positively correlated with reported discomfort in the same region (hypothesis 2c). This hypothesis was not supported. There are a number of reasons this may be the case, most likely because of the lack of variability in reported discomfort; all levels were on the low end of the scale. It is difficult to identify trends when the majority of participants reported experiencing very little discomfort. In addition, because posture changed slightly throughout task, the average position had to be correlated with the single number of discomfort collected at the end of the task. Consequently, the value for posture used in 
this correlation may not be representative of the actual posture, as was demonstrated with the differences in information revealed by the average postural angle compared to the distribution of posture. Because of the lack of variability in the discomfort data, further statistical tests to investigate the correlation between posture and discomfort were not conducted. There was no significant association when the data for the three conditions (and males and females) were combined.

\subsubsection{Limitations}

This study does not answer the broad question of whether using a laptop on a bed is associated with musculoskeletal discomfort. It only answers this question for the three positions tested. In order to further identify the risks associated with using a laptop on a bed, a postural analysis of the configurations most frequently utilized on a bed should be performed. This study did not necessarily assess the configurations that are most common; rather, it analyzed the configurations that females use more often than males. The top five configurations included the three we analyzed, and also "sitting on a bed, leaning back against a wall or headboard, knees bent, laptop resting on your lap" and "lying on your stomach on a bed, laptop resting on the bed in front of you". It is also important to qualify that males reported working in the two configurations tested where the legs were crossed somewhat infrequently (over half of the males surveyed in Part I reported never working in these positions). It became apparent rather quickly why males do not work with their legs crossed; generally they had difficulty with these poses and looked very awkward. Consequently, these may not have been the best positions to test to see whether there are postural gender differences when working on a bed. Future studies would be required assessing configurations that are commonly utilized by both genders in order to determine whether general postural differences exist. This study better assesses the question of 
whether females experience increased discomfort due to the fact that they work in these configurations more often than males do. These positions were selected to test the hypothesis that the configurations in which females work in place them at risk of injury. To really look at postural differences, or risk factors for males specifically, researchers should examine configurations that are utilized frequently by both genders. Postural differences between males and females were investigated as an alternative hypothesis that it is individual posture not choice of configuration that is the source of increased discomfort in females. Because it was discovered that there are some postural differences, none of the hypotheses are really ruled out. Consequently, these ideas need to be investigated further.

There were a number of limitations regarding the methodology used in this study. In general, data collected through self-report is limited due to memory and honesty. This limitation was clear throughout this study; in the demographic survey, some participants reported that they do not experience and pain or discomfort during laptop use, but then when asked to identify in which specific body parts they experience discomfort, they would still identify certain body regions. This implies that a general yes/no question (i.e. do you experience discomfort with laptop use?) may not be very accurate. In addition, participants who reported in this questionnaire that they never experience discomfort during laptop use all reported some level of discomfort following the typing tasks. It is possible that the questions were worded too generally, leaving them open to interpretation. This calls into question the findings from Part I of this experiment, and previous research that has or has not found gender differences in the prevalence of discomfort.

Another limitation with the methodology is that the postural measurements were taken using photographs. The angles may not have been measured accurately due to issues with 
parallax distortions if the camera was not entirely straight on the participant. Measuring the elbow with a goniometer would have been helpful in improving the accuracy of the findings. If the elbow was flexed but also abducted, it may have altered the perception of the angle measured from a photograph taken from the side. Similarly, shoulder abduction and adduction were measured from a photograph taken straight in front of the participant. If the participant was not sitting perfectly straight on the mattress, the angle would not have been presented accurately in the photograph. Another issue related to the photographs is that some participants did not sit with their back completely straight in the calibration picture, so when they looked straight ahead their neck might have been in slight extension. It would have been useful to calibrate the neck when the participants were standing, as it is easier to ensure they are looking straight ahead with a relaxed neck. This was added to the protocol partway through the experiment, and calibration photographs were retaken for participants who were obviously not in a neutral neck position.

It is unclear how generalizable the findings from this study are. For example, one participant mentioned that she works on her bed frequently, but whenever she feels discomfort she changes her position. Consequently, asking participants to sit in one position for a predetermined amount of time may not be realistic. Many participants reported that their legs and/or feet fell asleep during the experiment. This problem was most frequent in the positions where participants were required to sit with their legs crossed, and implies that participants would probably not sit in these positions for very long. To better understand the ways in which students interact with their laptop computers and their patterns of laptop use, it would be interesting to conduct a study that looks at self induced postural variation (i.e. moving from lying down, to sitting with legs crossed, to straightening the legs, etc.) throughout a task. In addition, the findings from this study likely do not generalize to populations other than college students. It 
can be expected that adults and professionals may have different patterns of laptop use, both in terms of context and frequency of use.

It would have been useful to ask participants whether or not they were proficient typists and had normal corrected vision. These factors should have been controlled for, as they may have caused participants to hunch/lean forward more if they are not/do not. Typing speed was measured and interpreted as a measure of typing proficiency, and participants were told to adjust screen brightness and font size to suit their needs, however this could have been controlled for in a more robust manner. Also, the method of measuring discomfort could be improved. It would have been useful to measure discomfort before and after each task in order to determine exactly how much discomfort was attributable to the task. There is a need to establish a more accurate baseline in order to pinpoint the exact amount of discomfort due to working in each position. Doing a comparison to our baseline (the discomfort data collected before participants started the experiment) showed significant differences between males and females, as was expected. However, this analysis was not included because it is not a fair assumption that individuals returned to this same baseline in between conditions. A future study that gave a discomfort survey before and after each condition would allow us to use this data in order to quantify the exact increase or decrease in discomfort due to working in each specific configuration.

Participants were instructed to take a break and get up and stretch for as long as they wanted in between each condition, but to at least wait until their discomfort subsided. Most participants took short breaks; all were under 5 minutes long. It is unknown whether this was due to impatience or because discomfort actually reduced to a base level. In the future requiring a longer break of a set time would be beneficial. 


\subsubsection{Implications and Recommendations}

Laptop use appears to exacerbate the non-neutral postures that are often seen during desktop computer use. This study has demonstrated that laptop use in non-desk settings and in non-traditional positions may be even more problematic. There are many ergonomic products on the market today that exist as an attempt to alleviate the discomfort and risks associated with laptop use that could be useful for individuals using a laptop while on a bed. One of the main postural concerns associated with laptop use on a bed that was identified in this study is the position of the neck. All positions tested were characterized be a large degree of neck flexion or extension, both of which are related to the low position of the laptop relative to the eyes. Consequently, a tool or method to raise the laptop would be beneficial in reducing flexion and consequently strain on the neck. Asundi et al. (2010) compared laptop use on the lap to use with a lapdesk, finding postural advantages of lapdesk use. A lapdesk simply rests on the lap of the user, raising the vertical position of the computer. The lapdesk reduced neck flexion, downward head tilt, and wrist extension, bringing the position of the user to a similar position as is found when the laptop is positioned on a desk. In order to reduce wrist extension, the lapdesk should have a negative slope, which will encourage neutral wrist position (Hedge et al., 1999). However, placement of the lapdesk too high may result in elevation of the shoulders, so it is important to consider the tradeoffs. One of the participants in the current experiment found a way to slope the keyboard negatively during the CB task. He propped the front edge of the laptop up on his feet/shins, which allowed the keyboard to slope towards the back. This indicates that at least some individuals already intuitively realize that this position helps reduce strain and discomfort in the wrists. 
Provision of a method that would allow laptop users to separate the screen from the keyboard would be an ideal solution, such as through the use of a laptop riser and external keyboard and mouse. Berkhout et al. (2004) found that use of a laptop with a laptop station and external keyboard reduced neck flexion and subjective reports of neck strain. Jacobs et al. (2011) also found a decrease in self-reported musculoskeletal pain in the fingers, forearms, and shoulders when a notebook riser was used, however, the benefits of the stand were minimal once hours of computer use was controlled for. Sommerich et al. (2002) also found that neck position and discomfort was improved through the use of an external mouse and keyboard. Price and Dowell (1998) found that users reported less discomfort in the right wrist when an external mouse was used, as opposed to the laptop's internal trackpad. While it is likely not feasible when using a laptop as a portable device, the provision of a set up that included an external keyboard would be highly beneficial to improving posture when using a laptop on a bed. If a laptop is being used on a bed, it is likely being done in the users home. Consequently, providing a desk or table that can rest on the bed, with different levels for the screen and keyboard, could be beneficial. In addition, one of the main things missing when using a laptop on a bed is lumbar support. Adding external lumbar support is generally not recommended during computer use at a desk, however when sitting on a bed the provision of this would be highly beneficial. It was observed throughout the study that participants had a tendency to hunch over and exhibit pronounced kyphotic spinal curvature, which places a large amount of stress on the spine. The natural curve of the lumbar portion of the spine is lordotic, and this can be encouraged through the use of a back support. This could easily be implemented with a shaped pillow or other portable backrest. 
Another issue identified in this study was wrist extension. Often users do not properly utilize the built in palm rest on laptops, and may anchor their wrists down at the wrist crease and extend the wrists instead. This is a highly risky posture, and can result in compression of the median nerve, especially due to the hard surface that laptop computers are often made of. Provision of a negatively sloped keyboard and built in palm rest that encouraged neutral wrist position would be a great improvement. Designing a laptop or accessory that has a section on the bottom that can rise up to afford a negative slope to the keyboard would encourage proper use of the palm rest, and greatly reduce wrist extension and anchoring. Despite this recommendation, Moffet et al. (2002) has previously found that the presence of a built-in palm rest on a laptop does not significantly affect wrist posture. This study investigated laptop use at a desk, and the authors noted that a large proportion of subjects rested their wrist/forearm on the desk or edge of the laptop in the condition in which there was no built-in palm rest. This indicates that users were using some sort of postural support in both conditions, regardless of whether it was built in to the laptop design or not. Consequently, while this study showed no direct benefit of a built-in palm rest, the experimenter's subjective observations indicate that it may be a beneficial design component, as users look to compensate to support their wrist otherwise. One of the issues is that users often use palm rests incorrectly, thinking they are meant to be used as a rest for the wrist. As mentioned, this leads to anchoring of the wrist on a raised surface, which degrades posture. It is apparent that there is a need for education along with the implementation of these products.

Jacobs et al. (2011) found that while use of an ergonomic chair and a laptop stand both contributed to a decrease in subjective report of musculoskeletal pain, it was the combination of these tools with ergonomic training that resulted in the greatest impact. This indicates that user knowledge about ergonomics is key in reducing the negative effects of computer use on the 
body. Individuals may experience pain, but may not know how to alleviate it through use of postural changes or changes in or addition of furniture or ergonomic products. Provision of an ergonomic instrument alone is not sufficient; it must be coupled with instruction. For example, Jacobs et al. (2006) reported a significant correlation between self-reported musculoskeletal pain and adherence to ergonomic suggestions in a group of middle school students. After listening to educational instruction about proper computer use, a decrease in symptoms was found to be related to the placement of feet flat on the floor, appropriate seat adjustment, contouring of the backrest to the students back, an increase in number of breaks taken, and a reduction in glare on the monitor.

Specifically regarding laptop use, educational measures to promote healthy working postures and break taking are critical. Systems can be implemented on computers that remind users to take breaks, which may be a much easier intervention than trying to ensure that users all maintain acceptable postures all the time. The findings of this study indicate that despite the highly deviated and risky postures seen in the configurations tested, working in these positions for 25 minutes did not induce very much discomfort. In the case that someone is unwilling or unable to purchase tools or furniture that promotes healthy posture, simply remembering to get up and take a break can help reduce the risk of injury. Integrating a reminder system directly onto the laptop would require minimal effort on the part of the user. Similarly, a tool installed on the laptop or even on a Smartphone to encourage healthy posture could be helpful. Persuasive computing systems have been successfully tested and implemented for a number of purposes, such as the encouragement of a healthy and active lifestyle, so it is conceivable that a system could be developed in order to promote proper posture and other healthy working habits as well (Consolvo et al., 2009). 
It is important to consider the outcomes associated with working in these positions other than purely physical and health related. For example, individuals working on a laptop while sitting in bed may not be as productive as those working in a designated work area consisting of a desk and chair. Because sitting in bed is more casual than other more traditional workspaces are, users may be more likely to become distracted or suffer from interruptions. During the experiment, one of the participants appeared to have trouble staying awake, which may be an issue when working in this environment. Another outcome from working on a bed could be related to mood. There are a number of different ways this could manifest; participants may be more relaxed and comfortable, which could affect the content of their online interactions and the structure of the language used. On the other hand, if working in this way for too long and in discomfort, it could have a negative impact on participation in online communities or distributed projects, or on other interpersonal interactions. Individuals may choose to work on a bed for certain tasks and not others, depending on the type of work and whether other individuals are involved. Using a laptop computer frequently while in bed may have adverse effects on sleep patterns, if an individual starts to associate the area with work rather than rest. These dynamics can influence the frequency and duration with which students or other populations work in this setting, and would be a valuable avenue for further investigation.

\subsection{Conclusions}

This study did not support our supposition that females experience greater musculoskeletal discomfort associated with laptop use than males. Although females selfreported a greater prevalence of discomfort in the neck and shoulders, this was not found to hold true during the experiment. In order to try to understand this discrepancy, it would be valuable to test participants using a laptop for longer periods of time, and also consider duration and patterns 
of actual laptop use. The hypothesis that females use laptop computers more frequently in configurations that are associated with deviated postures was supported by this study. The three configurations tested were those with which females reported working in more frequently than males. All three configurations were found to produce highly deviated postures in both males and females. These deviated postures place users at a risk of injury, especially if these positions are sustained for long periods of time. Because females report working in these configurations more frequently than males, it follows that they are placed at a greater risk of injury. However, these positions were not associated with high levels of discomfort during a 25-minute task, which suggests that they may be acceptable working positions for short periods of time. Finally, the hypothesis that females adopt more risky (deviated) postures than males was not supported. Although males and females did exhibit different patterns of posture over time, it was not the case that females were consistently in a more degraded posture than males were. Rather, males often spent a greater proportion of time in more deviated positions than females. Consequently, it is most likely that any increased prevalence of discomfort in females compared to males is due to their choice of working configuration, rather than inherent differences in posture. Another important factor that may contribute to this is the finding that females tend to report spending more hours per week using a computer than males. Future work to parse out the contribution of each factor, both in males and females, would be valuable in order to understand the impact that working configuration has on musculoskeletal discomfort and injury. 


\section{REFERENCES}

Allie, P., Purvis, C., \& Kokot, D. (2005). Computer display viewing angles: is it time to shed a few degrees? Proceedings of the Human Factors and Ergonomics Society Annual Meeting, 49(8), 798-802.

Amell, T. K. \& Kumar, S. (1999). Cumulative trauma disorders and keyboard use. International Journal of Industrial Ergonomics, 25, 69-78.

Asundi, K., Odell, D., Luce, A., \& Dennerlein, J. T. (2012). Changes in posture through the use of simple inclines with notebook computers placed on a standard desk. Applied Ergonomics, 43, 400-407.

Asundi, K., Odell, D., Luce, A., \& Dennerlein, J. T. (2010). Notebook computer use on a desk, lap and lap support: effects on posture, performance and comfort. Ergonomics, 53(1), 7482.

Bach, J. M., Honan, M., \& Rempel, D. M. (1997). Carpal tunnel pressure while typing with the wrist at different postures, in Proceedings of the Marconi Research Conference (San Francisco: University of California, San Francisco and Center for Ergonomics), Paper 17, 4 pages.

Bergqvist, U., Wolgast, E., Nilsson, B., \& Voss, M. (1995). Musculoskeletal disorders among visual display terminal workers: individual, ergonomic, and work organizational factors. Ergonomics, 38(4), 763-776.

Bergqvist, U. \& Knave, B. (1994). Eye discomfort and work with visual display terminals. Scandinavian Journal of Work, Environment and Health, 20. 27-33. 
Bernard, B., Sauter, S., Fine, L., Peterson, M., \& Hales, T. (1994). Job task and psychosocial risk factors for work-related musculoskeletal disorders among newspaper employees. Scandinavian Journal of Work, Environment and Health, 20, 417-426.

Blehm, C., Vishnu, S., Khattak, A., Mitra, S., \& Yee, R. W. (2005). Computer vision syndrome: a review. Survey of ophthalmology, 50(3), 253-262.

Bureau of Labor Statistics. (2012a, November 8). Nonfatal Occupational Injuries and Illnesses Requiring Days Away From Work. Retrieved from: http://www.bls.gov/news.release/osh2.toc.htm.

Bureau of Labor Statistics. (2012b, June 22). American Time Use Survey - 2011 Results. USDL12-1246. Retrieved from: http://www.bls.gov/news.release/archives/atus_06222012.pdf.

Burgess-Limerick, R., Mon-Williams, M., Coppard, V., 2000. Visual Display Height, Human Factors 2(1), 140-150.

Burgess-Limerick, R., Plooy, A., \& Ankrum, D. R. (1998). The effect of imposed and selfselected computer monitor height on posture and gaze angle. Clinical Biomechanics, 13, 584-592.

Carter, J. B. \& Banister, E. W. (1994). Musculoskeletal problems in VDT work: a review. Ergonomics, 37(10), 1623-1648.

Chaffin, D. B. (1973). Localized muscle fatigue - definition and measurement. Journal of Occupational Medicine, 15(4), 346-354.

Chang, C. -H., Amick, B. C., Menendez, C. C., Robertson, M., del Pino, R. J., \& Dennerlein, J. T. (2008). Where and how college students use their laptop computers. Proceedings of the Human Factors and Ergonomics Society Annual Meeting, 52, 1010-1014. 
Consolvo, S., McDonald, D. W., \& Landay, J. A. (2009, April). Theory-driven design strategies for technologies that support behavior change in everyday life. In Proceedings of the SIGCHI Conference on Human Factors in Computing Systems (pp. 405-414). ACM.

Dunk, N. M. \& Callaghan, J. P. (2005). Gender-based differences in postural responses to seated exposures. Clinical Biomechanics, 20, 1101-1110.

Erdinc, O. (2011). Upper extremity musculoskeletal discomfort among occupational notebook personal computer users: work interference, associations with risk factors and the use of notebook computer stand and docking station. Work, 39, 455-463.

Gerr, F., Monteilh, C. P., \& Marcus, M. (2006). Keyboard use and musculoskeletal outcomes among computer users. Journal of Occupational Rehabilitation, 16, 265-277.

Gelberman, R. H., Szabo, R. M., \& Mortenson, W. W. (1984). Carpal tunnel pressures and wrist position in patients with Colle's fractures, Journal of Trauma, 24, 747-749.

Gold, J. E., Driban, J. B., Yingling, V. R., \& Komaroff, E. (2012). Characterization of posture and comfort in laptop users in non-desk settings. Applied Ergonomics, 43, $392-399$.

Grandjean, E. (1987). Ergonomics in Computerized Offices, Taylor and Francis, London Hamilton, M. T., Hamilton, D. G., \& Zderic, T. W. (2007). Role of low energy expenditure and sitting in obesity, metabolic syndrome, type 2 diabetes, and cardiovascular disease. Diabetes, 56(11), 2655-2667.

Hedge, A., Morimoto, S., \& Mccrobie, D. (1999). Effects of keyboard tray geometry on upper body posture and comfort. Ergonomics, 42(10), 1333-1349.

Heyer, N., Checkoway, H., Daniell, W., Horstman, S., \& Camp, J. (1990). Self reported musculoskeletal symptoms among office video display terminal operators. In: Sakurai H, ed. Occupational Epidemiology. Amsterdam: Elsevier Science Publishers BV: 255-258. 
Horrigan, J. (2009). Wireless Internet Use, Pew Internet and American Life Project. Pew Research Center, Washington, DC.

Hunting, W. Laubli, T. H., \& Grandjean, E. (1981). Postural and visual loads at VDT workplaces, I. Constrained postures. Ergonomics, 24, 917-931.

Hupert, N., Amick, B. C., Fossel, A. H., Coley, C. M., Robertson, M. M., \& Katz, J. N. (2004). Upper extremity musculoskeletal symptoms and functional impairment associated with computer use among college students. Work, 23(2), 85-93.

Jenkins, M., Menendez, C. C., Amick, B. C., Tullar, J., Hupert, N., Robertson, M. M., \& Katz, J. N. (2007). Undergraduate college students' upper extremity symptoms and functional limitations related to computer use: a replication study. Work, 28(3), 231-238.

Jacobs, K., Foley, G., Punnett, L., Hall, V., Gore, R., Brownson, E., ..., Ing, A. (2011). University students' notebook computer use: lessons learned using e-diaries to report musculoskeletal discomfort. Ergonomics, 54(2), 206-219.

Jacobs, K., Hudak, S., \& McGiffert, J. (2006). Musculoskeletal complaints by Middle school students with computer use. Congress proceedings 2006 IEA Conference, The Netherlands.

Kotani, K., Barrero, L. H., Lee, D. L., \& Dennerlein, J. T. (2007). Effect of horizontal position of the computer keyboard on upper extremity posture and muscular load during computer work. Ergonomics, 50(9), 1419-1432.

Kroemer, K.H.E. (1989). Cumulative trauma disorders: Their recognition and ergonomics measures to avoid them. Applied Ergonomics, 20(4), 274-280.

Liao, M. H., \& Drury, C. G. (2000). Posture, discomfort and performance in a VDT task. Ergonomics, 43(3), 345-359. 
Malińska, M., Bugajska, J., Kamińska, J., \& Jędryka-Góral, A. (2012). Analysis of conditions and organization of work of notebook computer users. International Journal of Occupational Safety and Ergonomics (JOSE), 18(3), 443-449.

Moffet, H., Hagberg, M., Hansson-Risberg, E., \& Karlqvist, L. (2002). Influence of laptop computer design and working position on physical exposure variables. Clinical Biomechanics, 17, 368-375.

Noack-Cooper, K. L., Sommerich, C. M., \& Mirka, G. A. (2009). College students and computers: assessment of usage patterns and musculoskeletal discomfort. Work: A Journal of Prevention, Assessment and Rehabilitation, 32(3), 285-298.

Price, J. M. \& Dowell, W .R. (1998). Laptop configurations in offices: effects of posture and discomfort. Proceedings of the Human Factors and Ergonomics Society Annual Meeting, 42, 629-633.

Punnett, L. \& Bergqvist, U. (1997). Visual display unit work and upper extremity musculoskeletal disorders: a review of epidemiological findings. National Institute for Working Life, Solna, Sweden.

Rajagopal, V., Rosli, R. M., Rintai, P., Rustim, N., Benadus, R., \& Usai, W. (2012). The prevalence of computer-related musculoskeletal pain among college students: a crosssectional study. American Medical Journal, 3(1), 33-36.

Rempel, D., Bach, J. M., Gordon, L., \& So, Y. (1998). Effects of forearm pronation/supination on carpal tunnel pressure. The Journal of hand surgery, 23(1), 38-42.

Reuters: Reaney, P. (2012, Jan. 24). About one in five workers worldwide telecommute: poll. Retrieved from: http://www.reuters.com/article/2012/01/24/us-telecommutingidUSTRE80N1IL20120124. 
Saito, S., Miyao, M., Kondo, T., Sakakibara, H., \& Toyoshima, H. (1997). Ergonomic evaluation of working posture of VDT operation using personal computer with flat panel display. Industrial health, 35(2), 264.

Scalet, E. (1987). Strain and injury. VDT Health and Safety: Issues and Solutions (Ergosyst Associates).

Schlossberg, E. B., Morrow, S., Llosa, A. E., Mamary, E., Dietrich, P., \& Rempel, D. (2004). Upper extremity pain and computer use among engineering graduate students. American Journal of Industrial Medicine, 46, 297-303.

Seghers, J., Jochem, A., \& Spaepen, A. (2003). Posture, muscle activity and muscle fatigue in prolonged VDT work at different screen height settings. Ergonomics, 46(7), 714-730.

Silverstein, M.A., Silverstein, B.A., Franklin, G.M., 1996. Evidence for work-related musculoskeletal disorders: A scientific counterargument. Journal of Occupational and Environmental Medicine, 38(5), 477-484.

Silverstein, B.A., Fine, L.J., Armstrong, T.J., 1986. Hand wrist cumulative trauma disorders in industry. British Journal of Industrial Medicine, 43, 779-784.

Smith, S., Salaway, G., \& Borreson Caruso, J. (2009). The ECAR study of undergraduate students and information technology, 2009. Research Study, Vol. 6. Boulder, CO: EDUCAUSE Center for Applied Research. Retrieved from: http://www.educause.edu/ecar.

Smith, M. J., Conway, F. T., \& Karsh, B. (1999). Occupations stress in human computer interaction. Industrial Health, 37, 157-173.

Sommerich, C. M. \& Korkmaz, S. V. (2008). Survey response comparisons between student and teacher participants in a mobile instructional technology program in a high school setting. Proceedings of the Human Factors and Ergonomics Society Annual Meeting, 52, 634-637. 
Sommerich, C. M., Starr, H., Smith, C. A., \& Shivers, C. (2002). Effects of notebook computer configuration and task on user biomechanics, productivity, and comfort. International Journal of Industrial Ergonomics, 30, 7-31.

Sommerich, C. M., Joines, S. M. B., \& Psihogios, J. P. (2001). Effect of Computer Monitor Viewing Angle and Related Factors on Strain, Performance, and Preference Outcomes. Human Factors, 43, 39-55.

Straker, L., Skoss, R., Burnett, A., \& Burgess-Limerick, R. (2009a). Effect of visual display height on modeled upper and lower cervical gravitational moment, muscle capacity and relative strain. Ergonomics, 52(2), 204-221.

Straker, L. M., O'Sullivan, P. B., Smith, A. J., \& Perry, M. C. (2009b). Relationships between prolonged neck/shoulder pain and sitting spinal posture in male and female adolescents. Manual therapy, 14(3), 321-329.

Straker, L., Jones, K. J., \& Miller, J. (1997). A comparison of the postures assumed when using laptop computers and desktop computers. Applied Ergonomics, 28(4), 263-268.

Szeto, G. P. \& Lee, R. (2002). An ergonomic evaluation comparing desktop, notebook, and subnotebook computers. Archives of Physical Medicine and Rehabilitation, 83, 527-532.

Thomson, W. D. (1998). Eye problems and visual display terminals-the facts and the fallacies. Ophthalmic and physiological optics, 18(2), 111-119.

Turhan, N., Akat, C., Akyuz, M., \& Cakci, A. (2008). Ergonomic risk factors for cumulative trauma disorders in VDU operators. International Journal of Occupational Safety and Ergonomics, 14(4), 417-422. 
Turville, K. L., Psihogios, J. P., Ulmer, T. R., \& Mirka, G. A. (1998). The effects of video display terminal height on the operator: a comparison of the 158 and 408 recommendations. Applied Ergonomics, 29, 239-246.

United States Census Bureau. (2013). Computer and Internet Use in the United States: population characteristics. Retrieved from: http://www.census.gov/prod/2013pubs/p20569.pdf.

Villanueva, M. B. G., Jonai, H., \& Saito, S. (1998). Ergonomic aspects of portable personal computers with flat panel displays (PC-FPDs): evaluation of posture, muscle activities, discomfort and performance. Industrial Health, 36, 282-289.

Villanueva, M. B. G., Jonai, H., Sotoyama, M., Hisanaga, N., Takeuchi, Y., \& Saito, S. (1997). Sitting Posture and Neck and Shoulder Muscle Activities at Different Screen Height of the Visual Display Terminal. Industrial Health, 35, 330-336.

Villanueva, M. B. G., Sotoyama, M., Jonai, H., Takeuchi, Y., \& Saito, S. (1996). Adjustments of posture and viewing parameters of the eye to changes in the screen height of the visual display terminal. Ergonomics, 39, 933-945.

Waersted, M., Hanvold, T. N., \& Veiersted, K. B. (2010). Computer work and musculoskeletal disorders of the neck and upper extremity: a systematic review. BMC Musculoskeletal Disorders, 11(1), 79-94.

Werth, A. J. \& Babski-Reeves, K. (2012). Assessing posture while typing on portable computing devices in traditional work environments and at home. Proceedings of the Human Factors and Ergonomics Society Annual Meeting, 56, 1258-1262.

Yaginumya, Y., Yamada, H., \& Nagai, H. (1990). Study of the relationship between lacrimation and blink in VDT work. Ergonomics, 33. 799-809. 


\section{APPENDIX A}

\section{Laptop Use Configuration Survey}

You have been invited to participate in a pilot study investigating the configurations in which students commonly use their laptop computers. The goal of this study is to understand the ways in which students frequently use their laptops, and how often individuals work in these ways. The following survey asks questions about how you use your laptop computer; please answer the questions to the best of your ability. It will take approximately 20 minutes to complete the survey.

In order to be eligible to participate in this study, you must be 18 years of age or older and the owner of a laptop computer. Participation in this study is voluntary, and you may withdraw at any time. We anticipate that your participation in this survey presents no greater risk than everyday use of the Internet. Your responses will by kept confidential and anonymous. By completing the survey you are agreeing to participate in this research.

If you have any questions about this study, please contact Katherine Bubric (kab435@cornell.edu) 
Q2 What is your age?

Q3 What is your gender?

O Male

O Female

Q4 Are you $a(n)$

O Undergraduate student

O Graduate student

Other (please specify)

Q5 What is your major?

Q6 Rate your overall level of physical activity on a scale from 1--5

O 1 (very low)

m 2

m 3

m 4

5 (very high)

Q7 Do you own a laptop computer?

O Yes

O No

Q8 Do you experience any pain or discomfort associated with laptop computer use?

O Yes

O No

Q9 In which body regions do you experience pain or discomfort associated with laptop computer use? (check all that apply)

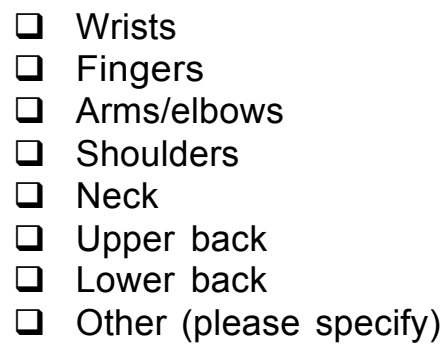


The following pages list some of the possible configurations in which you might use your laptop. Please indicate the frequency with which you use your laptop in each position by checking the appropriate response. Do not count time spent using an external mouse and/or keyboard, or extended periods of time spent viewing the screen without interaction with the keyboard and/or mouse (i.e. watching movies). We are interested in examining the positions in which you spend time actively engaging with the laptop.

If you use your laptop in any positions that are not listed, please describe them in the provided space at the end of the questionnaire, and indicate how often you use it in these ways.

Please take your time in responding and answer to the best of your memory. 
Q11 How often do you use your laptop...

Sitting on a sofa with your feet on the floor (knees at 90 degrees), laptop resting on lap

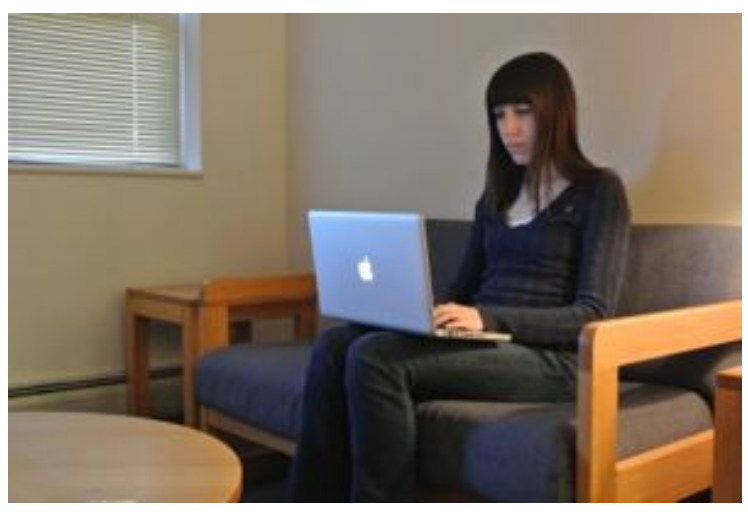

O Never

Occasionally ( $<1$ hour per week)

O 1-5 hours per week

O 5-10 hours per week

O 10-15 hours per week

O > 15 hours per week

Q12 How often do you use a laptop...

Sitting on a sofa with your legs straight out, feet supported on a coffee table or ottoman, laptop resting on your lap

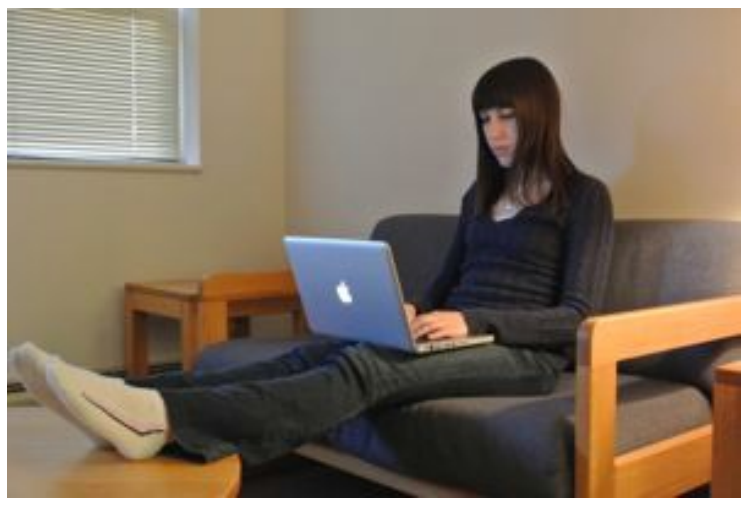
O Never
Occasionally (< 1 hour per week)
O 1-5 hours per week
O 5-10 hours per week
O 10-15 hours per week
O > 15 hours per week 
Q13 How often do you use your laptop...

Sitting on a sofa with your legs bent, feet resting on a coffee table, laptop resting on your lap

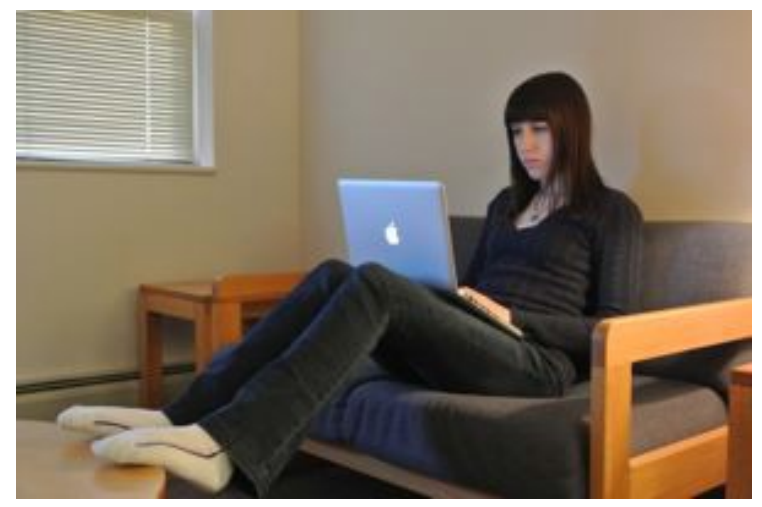

O Never

Occasionally ( $<1$ hour per week)

O 1-5 hours per week

O 5-10 hours per week

O 10-15 hours per week

O > 15 hours per week

Q14 How often do you use your laptop...

Sitting on a sofa with your feet on the floor (knees at 90 degrees), bending over to use a laptop that is resting on a coffee table or ottoman in front of you

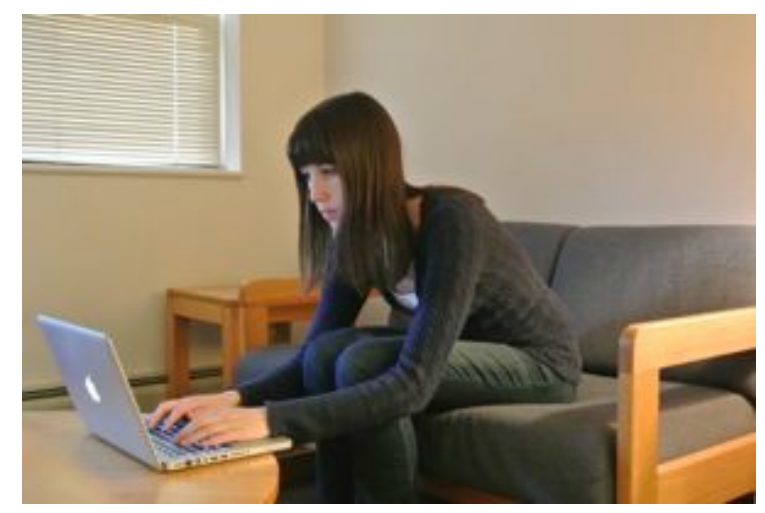

O Never

Occasionally ( $<1$ hour per week)

O 1-5 hours per week

O 5-10 hours per week

O 10-15 hours per week

O > 15 hours per week 
Q15 How often do you use your laptop...

Sitting on the floor, leaning against a wall or piece of furniture, legs straight out, laptop resting on your lap

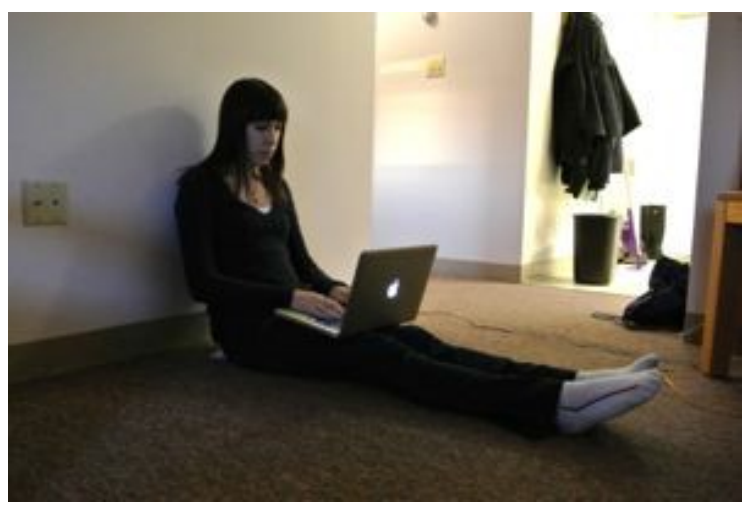

O Never

O Occasionally ( $<1$ hour per week)

O 1-5 hours per week

O 5-10 hours per week

O 10-15 hours per week

O > 15 hours per week

Q16 How often do you use your laptop...

Sitting on the floor, leaning against a wall or piece of furniture, knees bent, laptop resting on your lap

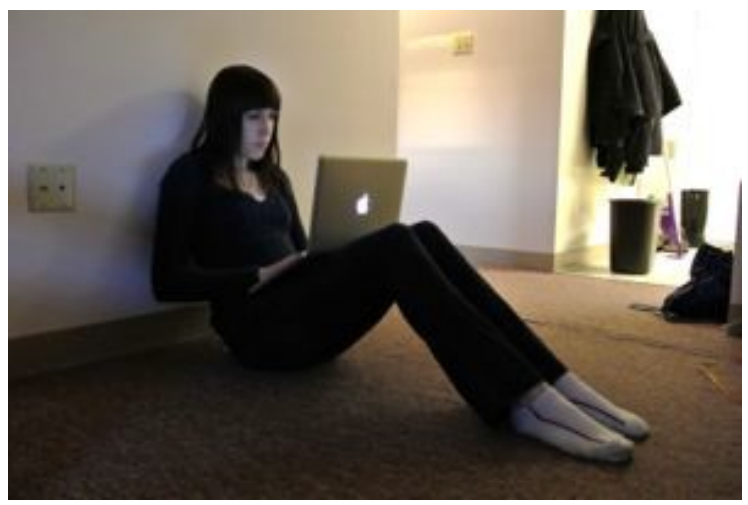

O Never

Occasionally (< 1 hour per week)

O 1-5 hours per week

O 5-10 hours per week

O 10-15 hours per week

O > 15 hours per week 
Q17 How often do you use your laptop...

Sitting on the floor, not leaning against anything, legs straight out, laptop resting on your lap

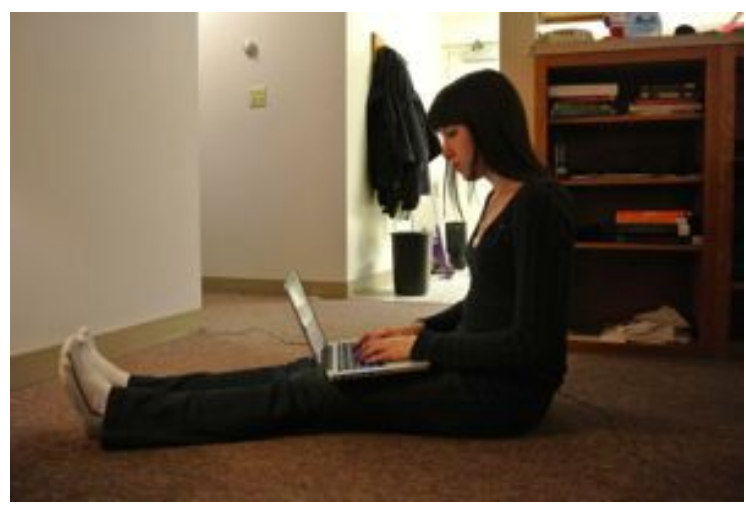

O Never

Occasionally (< 1 hour per week)

O 1-5 hours per week

O 5-10 hours per week

O 10-15 hours per week

O $>15$ hours per week

Q18 How often do you use your laptop...

Sitting on the floor, not leaning against anything, knees bent, laptop resting on your lap

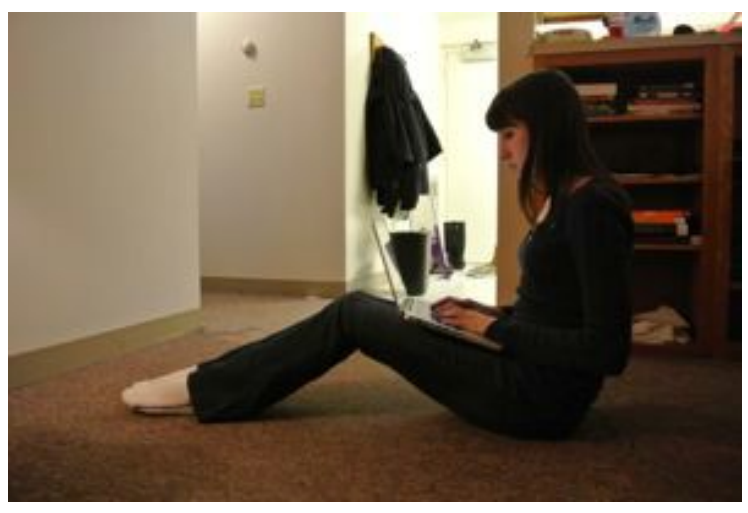

O Never

Occasionally ( $<1$ hour per week)

O 1-5 hours per week

O 5-10 hours per week

O 10-15 hours per week

O > 15 hours per week 
Q19 How often do you use your laptop...

Sitting on the floor with your legs crossed, laptop resting on your lap

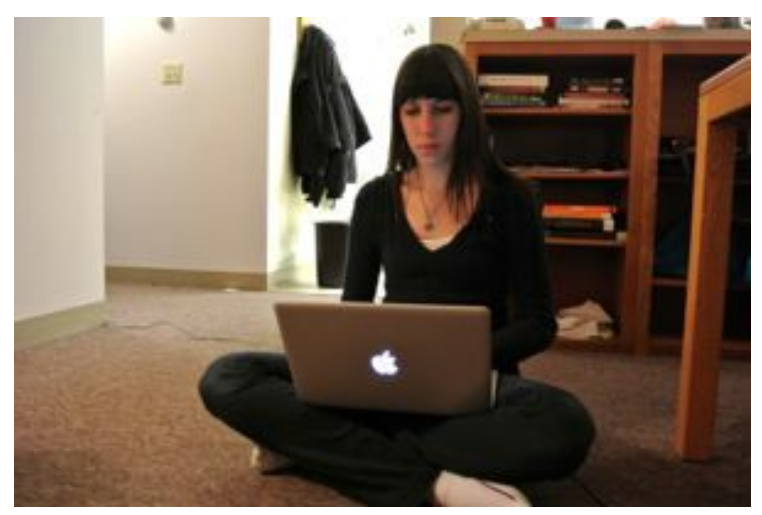

O Never

O Occasionally ( $<1$ hour per week)

O 1-5 hours per week

O 5-10 hours per week

O 10-15 hours per week

O > 15 hours per week

Q20 How often do you use your laptop...

Sitting on the floor, leaning against a wall or piece of furniture, legs straight out, laptop resting on the floor to the side of you

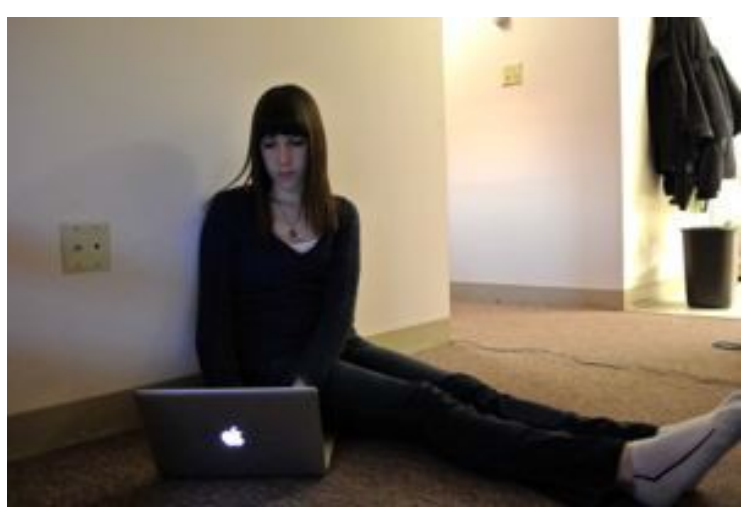

O Never

Occasionally ( $<1$ hour per week)

O 1-5 hours per week

O 5-10 hours per week

O 10-15 hours per week

O > 15 hours per week 
Q21 How often do you use your laptop...

Sitting on the floor, leaning against a wall or piece of furniture, knees bent, laptop resting on the floor to the side of you

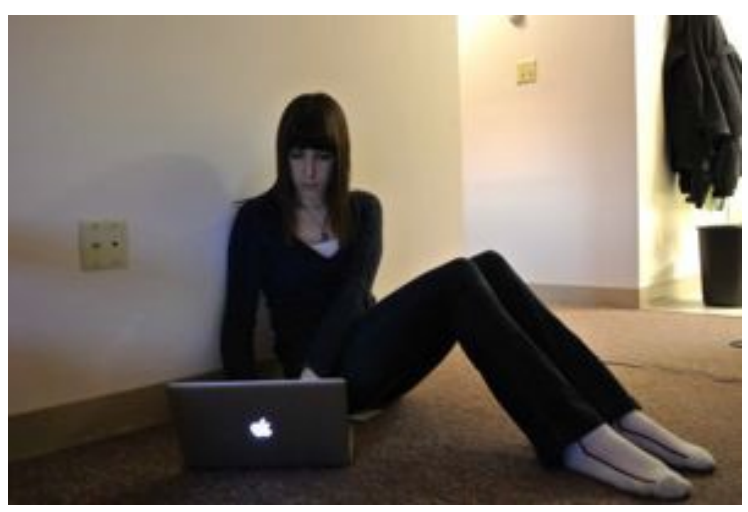

O Never

Occasionally ( $<1$ hour per week)

O 1-5 hours per week

O 5-10 hours per week

O 10-15 hours per week

O > 15 hours per week

Q22 How often do you use your laptop...

Sitting on the floor, not leaning against anything, legs straight out, laptop resting on the floor to the side of you

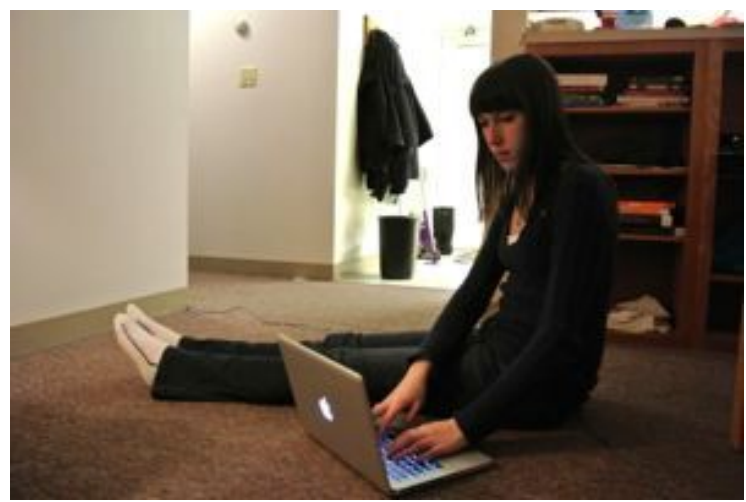

O Never

O Occasionally ( $<1$ hour per week)

O 1-5 hours per week

O 5-10 hours per week

O 10-15 hours per week

O > 15 hours per week 


\section{Q23 How often do you use your laptop}

Sitting on the floor with your legs crossed, laptop resting on the floor in front of you

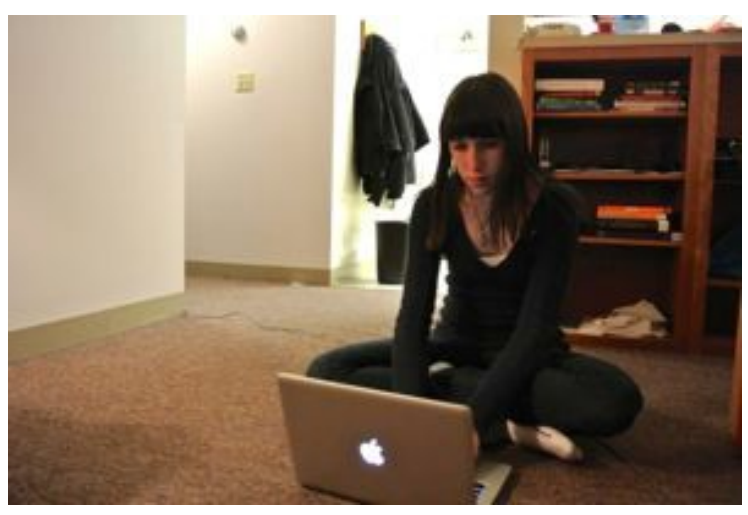

O Never

Occasionally ( $<1$ hour per week)

O 1-5 hours per week

O 5-10 hours per week

O 10-15 hours per week

O > 15 hours per week

Q24 How often do you use your laptop...

Sitting on the floor with your legs spread out in front of you, laptop resting on the floor in front of you

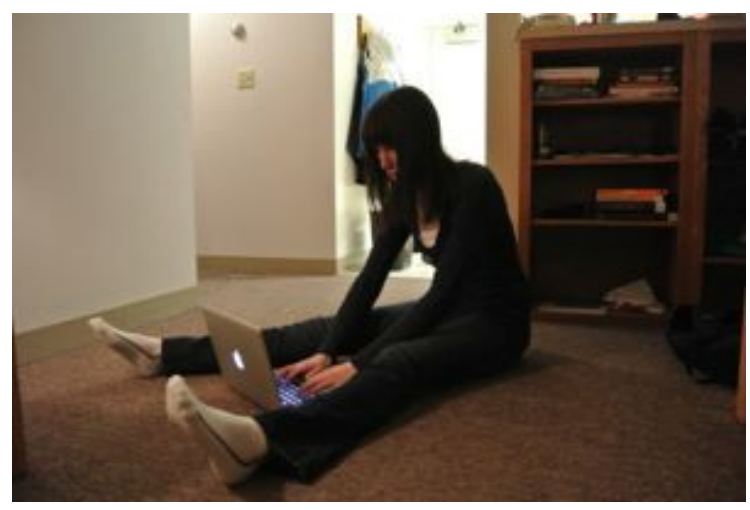
O Never
O Occasionally ( $<1$ hour per week)
O 1-5 hours per week
O 5-10 hours per week
O 10-15 hours per week
O > 15 hours per week 
Q25 How often do you use your laptop...

Lying on your stomach on the floor, laptop resting on the floor in front of you

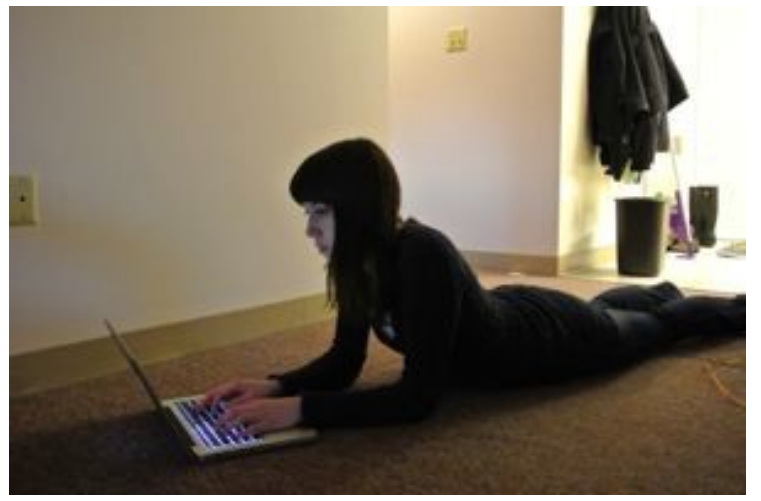

O Never

Occasionally ( $<1$ hour per week)

O 1-5 hours per week

O 5-10 hours per week

O 10-15 hours per week

O > 15 hours per week

Q26 How often do you use your laptop...

Sitting on a bed, leaning back against a wall or headboard, legs straight out, laptop resting on your lap

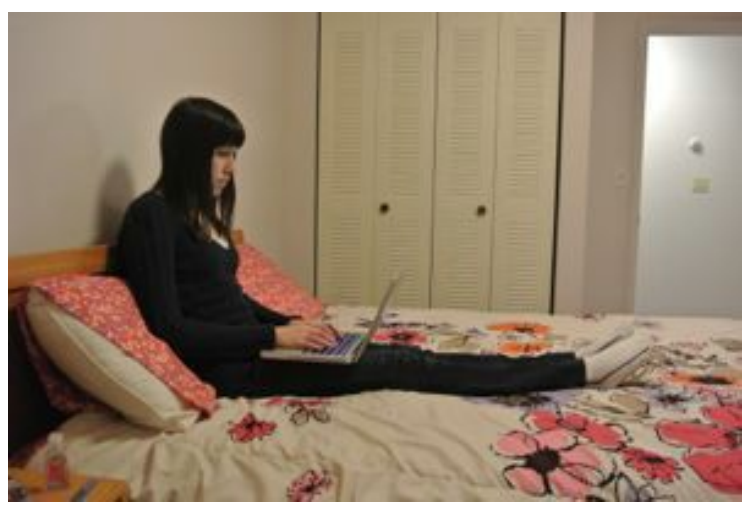

O Never

Occasionally ( $<1$ hour per week)

O 1-5 hours per week

O 5-10 hours per week

O 10-15 hours per week

O > 15 hours per week 
Q27 How often do you use your laptop...

Sitting on a bed, leaning back against a wall or headboard, legs straight out, laptop resting on the bed beside you

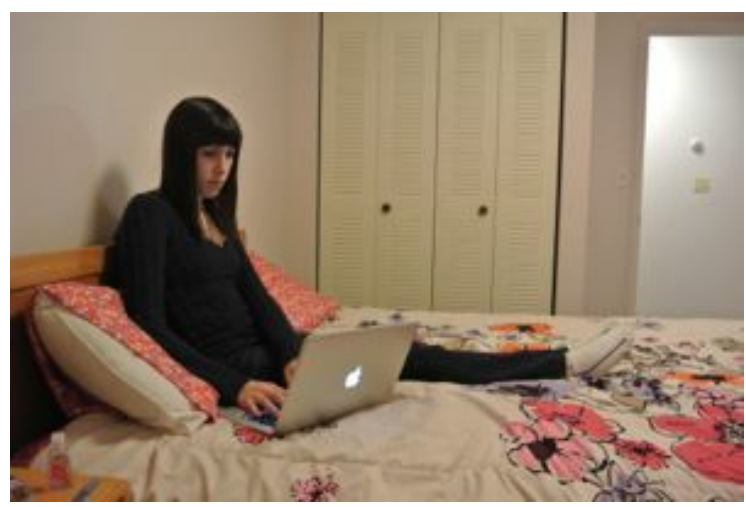

O Never

O Occasionally ( $<1$ hour per week)

O 1-5 hours per week

O 5-10 hours per week

O 10-15 hours per week

O > 15 hours per week

Q28 How often do you use your laptop...

Sitting on a bed, leaning back against a wall or headboard, knees bent, laptop resting on your lap

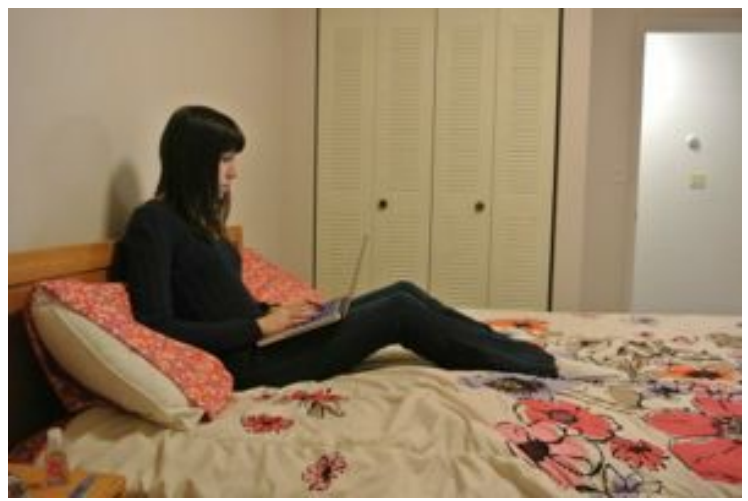

O Never

Occasionally ( $<1$ hour per week)

O 1-5 hours per week

O 5-10 hours per week

O 10-15 hours per week

O > 15 hours per week 
Q29 How often do you use your laptop...

Sitting on a bed, leaning back against a wall or headboard, knees bent, laptop resting on the bed beside you

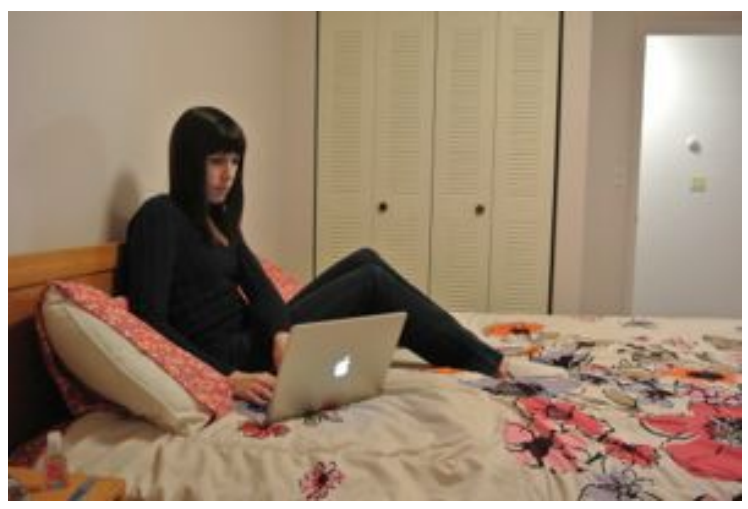

O Never

O Occasionally ( $<1$ hour per week)

O 1-5 hours per week

O 5-10 hours per week

O 10-15 hours per week

O > 15 hours per week

Q30 How often do you use your laptop...

Sitting on a bed with your legs crossed, laptop resting on your lap

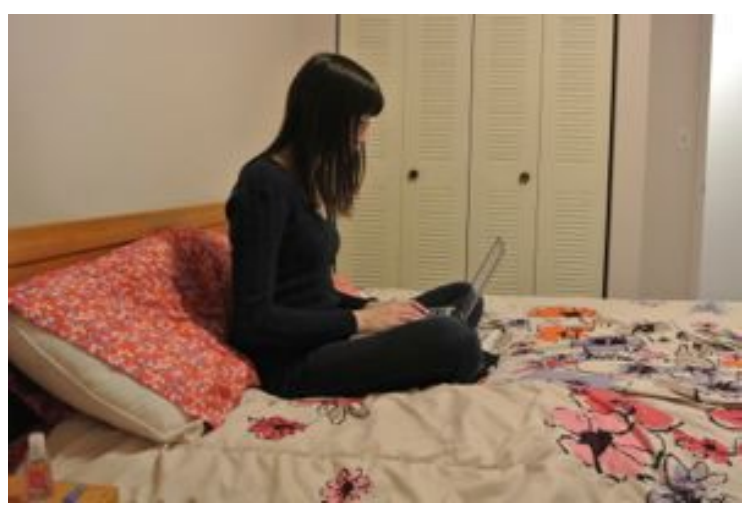

O Never

Occasionally ( $<1$ hour per week)

O 1-5 hours per week

O 5-10 hours per week

O 10-15 hours per week

O > 15 hours per week 
Q31 How often do you use your laptop...

Sitting on a bed with your legs crossed, laptop resting on the bed in front of you

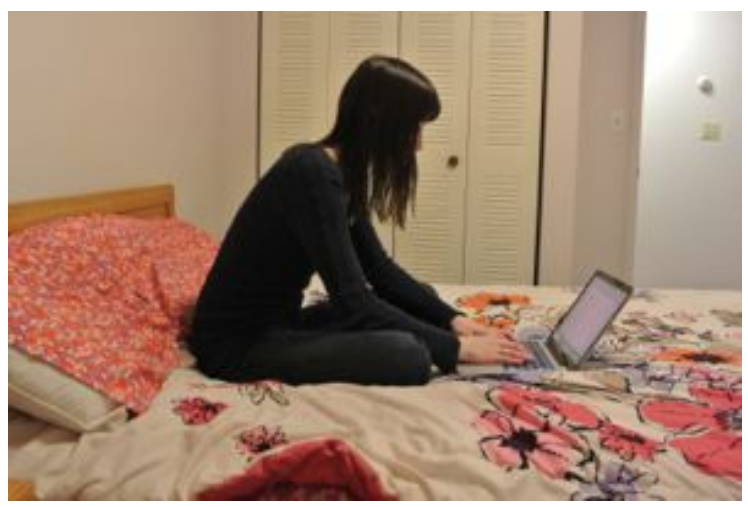

O Never

Occasionally ( $<1$ hour per week)

O 1-5 hours per week

O 5-10 hours per week

O 10-15 hours per week

O > 15 hours per week

Q32 How often do you use your laptop...

Sitting on a bed with your legs spread out in front of you, laptop resting on the bed in front of you

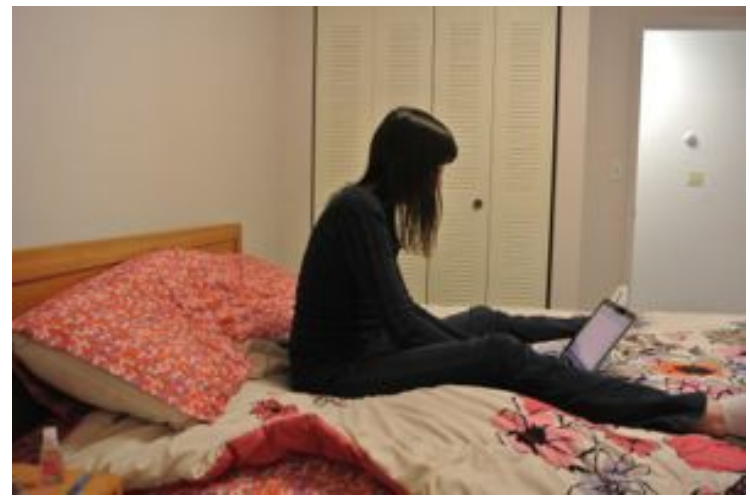

O Never

O Occasionally ( $<1$ hour per week)

O 1-5 hours per week

O 5-10 hours per week

O 10-15 hours per week

O > 15 hours per week 
Q33 How often do you use your laptop...

Lying on your stomach on a bed, laptop resting on the bed in front of you

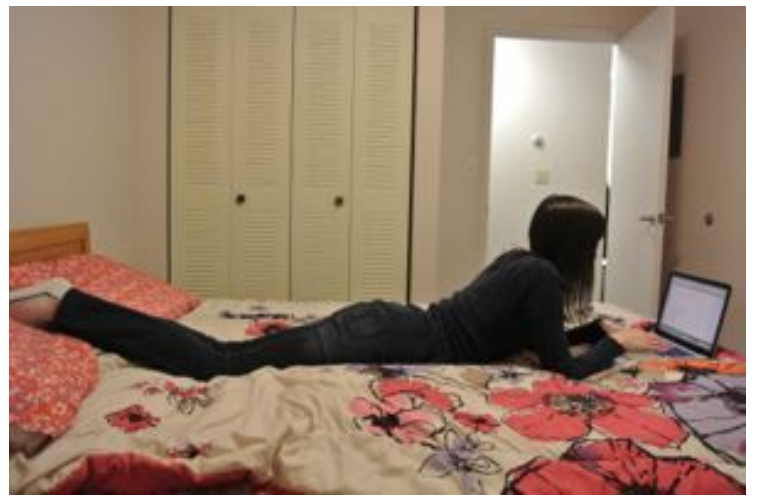

O Never

O Occasionally ( $<1$ hour per week)

O 1-5 hours per week

O 5-10 hours per week

O 10-15 hours per week

O $>15$ hours per week

Q34 How often do you use your laptop...

Standing, while laptop is on a counter or raised desk in front of you

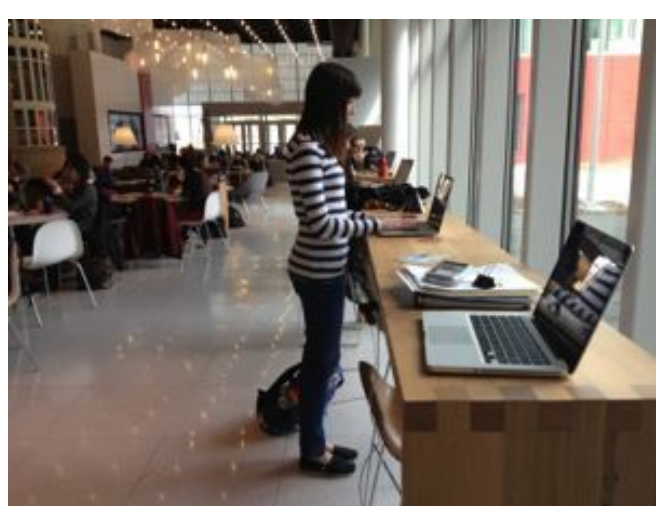

O Never

O Occasionally ( $<1$ hour per week)

O 1-5 hours per week

O 5-10 hours per week

O 10-15 hours per week

O > 15 hours per week 
Q35 How often do you use your laptop...

Standing, while laptop is on a standard desk in front of you

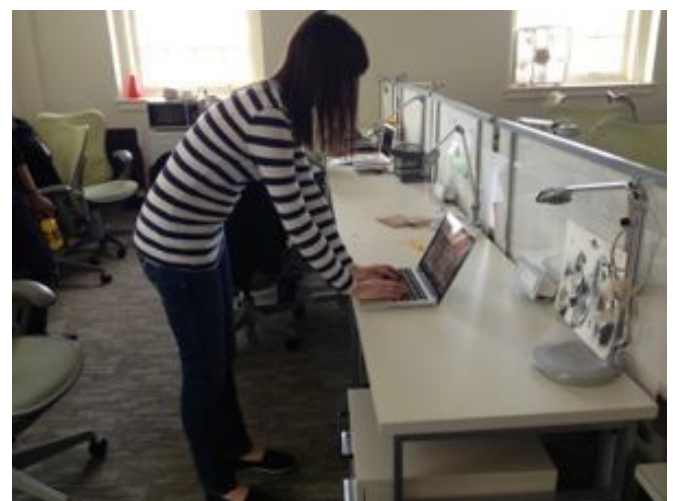

O Never

Occasionally (< 1 hour per week)

O 1-5 hours per week

5-10 hours per week

O 10-15 hours per week

O > 15 hours per week

Q36 How often do you use your laptop...

Sitting in an office chair at a desk

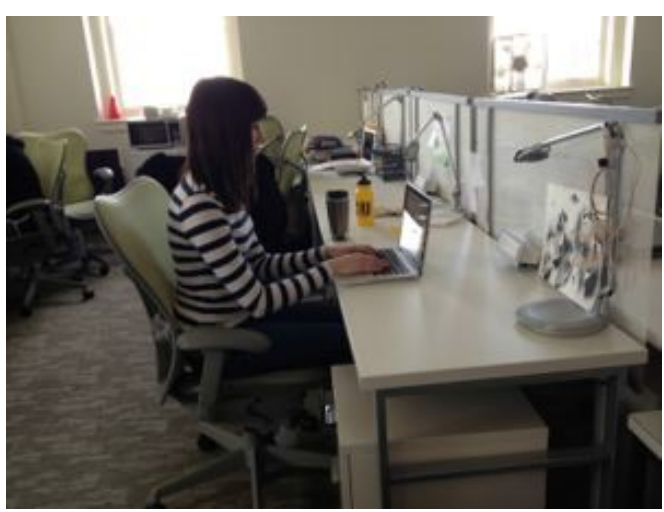

O Never

O Occasionally ( $<1$ hour per week)

O 1-5 hours per week

O 5-10 hours per week

O 10-15 hours per week

O > 15 hours per week 
Q37 How often do you use your laptop...

Sitting in an straight-back chair at a desk

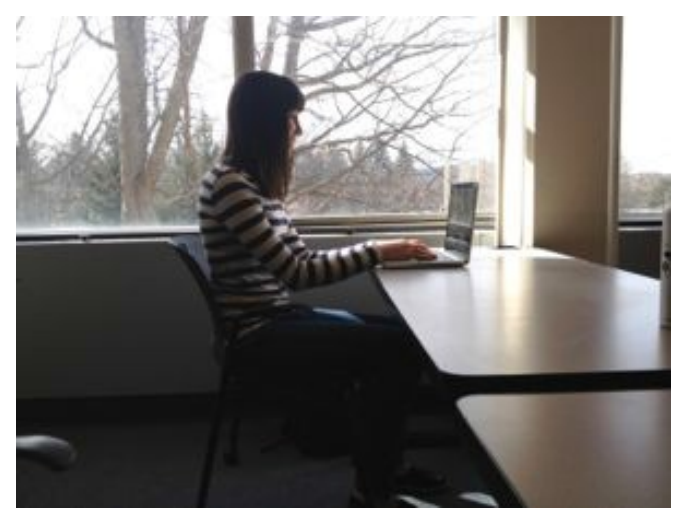

O Never

Occasionally ( $<1$ hour per week)

O 1-5 hours per week

O 5-10 hours per week

O 10-15 hours per week

O > 15 hours per week

Q38 How often do you use your laptop...

Sitting in a straight-back chair that has an attached work surface on the side (i.e. in a classroom)

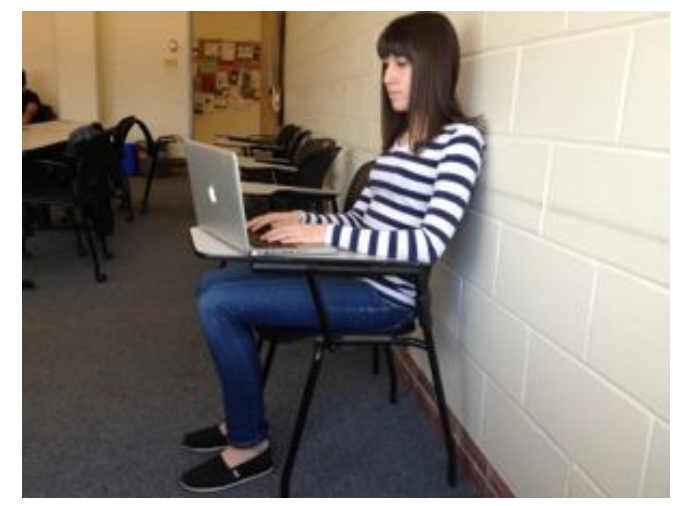

O Never

Occasionally ( $<1$ hour per week)

O 1-5 hours per week

O 5-10 hours per week

O 10-15 hours per week

O > 15 hours per week 
Q39 How often do you use your laptop...

Sitting on a stool at a counter, while the laptop is on the counter in front of you

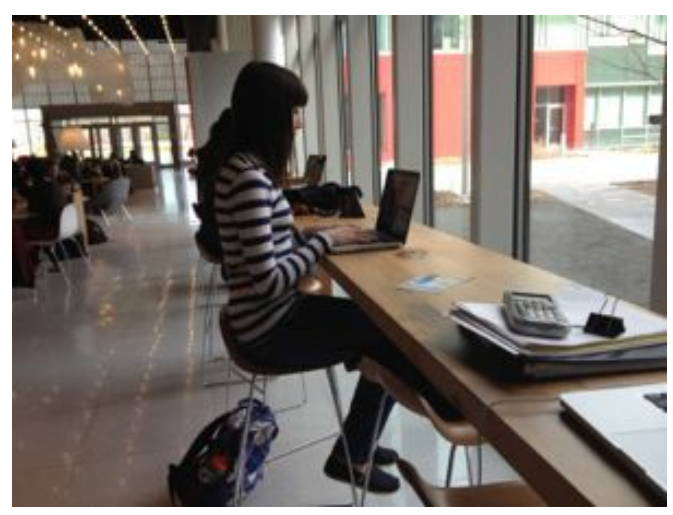

Never

Occasionally (< 1 hour per week)

O 1-5 hours per week

5-10 hours per week

O 10-15 hours per week

O > 15 hours per week

Q40 How often do you use your laptop...

Sitting in a lounge chair, laptop resting on your lap (i.e. chairs at a coffee shop)

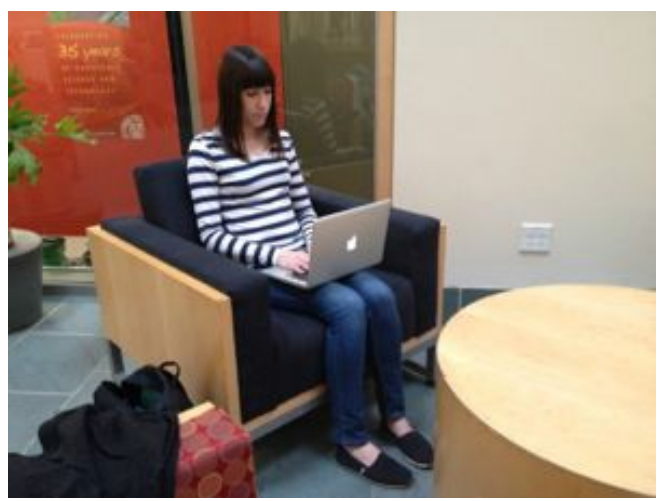

O Never

O Occasionally ( $<1$ hour per week)

O 1-5 hours per week

O 5-10 hours per week

O 10-15 hours per week

O > 15 hours per week 
Q41 How often do you use your laptop...

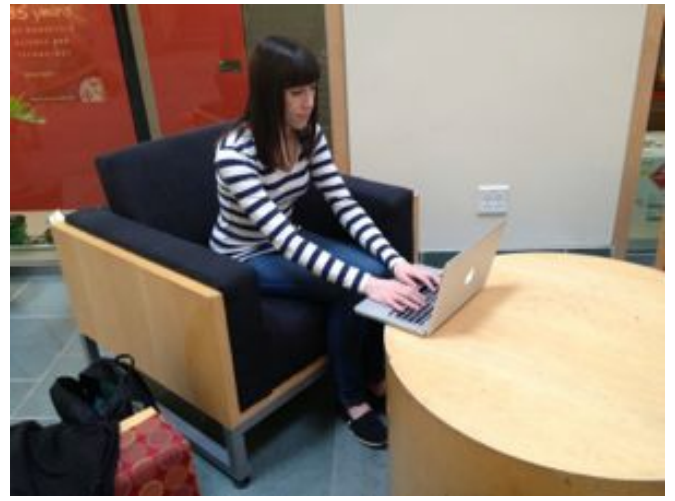

O Never

O Occasionally (< 1 hour per week)

O $1-5$ hours per week

O 5-10 hours per week

O 10-15 hours per week

O > 15 hours per week

Q42 If you use your laptop in any configurations not listed in the previous pages, please write them below, along with the frequencies with which you work these ways

Q43 In order to be entered in a draw to win one of three $\$ 25$ gift cards, please provide your email below (optional) 


\section{APPENDIX B}

Table 21. Frequency with which participants reported working in each configuration of laptop use

\begin{tabular}{|c|c|c|c|c|}
\hline \multirow{2}{*}{ Configuration described in questionnaire } & \multicolumn{4}{|c|}{$\begin{array}{c}\text { Percentage of subjects who selected } \\
\text { each response }\end{array}$} \\
\hline & Never & $\begin{array}{c}<1 \\
\mathrm{hr} / \mathrm{wk}\end{array}$ & $\begin{array}{c}1-5 \\
\mathrm{hr} / \mathrm{wk}\end{array}$ & $\begin{array}{c}>5 \\
\text { hr/wk }\end{array}$ \\
\hline $\begin{array}{l}\text { Sitting on a sofa with your feet on the floor (knees at } 90^{\circ} \text { ), laptop resting } \\
\text { on your lap }\end{array}$ & 15.6 & 41.4 & 32.8 & 10.2 \\
\hline $\begin{array}{l}\text { Sitting on a sofa with your legs straight out, feet supported on a coffee } \\
\text { table or ottoman, laptop resting on your lap }\end{array}$ & 22.2 & 32.4 & 31.9 & 13.5 \\
\hline $\begin{array}{l}\text { Sitting on a sofa with legs bent, feet resting on a coffee table, laptop } \\
\text { resting on your lap }\end{array}$ & 22.6 & 37.1 & 28.5 & 11.8 \\
\hline $\begin{array}{l}\left.\text { Sitting on a sofa with your feet on the floor (knees at } 90^{\circ}\right) \text {, bending over } \\
\text { to use laptop that is resting on a coffee table or ottoman in front of you }\end{array}$ & 41.6 & 38.9 & 11.4 & 8.1 \\
\hline $\begin{array}{l}\text { Sitting on the floor, leaning against a wall or piece of furniture, legs } \\
\text { straight out, laptop resting on your lap }\end{array}$ & 50.0 & 34.4 & 11.3 & 4.3 \\
\hline $\begin{array}{l}\text { Sitting on the floor, leaning against a wall or piece of furniture, knees } \\
\text { bent, laptop resting on your lap }\end{array}$ & 47.3 & 34.9 & 12.9 & 4.8 \\
\hline $\begin{array}{l}\text { Sitting on the floor, not leaning against anything, legs straight out, } \\
\text { laptop resting on your lap }\end{array}$ & 90.2 & 8.2 & 1.1 & 0.5 \\
\hline $\begin{array}{l}\text { Sitting on the floor, not leaning against anything, knees bent, laptop } \\
\text { resting on your lap }\end{array}$ & 86.4 & 10.9 & 1.6 & 1.1 \\
\hline Sitting on the floor with your legs crossed, laptop resting on your lap & 43.5 & 37.6 & 17.2 & 1.6 \\
\hline $\begin{array}{l}\text { Sitting on the floor, leaning against a wall or piece of furniture, legs } \\
\text { straight out, laptop resting on the floor to the side of you }\end{array}$ & 75.3 & 18.8 & 4.8 & 1.1 \\
\hline $\begin{array}{l}\text { Sitting on the floor, leaning against a wall or piece of furniture, knees } \\
\text { bent, laptop resting on the floor to the side of you }\end{array}$ & 76.9 & 19.4 & 2.7 & 1.1 \\
\hline $\begin{array}{l}\text { Sitting on the floor, not leaning against anything, legs straight out, } \\
\text { laptop resting on the floor to the side of you }\end{array}$ & 90.2 & 6.5 & 2.2 & 1.1 \\
\hline $\begin{array}{l}\text { Sitting on the floor with your legs crossed, laptop resting on the floor in } \\
\text { front of you }\end{array}$ & 43.0 & 43.0 & 11.3 & 2.7 \\
\hline $\begin{array}{l}\text { Sitting on the floor with your legs spread out in front of you, laptop } \\
\text { resting on the floor in front of you }\end{array}$ & 81.0 & 15.2 & 3.3 & 0.5 \\
\hline $\begin{array}{l}\text { Lying on your stomach on the floor, laptop resting on the floor in front } \\
\text { of you }\end{array}$ & 31.2 & 34.9 & 19.4 & 14.5 \\
\hline $\begin{array}{l}\text { Sitting on a bed, leaning back against a wall or headboard, legs straight } \\
\text { out, laptop resting on your lap }\end{array}$ & 16.7 & 20.4 & 34.9 & 28.0 \\
\hline $\begin{array}{l}\text { Sitting on a bed, leaning back against a wall or headboard, legs straight } \\
\text { out, laptop resting on the bed beside you }\end{array}$ & 54.3 & 19.4 & 17.7 & 8.6 \\
\hline $\begin{array}{l}\text { Sitting on a bed, leaning back against a wall or headboard, knees bent, } \\
\text { laptop resting on your lap }\end{array}$ & 26.9 & 28.5 & 30.1 & 14.5 \\
\hline $\begin{array}{l}\text { Sitting on a bed, leaning back against wall or headboard, knees bent, } \\
\text { laptop resting on the bed beside you }\end{array}$ & 68.8 & 20.4 & 7.5 & 3.2 \\
\hline Sitting on a bed with your legs crossed, laptop resting on your lap & 43.8 & 31.9 & 13.5 & 10.8 \\
\hline $\begin{array}{l}\text { Sitting on a bed with your legs crossed, laptop resting on the bed in front } \\
\text { of you }\end{array}$ & 41.9 & 33.3 & 16.7 & 8.1 \\
\hline $\begin{array}{l}\text { Sitting on a bed with your legs spread in front of you, laptop resting on } \\
\text { the bed in front of you }\end{array}$ & 85.9 & 10.8 & 2.2 & 1.1 \\
\hline $\begin{array}{l}\text { Lying on your stomach on a bed, laptop resting on the bed in front of } \\
\text { you }\end{array}$ & 22.0 & 31.2 & 23.7 & 23.1 \\
\hline Standing, while laptop is on a counter or raised desk in front of you & 57.5 & 31.2 & 7.5 & 3.8 \\
\hline
\end{tabular}




\begin{tabular}{|l|c|c|c|c|}
\hline Standing, while laptop is on a standard desk in front of you & 61.3 & 32.8 & 4.3 & 1.6 \\
\hline Sitting in an office chair at a desk & 10.3 & 13.5 & 18.4 & 57.8 \\
\hline Sitting in a straight-back chair at a desk & 8.1 & 19.4 & 23.7 & 48.9 \\
\hline $\begin{array}{l}\text { Sitting in a straight-back chair that has an attached work surface on the } \\
\text { side (i.e. in a classroom) }\end{array}$ & 27.7 & 27.7 & 26.6 & 17.9 \\
\hline $\begin{array}{l}\text { Sitting on a stool at a counter, while the laptop is on the counter in front } \\
\text { of you }\end{array}$ & 44.3 & 33.9 & 14.8 & 7.1 \\
\hline $\begin{array}{l}\text { Sitting in a lounge chair, laptop resting on your lap (i.e. chairs at a } \\
\text { coffee shop) }\end{array}$ & 20.5 & 36.2 & 29.7 & 13.5 \\
\hline $\begin{array}{l}\text { Sitting in a lounge chair, laptop resting on a table in front of you (i.e. } \\
\text { chairs at a coffee shop) }\end{array}$ & 51.4 & 34.1 & 9.7 & 4.9 \\
\hline
\end{tabular}




\section{APPENDIX C}

\section{Demographic and Laptop Use Questionnaire}

1. What is your age?

2. What is your gender?

3. Are you an undergraduate student?

4. What is your major?

5. Rate your overall level of physical activity on a scale from 1 (low) to 5 (high):

6. Are you left or right handed?

7. Do you currently suffer from a diagnosed physical impairment (scoliosis, arthritis, carpal tunnel, etc.)?

a. If so, please specify which impairment (and in which body region if relevant), when it was diagnosed, and any previous or ongoing treatment:

8. Do you own a laptop computer?

9. How many hours per week do you use a laptop computer?

10. How many hours per week do you use a laptop computer while sitting or lying on a bed?

11. Do you experience any pain or discomfort associated with laptop computer use? 
12. In which body regions do you experience pain or discomfort associated with laptop computer use? (circle all that apply)
a. Hands/fingers
b. Wrists
c. Forearms
d. Elbows
e. Upper arms
f. Neck
g. Shoulders
h. Upper back
i. Lower back
j. Buttocks
k. Thighs
I. Knees
m. Eyes
n. Other (please specify) 


\section{APPENDIX D}

Table 22. Diagrams and descriptions of the body markers used to measure angles of deviation

\begin{tabular}{|l|l|}
\hline \multicolumn{1}{|c|}{ Angle } & \multicolumn{1}{|c|}{ Description } \\
\hline $\begin{array}{l}\text { Neck } \\
\text { flexion/extension }\end{array}$ & $\begin{array}{l}\text { The intersection of the line between the } \\
\text { tragus and C7 vertebrae of the spine with } \\
\text { the line between the C7 vertebrae of the } \\
\text { spine and the L5 vertebrae of the spine. } \\
\text { Angle of deviation is calculated by } \\
\text { comparison to a calibration photo taken in } \\
\text { a neutral position. }\end{array}$ \\
\hline $\begin{array}{l}\text { Shoulder } \\
\text { abduction/adduction }\end{array}$ & $\begin{array}{l}\text { The intersection of the line between the } \\
\text { lateral epicondyle and acromion process } \\
\text { with the line extending vertically } \\
\text { downwards from the acromion process. }\end{array}$ \\
\hline $\begin{array}{l}\text { Shoulder } \\
\text { flexion/extension }\end{array}$ & $\begin{array}{l}\text { The intersection of the line between the } \\
\text { acromion process and lateral epicondyle } \\
\text { with the line between the lateral } \\
\text { epicondyle and top iliac crest (in line with } \\
\text { the lateral epicondyle) }\end{array}$ \\
\hline $\begin{array}{l}\text { Trunk } \\
\text { Elexion/extension } \\
\text { flexion/extension }\end{array}$ & $\begin{array}{l}\text { The intersection of the line between the } \\
\text { vertebrae of the spine and top of iliac crest } \\
\text { with the line extending from the top of } \\
\text { iliac crest to the horizontal. } \\
\text { ulnar styloid process and lateral epicondyle } \\
\text { with the line between the lateral } \\
\text { epicondyle and the acromion process. }\end{array}$ \\
\hline
\end{tabular}


APPENDIX E

\section{Comfort/Discomfort Questionnaire}

Please rate the level of discomfort in each body part below by placing an " $X$ " on the line in the corresponding position.

\section{Hands}

\begin{tabular}{l|l|l}
\multirow{3}{*}{ No Discomfort } & \multirow{2}{*}{ Extreme Discomfort }
\end{tabular}

\section{Wrists}

\begin{tabular}{l|l|l}
\multirow{3}{*}{ No Discomfort } & Extreme Discomfort
\end{tabular}

\section{Forearms}

\begin{tabular}{l|l|l}
\multirow{2}{*}{ No Discomfort } & Extreme Discomfort \\
\cline { 2 - 2 } & Excoment
\end{tabular}

\section{Elbows}

\begin{tabular}{l|l|l}
\multirow{2}{*}{ No Discomfort } & Extreme Discomfort \\
\cline { 2 - 2 } & Extrem
\end{tabular}

\section{Neck}

\begin{tabular}{l|l|l}
\multirow{2}{*}{ No Discomfort } & Extreme Discomfort \\
\cline { 2 - 2 } & Extrem
\end{tabular} 
6. Shoulders

\begin{tabular}{l|l|l}
\multirow{3}{*}{ No Discomfort } & \multirow{2}{*}{ Extreme Discomfort }
\end{tabular}

\section{Upper back}

\begin{tabular}{l|l|l}
\multirow{3}{*}{ No Discomfort } & \multirow{2}{*}{ Extreme Discomfort }
\end{tabular}

\section{Lower back}

\begin{tabular}{l|l}
\multirow{2}{*}{ No Discomfort } & \\
\cline { 2 - 2 } &
\end{tabular}

Extreme Discomfort

\section{Buttocks}

\begin{tabular}{l|l|l}
\multirow{2}{*}{ No Discomfort } & Extreme Discomfort
\end{tabular}

10. Thighs

\begin{tabular}{l|l|l}
\multirow{2}{*}{ No Discomfort } & \multirow{2}{*}{ Extreme Discomfort }
\end{tabular}

\section{Knees}

No Discomfort

Extreme Discomfort 


\section{APPENDIX F}

Table 23. Average number of hours per week spent using a laptop computer

\begin{tabular}{|l|l|l|}
\hline \multicolumn{1}{|c|}{ Gender } & \multicolumn{1}{c|}{ Mean (hours) } & \multicolumn{1}{c|}{ Std. Dev. } \\
\hline Male & 30.56 & 24.21 \\
\hline Female & 41.67 & 12.83 \\
\hline
\end{tabular}

Notes: includes outliers. $t(34)=-1.720, p=.094$.

Table 24. Average number of hours per week spent using a laptop computer on a bed

\begin{tabular}{|l|l|l|}
\hline \multicolumn{1}{|c|}{ Gender } & \multicolumn{1}{c|}{ Mean (hours) } & \multicolumn{1}{c|}{ Std. Dev. } \\
\hline Male & 11.00 & 23.41 \\
\hline Female & 16.36 & 15.34 \\
\hline
\end{tabular}

Notes: includes outliers. $t(34)=-.812, p=.422$. 


\section{APPENDIX G}

Table 25. Average height of males and females

\begin{tabular}{|l|l|l|}
\hline \multicolumn{1}{|c|}{ Gender } & \multicolumn{1}{c|}{ Mean $(\mathbf{c m})$} & \multicolumn{1}{c|}{ Std. Error } \\
\hline Male & 176.83 & .83 \\
\hline Female & 166.06 & 1.21 \\
\hline
\end{tabular}

Table 26. Pearson-product correlation between height and average neck flexion

\begin{tabular}{|l|l|l|}
\hline \multicolumn{2}{|c|}{} & \multicolumn{1}{|c|}{ Average Neck Flexion } \\
\hline \multirow{3}{*}{ Height } & Pearson Correlation & .030 \\
\cline { 2 - 3 } & Sig. (2-tailed) & .761 \\
\cline { 2 - 3 } & $\mathrm{N}$ & 108 \\
\hline
\end{tabular}

Notes: average neck flexion for each condition was compared to the height of the participant.

Table 27. Number of words typed in each condition

\begin{tabular}{|l|l|l|l|l|l|}
\hline Condition & Gender & Mean Total & $\begin{array}{c}\text { Mean } \\
\mathbf{w p m}\end{array}$ & Std. Error & \multirow{2}{*}{ Sig. } \\
\hline \multirow{2}{*}{ LS } & Male & 943.83 & 37.75 & 85.15 & \multirow{2}{*}{.454} \\
\cline { 2 - 6 } & Female & 1029.00 & 41.16 & 73.49 & \\
\hline \multirow{2}{*}{ CL } & Male & 973.39 & 38.94 & 78.33 & \multirow{2}{*}{.485} \\
\cline { 2 - 6 } & Female & 1045.44 & 41.82 & 65.43 & \\
\hline \multirow{2}{*}{ CB } & Male & 923.22 & 36.93 & 83.32 & \multirow{2}{*}{.555} \\
\cline { 2 - 6 } & Female & 984.67 & 39.39 & 60.84 & \\
\hline \multirow{2}{*}{ Total } & Male & 2840.44 & 37.87 & 242.05 & \multirow{2}{*}{.486} \\
\cline { 2 - 6 } & Female & 3059.11 & 40.79 & 194.20 & \\
\hline
\end{tabular}

